\title{
Economics of higher education : study choice, mobility and job preferences
}

Citation for published version (APA):

Seegers, P. K. (2016). Economics of higher education : study choice, mobility and job preferences.

[Doctoral Thesis, Maastricht University]. Datawyse / Universitaire Pers Maastricht.

https://doi.org/10.26481/dis.20160113ps

Document status and date:

Published: 01/01/2016

DOI:

10.26481/dis.20160113ps

Document Version:

Publisher's PDF, also known as Version of record

\section{Please check the document version of this publication:}

- A submitted manuscript is the version of the article upon submission and before peer-review. There can be important differences between the submitted version and the official published version of record.

People interested in the research are advised to contact the author for the final version of the publication, or visit the DOI to the publisher's website.

- The final author version and the galley proof are versions of the publication after peer review.

- The final published version features the final layout of the paper including the volume, issue and page numbers.

Link to publication

\footnotetext{
General rights rights.

- You may freely distribute the URL identifying the publication in the public portal. please follow below link for the End User Agreement:

www.umlib.nl/taverne-license

Take down policy

If you believe that this document breaches copyright please contact us at:

repository@maastrichtuniversity.nl

providing details and we will investigate your claim.
}

Copyright and moral rights for the publications made accessible in the public portal are retained by the authors and/or other copyright owners and it is a condition of accessing publications that users recognise and abide by the legal requirements associated with these

- Users may download and print one copy of any publication from the public portal for the purpose of private study or research.

- You may not further distribute the material or use it for any profit-making activity or commercial gain

If the publication is distributed under the terms of Article $25 \mathrm{fa}$ of the Dutch Copyright Act, indicated by the "Taverne" license above, 


\section{Economics of Higher Education Study Choice, Mobility and Job Preferences}

Philipp Karl Seegers 
(C)Philipp Karl Seegers, Maastricht 2015

All rights reserved. No part of this publication may be reproduced, stored in a retrieval system, or transmitted in any form, or by any means, electronic, mechanical, photocopying, recording or otherwise, without the prior permission in writing from the author.

This book was typeset by the author using $\mathrm{H}_{\mathrm{H}} \mathrm{T} \mathrm{X}$

ISBN: 9789461595164 


\title{
Economics of Higher Education
}

\section{Study Choice, Mobility and Job Preferences}

\author{
DISSERTATION
}

to obtain the degree of Doctor at Maastricht University, on the authority of the Rector Magnificus, Prof. dr. L.L.G. Soete,

in accordance with the decision of the Board of Deans, to be defended in public on January 13th 2016, at 16.00 hrs

by

Philipp Karl Seegers

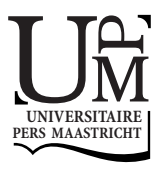




\title{
Supervisor:
}

Prof. dr. Lex Borghans

\author{
Assessment Committee: \\ Prof. dr. Hans Heijke (Maastricht University, Chair) \\ Prof. dr. Michael Heister (BIBB Bonn) \\ Prof. dr. Pia Pinger (Bonn University) \\ Prof. dr. Jo Ritzen (Maastricht University)
}



MY MOTHER 


\section{Acknowledgements}

First and foremost, I am very grateful to Lex Borghans. While Lex is certainly not the most available supervisor, he is plainly brilliant. I have benefited a lot from his input. He always encouraged me to take on projects, be it the collection of new data, an idea for a paper, a new cooperation or starting up a company. Despite his time constraints he worked closely with me on the Chapters. He is one of the people who prefers to raise questions he does not know the answers to. Still, if you ask him something he will give you valuable advise, packaged into a small anecdote that hints you towards the solution while giving you the feeling that you somehow solved it yourself. In that sense he is a true researcher and an excellent supervisor - thank you Lex!

I would like to thank the members of the reading committee, Hans Heijke, Jo Ritzen, Michael Heister and Pia Pinger, for their time and interest in my dissertation. The comments I received allowed me to further improve my dissertation. Special thanks go to Tom van Veen who supervised my Bachelor thesis and encouraged me to enroll in a Research Master and later a Ph.D. program. Without Tom's support and counsel I might have chosen a different path.

Moreover, I like to give thanks to all the colleagues at our "Economics of Education Club" for the many nice discussions in seminars, during our weekly lunch or in the hallways. Even though I have not been at the office too often, many thanks need to go to my office mates Lennart, Tom and Dominik. More generally I would like to acknowledge the many fellow researchers I met at various events at and outside of Maastricht University.

This dissertation would have looked very different without my co-authors and co-workers on the Fachkraft project. Particular thanks go to Jan Bergerhoff who accompanied me since the very first group projects in the Bachelor programme. Back then as well as now we form a great team and I am more than happy to have him as a college and co-founder. I would also like to thank Marion Collewet who worked with me on the last Chapter of this dissertation. Thanks go to the Studitemps team in Cologne for supporting me in collecting the Fachkraft data. The whole Fachkraft project would not have been possible without Stephan Hartmann. He added a completely different perspective, constantly forced me to explain what I was doing 
and, most importantly, made the work much more enjoyable. Thank you, Stephan.

Luckily I have very good friends and while most of them added little to this dissertation they strongly contributed to my Ph.D. experience. Many thanks go to my Ph.D.-housemates Lukas, Tobi, Joscha and Alex. Whenever I managed to escape the Netherlands Tim, Henry and Benny were there to entertain me. Moreover, I want to thank Linda, Phips, Thommy, Hannes, Malte, Nori, Ari, Dodo and many others for the many experiences we shared during the years in Maastricht.

I am very grateful for the interest and support of my godmother Elfriede. On top of that I am blessed with a small but very supportive family. Whenever I need help they are there for me. Equally important, whenever I need to be questioned they challenge me. And despite everything they always love me. Mama, I am most indebted to you. Jule, Oma and Opa, I am infinitely happy that you are there.

Final thanks go to my loving girlfriend Johanna. You keep me down to earth, support as well as distract me when needed and always manage to make me smile. With the successful completion of your own Ph.D. you created the pressure I needed to finish writing up this dissertation. I treasure all the experiences we already shared and look forward to the many more that will come. I love you! 


\section{Contents}

Acknowledgements viii

Contents $x$

1 Introduction 1

2 Fachkraft Data $\mathbf{5}$

2.1 Key Facts . . . . . . . . . . . . . . . . . . . 5

2.2 Data Collection . . . . . . . . . . . . . . . . . . . 6

2.3 Sample Characteristics . . . . . . . . . . . . . . 8

2.4 Selected descriptive Outcomes . . . . . . . . . . . . . . 13

2.4.1 Migration Flows within Germany . . . . . . . . . . . 14

2.4.2 Differences in Rental Prices . . . . . . . . . . . . 17

2.4.3 Timing of Student Jobs . . . . . . . . . . . . . . 19

2.4.4 First Results on Job Preferences . . . . . . . . . . . . 21

3 Study Choice and Personality 23

3.1 Introduction . . . . . . . . . . . . . . . . 23

3.2 Data........................... 26

3.3 Methodology . . . . . . . . . . . . . . . 26

3.4 Results. . . . . . . . . . . . . . . . . . . . . 28

3.4.1 Selection and Mean Level Change . . . . . . . . . . 28

3.4.2 Personality Profiles . . . . . . . . . . . . . . . 30

3.4.3 Change in Dispersion . . . . . . . . . . . . . 34

3.5 Conclusion ................... . . . 36

4 International Education $\quad 39$

4.1 Introduction . . . . . . . . . . . . . . . . . . 39

4.2 The Model . . . . . . . . . . . . . . . . . . . 42

4.2.1 Basic Equations . . . . . . . . . . . . . . . . . . 42

4.2 .2 Solution . . . . . . . . . . . . . . . . . 44

4.2.3 The Effects of International Education . . . . . . . . 45

4.3 Empirics . . . . . . . . . . . . . . . . . . 48

4.3.1 Parameter Calibration . . . . . . . . . . . 48 
4.3 .2 Simulations .................. . . 49

4.4 Conclusions ........................ 52

5 Investing in Personality $\mathbf{5 5}$

5.1 Introduction . . . . . . . . . . . . . . . . . 55

5.2 Personality Measures and Data . . . . . . . . . . . 59

5.3 Results . . . . . . . . . . . . . . . . 60

5.4 The Size of the Effect . . . . . . . . . . . . . . 66

5.5 Conclusion ........................... 69

6 Job Preferences $\quad 71$

6.1 Introduction . . . . . . . . . . . . . . . . 71

6.2 Question Design ................... . . . 73

6.2.1 General Vignette Design . . . . . . . . . . . 73

6.2.2 Part-Time Job Vignette Design . . . . . . . . . . . . . . . 74

6.2.3 Graduate Job Vignette Design . . . . . . . . . . . . . 75

6.3 Estimation Method . . . . . . . . . . . . . . 78

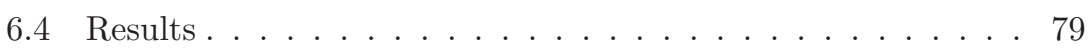

6.4.1 Part-Time Job Vignette . . . . . . . . . . . . . . 79

6.4.2 Graduate Job Vignette . . . . . . . . . . . . . . . 83

6.5 Conclusion ..................... . . 89

$\begin{array}{lll}7 & \text { Preference for Leisure } & 91\end{array}$

7.1 Introduction . . . . . . . . . . . . . . . . . 91

7.2 Measuring Preference for Leisure . . . . . . . . . . . . . . 93

7.2.1 Preference for Leisure and Opportunity Costs of Work 93

7.2.2 Open hypothetical questions ........... . 94

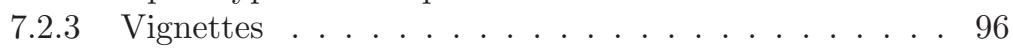

7.3 Data . . . . . . . . . . . . . . . . . . . 97

7.4 Main results: Distribution of Preference for Leisure . . . . . . 98

7.4.1 Indifference Curves: Working Time and Wage . . . . . 98

7.4.2 Slope of the Indifference Curve . . . . . . . . . . . . . 98

7.5 Heterogeneity of Preference for Leisure . . . . . . . . . . . . . 101

7.6 Robustness Checks . . . . . . . . . . . . . . . . . . . . . 104

7.6.1 Testing for Measurement Error . . . . . . . . . . . . . 104

7.6.2 Comparison of Open Questions and Vignettes . . . . . 106

7.7 Policy Simulations . . . . . . . . . . . . . . . . 108

7.8 Conclusion . . . . . . . . . . . . . . . . 109

8 Conclusion

111

References

115 


\section{Chapter 1}

\section{Introduction}

Engaging in higher education is by itself a choice. In addition, students have to make many more decisions within higher education. The motivations to make such choices may be very different. Future labour market outcomes are one aspect, but the preferences and life circumstances of students need to be considered as well. The present dissertation has the title "Economics of Higher Education - Study Choice, Mobility and Job Preferences". It evaluates the decisions students face within higher education. Right at the start students need to select a field of study. Once enrolled, some students decide for a semester abroad. Furthermore, to earn money or to gain experience many students choose to work next to their studies. Finally, after graduation students enter the labour market and need to pick a graduate job. This dissertation studies how students make such choices and what effect these have on them.

To some readers the combination of economics and education research might be surprising. Nonetheless, in my very first economics textbook I learned that in economics "we examine how individual consumers and firms make decisions and how the interaction of many individual decisions affects markets" (Perloff (2012), p.23). In other words, economics is all about choices and the consequences of these choices. In this spirit, the present dissertation is about the choices of students in higher education and their consequences.

The field of labour economics analyses a variety of questions regarding the skill acquisition and employability of workers. Within that field, economics of education focuses on the choices made in education and their effects later in life. Early literature in education economics models this process and tries to answer questions on optimal education length (G. S. Becker, 1962). This theoretical approach already hints towards the main problem in education economics: Identification. If individuals with certain unobservable characteristics are more likely to make certain decisions, then it is hard to distinguish between the effect of the decision and that of the 
shared characteristic. In other words, the fact that students make choices causes identification problems. As a response to this, the focus in education economics shifted more towards empirical strategies. Estimating the unbiased return to education is a central question in this respect (e.g. Angrist and Krueger (1991); Ashenfelter and Krueger (1994); Harmon and Walker (1995)).

Within the field of education economics this dissertation focuses on higher education. Students who finish higher education earn higher wages, but also give up salary while studying. High ability students could graduate faster, thereby facing lower opportunity costs. Alternatively, these students might learn more and show a stronger increase in wages. In both cases high ability students are more likely to select into higher education. Certainly, forgone and future wages are only one example for costs and benefits in schooling choice. Additional factors are likely to have an impact on the selection into higher education. Some people enjoy learning, other have a distaste for education. The same logic applies to the preference for working. Furthermore, the educational background of the parents can influence the goals and expectations of students.

Choices in higher education should, however, not be reduced to the initial selection into higher education. The present dissertation analyses the many more decisions that need to be made by students in higher education. To analyse such choices we collect a unique data set on German students in higher education, called the Fachkraft data. The first data collection took place in 2012. Since then there have been a total of six rounds with more than 130,000 participants. Chapter 2 gives an overview of the data collection and shows first descriptive results. The data set lays the basis of the analysis done in Chapters 3, 6 and 7. Moreover, Chapter 5 uses other data that we collected on students from Maastricht at three different points in time.

Selection into higher education goes hand in hand with the choice of study field. If wage and opportunity costs were the only criteria, students would select a subject that balances a high future wage with the chances of successful graduation. Such a model, while including ability, ignores the preferences of students. Gaining a good understanding of the factors that drive selection into study fields is by itself relevant. In a next step it is then necessary to ask if this choice of study field changes the students. If the latter is true it could even be the case that some students choose certain study fields because they would like to alter their personality.

Chapter 3 analyses the link between personality and study fields. Selection into study fields takes place because of certain personality traits. This means that non-cognitive skills contribute to study choice. Furthermore, the reverse effect is studied by asking if subject choice alters the personality of students. If this was true, then studying certain subjects could increase or decrease the employability of students in terms of their personality. In Chapter 3, however, no convincing evidence for personality change as a result of study choice can be found. 
During their study students face further choices. One such decision is mobility. Generally, one needs to distinguish between an exchange programme and degree mobility. While exchange programmes are by definition balanced, countries can receive a large inflow or outflow of students due to degree mobility. Concerning the latter, it is unclear whether receiving or sending countries gain or lose from international education in Europe.

In Chapter 4 a two-country model is developed to analyse the macro level effects of degree mobility. The mathematical model helps to understand the many facets of international education. The model is calibrated to find that student mobility can increase average growth in the sending and receiving country by 0.013 percentage points. Small countries that receive foreign students can benefit even more by experiencing additional growth of 0.049 percentage points. The effectiveness of international education is a crucial parameter in the calibration of this model. Hence, it is interesting in which aspects international education is different from domestic education.

For both, exchange programmes and degree mobility, it is possible that certain types of students are more likely to select into international education. The questions that arise are comparable: What are the differences between mobile and non-mobile students? And: What is the effect of being educated internationally? Especially the second question is a challenging one to answer. If certain students select into international education, the effect of going abroad needs to be isolated from that of any shared, potentially unobservable, characteristic.

Using a three survey design and a control group Chapter 5 finds that the personality of students changes as a result of studying abroad. As a result of a six month period abroad students become less neurotic and gain a more inward locus of control. This change can be translated into a change in the labour market value of students. Under some assumptions, the change in personality that results from a semester abroad carries a net present value of $€ 21,525$. Therefore the decision of students to study abroad can be seen as an investment into non-cognitive skills. As noted previously, this is not only important for mobile students themselves. It also determines the macro-level effects of student mobility as can be seen in Chapter 4 .

Choosing a job is another relevant decision during and especially after higher education. Full comprehension of such decisions requires estimating how much students value certain job characteristics. Again, the typical problem arises. Unobservable characteristics can lead to some students receiving a higher wage and, for example, more flexibility or job security. In reality, however, an employee is willing to work for less money if granted an improvement in other job characteristics.

Chapter 6 analyses the preferences of students with respect to their parttime job using a vignette question design. Students are offered a selection of three different jobs and need to choose their most preferred one. By doing so, the trade-offs between differnt job attributes can be estimated. Students are willing to give up $€ 2.18$ per hour if they are allowed more 
flexible working schedule. With regard to undesired job attributes students ask for increases in their hourly wage. One such example is travelling to the job. For each minute of commuting students require an increase in their hourly wage of $€ 0.16$.

After graduation from higher education most students enter the labour market and face new choices. Chapter 6 also includes the analysis of a vignette type question on graduate jobs. Future graduates require a premium of $€ 349$ in monthly wage after taxes to move to another German state. At the same time graduates value job security. Receiving an openended contract, compared to a temporary one, is worth $€ 320$ in terms of net compensation per month.

The central trade-off with respect to graduate jobs is that between working hours and wage. Many policies dealing with the retirement age, unemployment benefits or taxation influence the supply of labour. In that respect, knowing that students like to receive a higher wage, but dislike to work longer hours is not enough. The exact value of this trade-off is important to understand the effect of such policies. Furthermore, it is relevant to see if such policies have different effects on certain groups of individuals. Again, preferences and life circumstances might lead to pronounced differences in the preference for leisure.

Chapter 7 develops a new framework to measure preference for leisure using hypothetical choices. In response to changes in the weekly working hours future graduates adjust their required compensation. The resulting hourly wage is around $€ 10$ and comparable to the results of the vignette question on graduate jobs in Chapter 6. A more detailed analysis reveals that preference for leisure is heterogeneous. Students who want to work long hours have a stronger distaste for increases in working time. Furthermore, students that are not in a stable relationship or study social sciences have a lower preferences for leisure. 


\section{Chapter 2}

\section{The Fachkraft Data}

Gaining insights into the choices of students requires a specific data set. To make sure that the relevant questions can be answered a unique data set was collected within the scope of this dissertation. This Chapter gives an overview of the data collection and the characteristics of this data set, called the Fachkraft data. The Fachkraft data is collected in a cooperation between us at Maastricht University and the German student network Jobmensa. So far there have been six rounds in which more than 100,000 German students participated. The data allows a detailed image of the German student population focusing on general study related information, the part-time student job market and the job expectations of future university graduates.

\section{$2.1 \quad$ Key Facts}

The Fachkraft data is the basis of the German student study "Fachkraft 2020 ". It is collected biannually in cooperation with Studitemps GmbH via the Studitemps student network called Jobmensa. Jobmensa is the largest network for student jobs and internships in Germany with currently more than 400,000 users. The first data collection took place in September 2012. Since then new data collections take place every six months, at the beginning of a new academic semester in Germany respectively. The latest collection in March 2015 marks the sixth round. Participation in the questionnaires ranges from 16,420 to 25,252 with a total of 127,404 observations. However, the panel dimension of the data set is small with each students participating on average in 1.28 rounds. Participation is incentivised by giving students the chance to win cash vouchers.

When compared to another large German student sample called Sozialerhebung only small differences with respect to the observable variables exist. Therefore neither the student network from which the contacts are taken nor the form of the data collection seem to create large biases. The Fachkraft 
data includes typical demographic variables as well as information on different personality measures such as the Big 5 or economic preferences. At the end, this Chapter displays selected descriptive results, while in the remainder of this dissertation Chapter 3, Chapter 6 and Chapter 7 use the Fachkraft data for a more detailed analysis. Overall, the focus of the questionnaire is on general study related information, the part-time student job market and the job expectations of future university graduates. Descriptive findings of the questionnaire are published in a reoccurring yearly study called "Fachkraft 2020" (Hartmann, Thiel, and Seegers (2012); Hartmann, Thiel, and Seegers (2013); Bergerhoff, Hartmann, and Seegers (2015)).

\subsection{Data Collection}

Since September 2012 data is collected every six months. Refer to Table 2.1 for the exact start and end date of each collection. ${ }^{1}$ The online questionnaire is created using the survey hosting service "fluidsurveys". Data collection typically takes place within a two week interval. During the first week all students in the database of Jobmensa receive an invitation to participate via email. A reminder to participate is sent in the second week of the collection. Round five and six are exceptions. In round five we made use of a second reminder to the full database which increased the collection period to roughly three weeks. For round six the second reminder was restricted to the students that participated in the previous round. Once all reminders are sent the online questionnaire remains active until daily participation drops below 100 students per day.

The general trend shows an increase in the amount of participants. The main force behind this is the growth in the database of Jobmensa which allows reaching out to more students. A close look at Table 2.1 shows that participation seems to decrease for the last two rounds. Note that since round five participants can classify themselves as being in secondary or higher education. In round six a new branch for graduates has been included. The Fachkraft data set, as explained in this Chapter and used in this dissertation, focuses on higher education. Hence high school students as well as graduates are excluded. Including them leads to ongoing growth in the sample size even in rounds five and six.

Conversion rates, both from sending emails to starting the questionnaire as well as from starting the questionnaire to finishing it, are monitored. ${ }^{2}$

\footnotetext{
${ }^{1}$ Schedules were occasionally shifted by a few weeks. Reasons were technical problems with the online questionnaire, coordination with the student database to avoid times with a high mail volume, leaving out the carnival celebrations, as well as delays for further improvements with respect to question design.

${ }^{2}$ The higher email conversion rate in the first round results from a pre-selection of contacts. Only contacts who filled out their complete profile in the Jobmensa database received an invitation to participate. In all later rounds all contacts that featured an email address were asked to participate.
} 
Before the first round a pre-test using 30,000 contacts took place to test different email subject lines, email lengths and prizes. Moreover, we tested the performance of different question types and the questionnaire design. To name just a few results, conversion increases if the prize (money) is featured prominently in the subject line. Other than that the subject line should be short. On the contrary, the email itself can be more detailed. ${ }^{3}$ As economic theory suggests cash prizes, in our case Amazon vouchers, are preferred over material prizes. ${ }^{4}$ This is still true, even though the effect becomes smaller, if students are offered the chance to choose between cash or material prizes. In this case economic theory would clearly suggest indifference. With respect to the questionnaire itself the amount of clicks necessary to fill out the survey should have a negative impact on conversion rates. For a small amount of possible choices, multiple choice questions are preferred to drop-down questions. Even more important, free text fields require the participant to switch between mouse and keyboard and lead to an even larger drop in conversion. With respect to the design, less colour and more white in the background improved conversion. ${ }^{5}$

Table 2.1 shows that the time respondents needed to fill out the online questionnaire increased almost monotonically from one round to another. The main reason for this increase in the completion time is that the questionnaire increased in length. Since round two, personality questions are included in the questionnaire. Participants, however, are given the option to skip this psychological section. ${ }^{6}$ The increase in completion time from round four to round five is the result of a new large section on wage expectations. ${ }^{7}$ The section on wage expectations was kept for round six, but this cannot explain why completion times went up by more than 15 minutes. This increase has been caused by the inclusion of a voluntary test for cognitive ability. It seems that, once students decide to participate in the psychological section of the questionnaire, they are willing to put in the required effort. Nevertheless, it is surprising that the within questionnaire conversion rate in the sixth round is above that in the first round even though the time needed to complete the questionnaire almost doubled. The previous paragraph already gives hints on how to improve the performance of an online questionnaire. Still, it is most likely true that, all else constant, a longer survey will lead to a lower within questionnaire conversion rate.

During the six rounds of data collection we varied both the intensity and the spread of the incentive. As the pre-test ruled out material prizes, all rounds were incentivised with the help of Amazon vouchers only. Round one

\footnotetext{
${ }^{3}$ The short and long test mails included 149 words and 233 words, respectively.

${ }^{4}$ Free newspaper subscriptions as well as e-readers were included.

${ }^{5}$ A 100 percent blue-green background was tested against a combination of blue-green and white. Blue-green marks the corporate identity of the student network Jobmensa and appears in its logo.

${ }^{6}$ Only roughly 20 percent of the participants decide to skip as they can double their chance to win an Amazon voucher and can request their own psychological profile.

${ }^{7}$ The research is still ongoing and not subject of this dissertation.
} 


\begin{tabular}{lcccccc}
\hline \hline & $\mathrm{R} 1$ & $\mathrm{R} 2$ & $\mathrm{R} 3$ & $\mathrm{R} 4$ & $\mathrm{R} 5$ & $\mathrm{R} 6$ \\
\hline Start d.c. & 02.10 .12 & 01.03 .13 & 02.09 .13 & 11.03 .14 & 16.09 .14 & 16.03 .15 \\
End d.c. & 16.10 .12 & 14.03 .13 & 16.09 .13 & 27.03 .14 & 09.10 .14 & 01.04 .15 \\
Email c.r. & $11 \%$ & $9 \%$ & $7 \%$ & $8 \%$ & $8 \%$ & $7 \%$ \\
Participants & 16,420 & 18,445 & 18,895 & 25,252 & 24,807 & 23,585 \\
Question. c.r. & $58 \%$ & $72 \%$ & $66 \%$ & $67 \%$ & $61 \%$ & $61 \%$ \\
Avg. time & $31: 55$ & $36: 35$ & $36: 01$ & $39: 07$ & $42: 31$ & $59: 53$ \\
Prize money & $€ 1,000$ & $€ 1,000$ & $€ 3,000$ & $€ 2,000$ & $€ 2,000$ & $€ 5,000$ \\
\hline \hline
\end{tabular}

Table 2.1: Overview of the six rounds of data collection (R1 - R6) including the start and end date of the collection (d.c.), the conversion rate (c.r.) linking emails sent out to participants starting the questionnaire, the participants starting the questionnaire, the conversion rate (c.r.) of participants starting to those ending the questionnaire, the average time taken by respondents to complete the full questionnaire and the prize money given away to the participants in form of a lottery.

and two included five Amazon vouchers of $€ 200$ respectively. Round three included a test using vouchers with a total value of $€ 3,000{ }^{8}$. However, 10 percent of the participants were told that the prize money is only $€ 1000$ and another 10 percent that it is $€ 2000$. Conversion in the $€ 2,000$ group was higher than in the $€ 1,000$ group, though, no difference between $€ 3,000$ and $€ 2,000$ could be found. As a result, in the two data collections thereafter we used a total price money of $€ 2,000 .{ }^{9}$ Finally, the price money was increased to $€ 5,000$ for the sixth data collection. ${ }^{10}$ Additionally, for students who filled out the questionnaire in the previous round the chances to win were increased by factor five. Both was done to increase incentives to be able to create a larger panel dimension in the data. Unfortunately, neither the panel dimension nor the conversion rate show an upward trend. Nevertheless, it is possible that the additional incentive helped to keep them constant given that the length of the questionnaire increased.

\subsection{Sample Characteristics}

The Fachkraft data includes the usual set of demographic variables. Close to the end of the questionnaire respondents are asked to fill in their gender, age, relationship status, amount of children, type of accommodation and nationality. ${ }^{11}$ Moreover, questions on the occupation of the partner

\footnotetext{
${ }^{8}$ The total amount was divided into five times $€ 200$ and 40 times $€ 50$

${ }^{9}$ The price money was split in one $€ 500$ voucher, five $€ 100$ vouchers and $20 € 50$ vouchers.

${ }^{10}$ One $€ 1,000$ voucher, four $€ 250$ vouchers, ten $€ 100$ vouchers and $40 € 50$ vouchers.

${ }^{11}$ Conversion rates are lower if participants need to fill in personal information right at the beginning. Close to end engagement with the questionnaire is higher and those type
} 
as well as the degrees of the parents are included. Some rounds are more detailed with respect to children and family planning or the type, size and satisfaction of / with the accommodation.

The average time taken to fill out the online survey already suggests that the Fachkraft data contains a variety of information. All rounds include a full description of the participants' study including, for example, the university, degree, semesters, subject or grade point average. Moreover, each round contains information on previous education such as type of high school, grades, majors or vocational education, if applicable. A section on student jobs is part of each round as well, however, the questions included in this section are subject to change. The same is true for a section featuring questions on future job expectations and intentions. Concerning their part-time job students have so far been asked, for instance, about their actual hourly wage, an hourly wage they consider "fair", weekly working hours and time slots or types of work they prefer, currently do or did in the past. The questionnaire section on future jobs included the intention and motives to migrate after finishing higher education, sectors, occupations and companies to work in / for as well as the amount of working hours and wage expected. Additionally, in each of the rounds three, four and five a vignette-type question has been included that asked participants to choose a part-time job, a future graduate job or a future life plan respectively. ${ }^{12}$

As the Fachkraft data is collected through a student job network it is important to analyse whether the data gives a representative image of German students. Comparing observable characteristics of the sample to another German student survey called Sozialerhebung reveals no large differences (Hartmann et al. (2013); Bergerhoff et al. (2015)). The Sozialerhebung is collected systematically on a university level since 1951 and is funded by the German government. Despite this systematic selection of participants the Sozialerhebung is also subject to non-response bias. Most notably, the true share of female students is close to 50\% in Germany (Middendorff, Apolinarski, Poskowsky, Kandulla, \& Netz, 2013). Table 2.2 displays the averages of selected key descriptive statistics. The somewhat larger difference in age is probably driven by the fact that we choose to drop students older than 40 years. Moreover, while the Sozialerhebung uses letters and printed questionnaires, we use emails and an online questionnaire. The different ways of communication may also lead to differences with respect to age. The strongest suspect is that students in the Fachkraft data are different in their working habits. The differences to the Sozialerhebung, however, are not only small for demographic variables, but also for the share of students that currently have a job. Finally, Table 2.2 does not display the subject of the participants and the region they live in. With respect to these variables the differences are, as well, minor.

Additional to the previously listed variables the survey includes various

of questions lead to less participants dropping out.

${ }^{12}$ Chapter 6 analyses the part-time and graduate job vignette questions. 


\begin{tabular}{lccccccc}
\hline \hline & R1 & R2 & R3 & R4 & R5 & R6 & SE'12 \\
\hline Age & 23.7 & 22.4 & 23.2 & 23.3 & 23.3 & 22.5 & 24.4 \\
Semesters studied & 5.0 & 4.7 & 5.6 & 5.7 & 5.9 & 5.9 & 5.1 \\
Male-Female ratio & $40: 60$ & $40: 60$ & $42: 58$ & $42: 58$ & $43: 57$ & $42: 58$ & $42: 58$ \\
Working students & $68 \%$ & $60 \%$ & $62 \%$ & $63 \%$ & $67 \%$ & $67 \%$ & $62 \%$ \\
\hline \hline
\end{tabular}

Table 2.2: Overview of key descriptive statistics of the participating students comparing the six rounds of the Fachkraft data set (R1-R6) to the Sozialerhebung in 2012 including the average age, the average amount of semesters studied, the gender ratio and the share of participants with a part-time job.

psychological measures. Rounds two, four and six include the fifty item IPIP Big 5 personality test. The IPIP test is scored on the five dimensions: Openness, Conscientiousness, Extraversion, Agreeableness and Emotional Stability (Goldberg et al., 2006). Moreover, rounds two to six feature a module for economic preferences or, in that sense, economic personality traits. The module was developed by Falk, Becker, Dohmen, Huffman, and Sunde (2014) by starting with a large pool of survey questions from which only those with the best predictive power of experimental outcomes were selected. The traits included in the module are Impatience, Risk Aversion, Trust, Altruism and Positive and Negative Reciprocity. Additionally, round five included a module to measure the attitude of work of the participants from the World Values Survey (2014) which has also been used in an experiment by Borghans, Meijers, and Ter Weel (2008). Questions to measure self-esteem were included in round six. Finally, round six included a measure for cognitive ability, more specific a selection of ten items from the Raven Progressive Matrices Test (Raven \& Court, 1998) that has been also been used by Falk and Szech (2013).

As the Big 5 personality traits will be used repeatedly in the following Chapters we present a brief syntheses of the literature. Individuals with high Openness to experience (or Intellect) are imaginative, aesthetically sensitive and have a rich emotional life. They are intellectually curious, have a need for variety and tend to be undogmatic and behaviourally flexible (McCrae and Costa (1989), McCrae and Costa (1985)). Empirical results linking Openness to labour market outcomes are mixed. Dunn, Mount, Barrick, and Ones (1995) report that from the perspective of recruiters Openness was considered important only for jobs which needed some degree of creativity. ${ }^{13}$ Rothmann and Coetzer (2003) find a positive correlation between Openness and management performance, but not with creativity or task performance. Barrick and Mount (1991) find that Openness is positively associated with job training performance ratings, but do not find a strong association with job performance.

\footnotetext{
${ }^{13}$ In their paper these occupations were journalist and medical technologist.
} 
Conscientiousness (or Will to Achieve) refers to the personal need for organisation (i.e. punctuality, hierarchy etc.), persistence and achievement. The American Psychology Association dictionary describes it as the "tendency to be organised, responsible and hard-working."' Perhaps unsurprisingly, Conscientiousness has been found to be a strong, positive predictor of job performance and labour-market outcomes (Barrick and Mount (1991), Salgado (1997), Nyhus and Pons (2005)). The ability to delay gratification, a component of Conscientiousness, for example predicts a large range of life time outcomes including health, happiness and educational attainment (Almlund, Duckworth, Heckman, \& Kautz, 2011); a channel through which part of the effect may be transmitted. Heckman, Humphries, Urzua, and Veramendi (2011) suggest in a working paper that much of the correlation with job performances should be moderated by educational attainment.

Extraversion (or Surgency) measures individual traits such as sociability, activity, dominance, and the tendency to be enthusiastic and experience positive emotions (McCrae \& Costa, 1989). Extraversion was found to predict job performance in occupations where success largely depends on social interaction like in management and sales, (Barrick \& Mount, 1991). In their meta analysis with a focus on sales Vinchur, Schippmann, Switzer III, and Roth (1998) find that both Extraversion and Conscientiousness predict success in actual sales better than cognitive ability.

Agreeableness (or Likeability) captures characteristics like sympathy, trust, cooperation, modesty and altruism. Agreeable subjects tend to be sensitive and try to maintain harmony in relationships. A. Becker, Deckers, Dohmen, Falk, and Kosse (2012) find that unlike other traits Agreeableness is correlated with several economic preferences such as patience, i.e., discount rates, trust, altruism and with positive as well as negative reciprocity. Nyhus and Pons (2005) report a negative correlation between earnings and Agreeableness for women. In contrast, Rothmann and Coetzer (2003) find a positive correlation between Agreeableness and management performance. Barrick and Mount (1991) find that Agreeableness does not show strong associations to any type of occupation ${ }^{14}$ investigated.

Neuroticism (or Emotional Instability) describes the tendency to experience negative emotions such as anxiety, anger, depression and other manifestations of emotional instability (McCrae \& Costa, 1989). High scores of Neuroticism may indicate some form of psychiatric problem. Neuroticism has been found to be negatively associated with job performance (Nyhus and Pons (2005), Salgado (1997)). Dunn et al. (1995) find that Neuroticism is the second most important personality component (after Conscientiousness) of employability in the eyes of recruiters. A possible explanation for this could be that subjects scoring high on Neuroticism find it harder to cope with stressful situation in the workplace.

More than 80 percent of the observations that make up the Fachkraft

\footnotetext{
${ }^{14}$ Their sample includes professionals (accountants, engineers, teachers etc.), managers, police, sales and skilled/semi-skilled (i.e. nurses, farmers, clerics etc.) occupations.
} 
data result from students that participated only once. Still, the data contains a small panel dimension. Of the total 127,404 observations sampled in the six rounds 13 percent are linked to students that participated twice. Table 2.3 lists the shares of observations by the amount of participation. Most notably, some students even participated in all rounds. Given that there is only one such student in a thousand participants, this dimension consist of little more than 20 individuals in total. On average each student participated in 1.28 rounds.

While a large panel dimension benefits the analysis of certain questions it can also hint towards biases in the sample. In a random sample the probability of participation should be the same irrespective of whether a student participated in the past. Hence, a large panel dimension would mean that certain individuals are more likely to participate than others potentially leading to a response bias. In the Fachkraft data the average chance of participation is close to 6 percent. The probability to participate given a participation in the previous round is between 7.5 percent and 10 percent. Therefore the panel dimension is already larger than one would expect given a completely random draw. Students are, however, explicitly encouraged to participate again. On the last page students can opt-in to be notified for future data collections. This probably explains the small gap in the chances to participate. ${ }^{15}$

\begin{tabular}{lc}
\hline \hline Number of participations & Share \\
\hline Once & $80.7 \%$ \\
Twice & $13.0 \%$ \\
Three times & $4.2 \%$ \\
Four times & $1.4 \%$ \\
Five times & $0.5 \%$ \\
Six times & $0.1 \%$ \\
\hline \hline
\end{tabular}

Table 2.3: Size of the panel dimension in rounds one to six of the Fachkraft data.

Later Chapters in this dissertation make use of the Fachkraft data. Chapter 3 uses rounds two and four of the Fachkraft data and links the study choice and the semesters studied of an individual to the Big 5 and economic personality traits. Age at entry into higher education, the highest parental education and the grade point average are used as control variables. In Chapter 6 two different vignette questions featured in rounds three and four of the data set are analysed. These questions allow to display the trade-offs between various job characteristics for student and graduate jobs. Examples for the characteristics used are the wage, the location of the job, hours that need to be worked as well as the type of job. Finally, Chapter 7

\footnotetext{
${ }^{15}$ The increased incentive for repeated participation in round six did not lead to an increase in the probability of participation.
} 
uses an open question from round four which measures five points along an indifference curve for working hours and wage to develop a framework for the preference for leisure of the participants. This is done with respect to the first graduate job.

\subsection{Selected descriptive Outcomes}

This section displays a selection of interesting findings that result from the Fachkraft data. Contrary to Chapter 3, Chapter 6 and Chapter 7, which also use the Fachkraft data, these selected outcomes are purely descriptive. More descriptive results are featured in the different volumes of the study "Fachkraft 2020" (Hartmann et al. (2012); Hartmann et al. (2013); Bergerhoff et al. (2015)). "Fachkraft 2020" is a yearly publication on the Fachkraft data collections released jointly by Maastricht University and Studitemps.

In the last years enrollment in higher education increased strongly in Germany. Between 2007 and 2012 the size of the German student population increased from below two million to over 2.5 million students (Statistisches Bundesamt Deutschland, 2014). This trend can be explained by multiple events. First, Germany suspended the mandatory military service in 2011. Already in the years before fewer high school graduates were called up for military service (Bundesministerium der Verteidigung, 2013). Second, most German states (Bundesländer) decreased the time needed to obtain the general qualification for entrance into higher education (Abitur) from 13 to twelve years. There is no unique time line for this shift as educational reform in Germany is not decided on the federal but on a state level. In any case, both reforms, suspending military service and reducing schooling, lead to dual high school cohorts entering higher education at the same time. These two reforms, however, surely did not cause the increase in the student population by themselves. Over the same time interval, 2007 until 2012 , the share of individuals of each cohort that enrolled into higher education increased from less than 40 percent to over 50 percent (Statistisches Bundesamt Deutschland, 2014). Other than the two reforms this effect is likely to lead to a permanently larger student population.

With the overall development in mind, the focus is now shifted to different aspects of student life or higher education policy. In the following migration flows within Germany before and after higher education will be analyzed. Moreover, the increase in the student population is likely to affect the rent of student apartments. In order to finance student life in general, including the rent, it is analyzed when students work next to their study. Finally, we give some first descriptive results on the job preferences of students which is the topic of Chapters 6 and 7 . 


\subsubsection{Migration Flows within Germany}

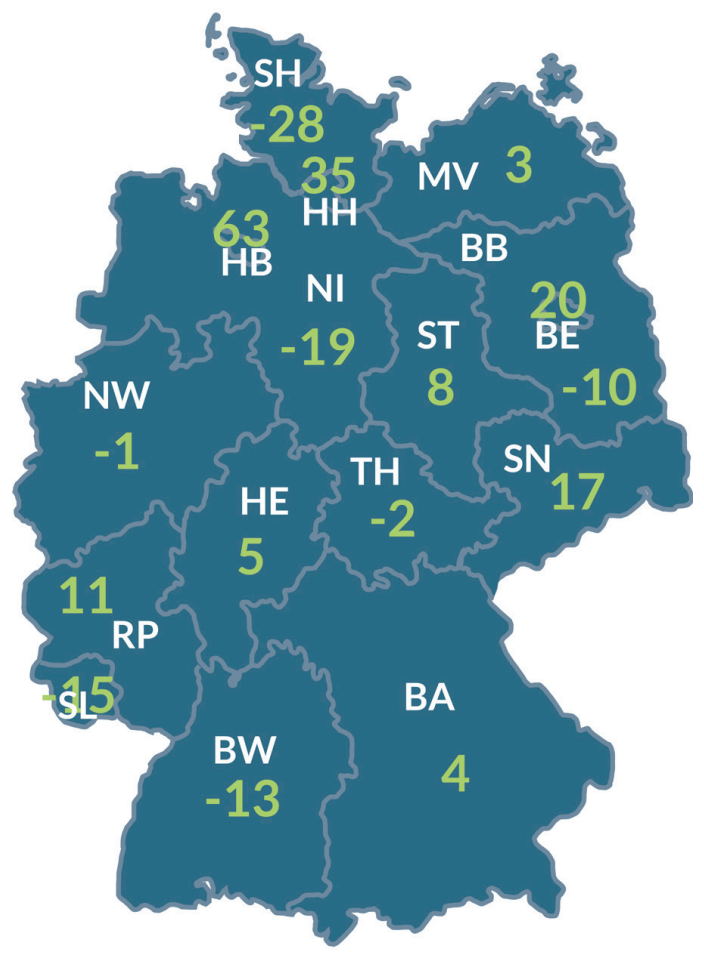

Figure 2.1: Net migration flows (\%) between German states at the intersection of secondary and higher education relative to local students.

More than 60 percent of all students change their postal code, and thereby their address, at the moment they move from secondary into higher education. Almost 50 percent of all students even move to a different Bundesland. ${ }^{16}$ There can be various reasons for this. Some study fields, such as Medicine, use a system in which spots are centrally assigned to students based on high school grades. In this system students can only list their preferred locations. Besides, not all institutions of higher education offer all kinds of study fields. Thereby students who want to study a certain field may be forced to move to a different city. In past years some German states also required students to pay tuition fees. However, Bayern was the last Bundesland to abolish tuition fees for public universities in 2013. Finally, students have clear preferences of where they would like to live during their

\footnotetext{
${ }^{16}$ The share of students living with their parents remained close to 25 percent over the different rounds of data collection. If at all, a small upward trend can be noted over the last three rounds. An explanation could be the increase in total student figures and the resulting higher rental prices.
} 


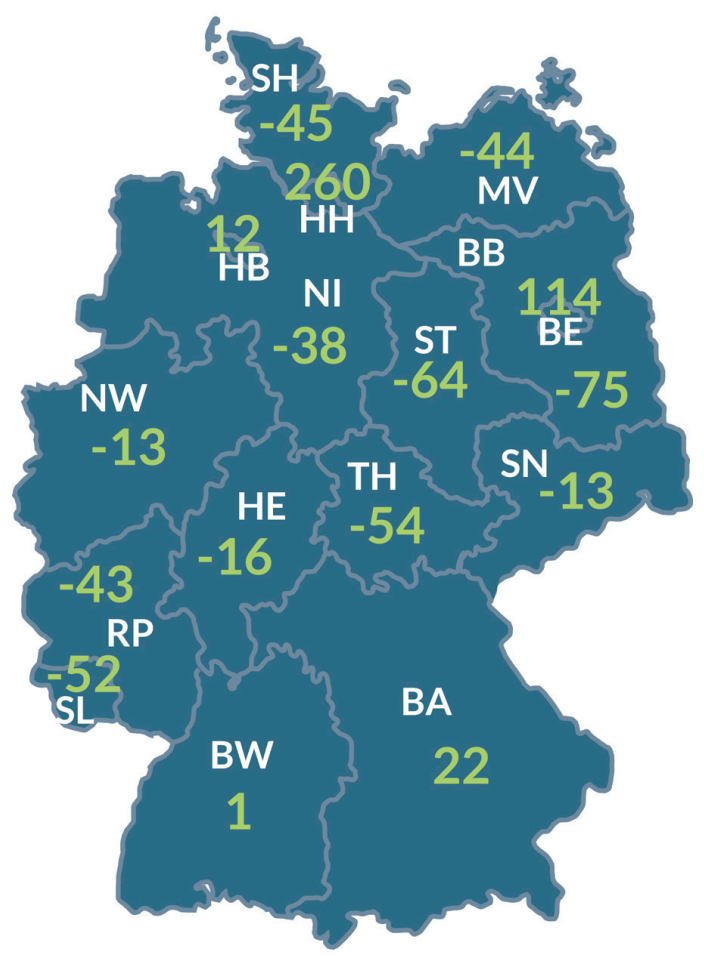

Figure 2.2: Net migration flows (\%) between German states from finishing secondary education to planed labour market entry (after higher education) relative to local students.

study. $^{17}$

All these aspects lead to domestic movements at the intersection of secondary and higher education. ${ }^{18}$ Figure 2.1 displays these as a share of the local student population at the end of secondary education. ${ }^{19}$ In northern Germany students are drawn towards the city states of Bremen and Hamburg and out of Niedersachsen or Schleswig-Holstein. The same logic applies to Berlin and Brandenburg in the East of Germany. The larger states lose students who migrate to the small city states nearby. Additionally, most East German states show a net gain of students. This leads, in total, to a

\footnotetext{
${ }^{17}$ The tendency to move before and after higher education is quite stable across different studies. With a difference of 13 percentage points students of Medical Sciences move least before higher education, while Law students are most likely to move.

${ }^{18}$ International student movements are not included in this analysis as students who leave Germany after secondary education to study in another country are most likely not part of the Jobmensa database. Only inward mobility of students who finished secondary education in another country can be measured: Around $10 \%$ of higher education students did not obtain their high school diploma in Germany.

${ }^{19}$ The Figure uses information from the second Fachkraft data collection.
} 
net loss of students in the Western Bundesländer.

Due to the size of some German states the numbers hide local patterns. While Bayern receives a net inflow of only 4 percent, its capital Munich is subject to a net inflow of 81 percent. In Baden-Württemberg, which as a state shows a net outflow of 13 percent, the capital Stuttgart grows with 91 percent. These two examples reveal inflows that are clearly larger than those observed in the city states Hamburg, Berlin or Bremen.

Students are also mobile during their studies. Given that we ask students at all different stages, however, these effects should cancel out in our data. The next big migrational step takes place at the intersection of higher education and the labour market. ${ }^{20}$ As the participants are still students we can only measure intentional migration in the future. ${ }^{21}$ Figure 2.2 illustrates the effect of migration before and after higher education. ${ }^{22}$ Thereby, a net inflow of students after higher education reinforces the inflow after secondary education in Hamburg and Berlin. On the contrary, the third city state, Bremen, is losing students at the intersection of higher education and the first graduate job. Even worse, the small inflow in the East German states right before higher education is outweighed by a stronger net outflow after higher education. The southern German Bundesländer, Baden-Württemberg and Bayern, are in total net receivers of higher education graduates.

The interaction between personality and mobility is potentially interesting. Chapter 5 shows that a semester abroad can change the personality of students. With the use of the Fachkraft data we can see that students with a certain personality are more likely to be mobile before as well as after higher education. The results are displayed in Table 2.4. Trust is positively related to mobility at both points in time. The same is true for agreeable students, however, in this case the correlation is negative. Impatience, Negative Reciprocity and Extraversion correlate negatively with moving before higher education, but no effect can be found for planned migration thereafter. On the contrary, Risk Aversion as well as Extraversion only play a role after higher education. Risk averse as well as emotionally stable students are less likely to move.

Given the overall demographic development in Western Europe it seems to be generally important to find solutions on how to attract educated workers. In that sense, whether a certain Bundesland gains or loses graduates is important for the local labour market. Additional to this general debate a second relevant aspect applies specifically to Germany. As noted before,

\footnotetext{
${ }^{20}$ Once more, international movements are not included in the analysis as foreign students who enter Germany after higher education for their first graduate job are most likely not part of the Jobmensa database. Only outward mobility of German students can be measured: Around $20 \%$ of German students plan to enter the labour market in another country

${ }^{21}$ The corresponding question asks for the state in which they would prefer their first graduate job to be located in.

${ }^{22}$ The Figure uses information from the second Fachkraft data collection.
} 


\begin{tabular}{l|c|c}
\hline \hline Personality Trait & Move at $(1)$ & Move at $(2)$ \\
\hline Altruism & 0.0264 & 0.0010 \\
& $(0.0213)$ & $(0.0209)$ \\
Impatience & $-0.0728^{* * *}$ & -0.0306 \\
& $(0.0236)$ & $(0.0231)$ \\
Neg. Reciprocity & $-0.0554^{* * *}$ & -0.0211 \\
& $(0.0204)$ & $(0.0200)$ \\
Pos. Reciprocity & -0.0030 & 0.0140 \\
& $(0.0228)$ & $(0.0224)$ \\
Risk & 0.0027 & $-0.0907^{* * *}$ \\
Trust & $(0.0206)$ & $(0.0203)$ \\
& $0.0807^{* * *}$ & $0.0825^{* * *}$ \\
Agreeableess & $(0.0222)$ & $(0.0217)$ \\
Conscientousness & $-0.0604^{* * *}$ & $-0.0636^{* * *}$ \\
& $(0.0231)$ & $(0.0226)$ \\
Extraversion & -0.0149 & 0.0043 \\
Emot. Stabilty & $(0.0240)$ & $(.0236)$ \\
& $-0.0470^{* *}$ & 0.0052 \\
Openness & $(0.0217)$ & $(0.0214)$ \\
& -0.0120 & $-0.04914^{* *}$ \\
\hline \hline
\end{tabular}

${ }^{*} p<0.10,{ }^{* *} p<0.05,{ }^{* * *} p<0.01$

Table 2.4: Correlation between moving (1) before higher education and (2) after higher education with personality shown by the coefficients and standard errors of a logistic regression model.

education is decided on a state level. Hence, institutions of higher education are also funded by the respective state and not by the federal government. ${ }^{23}$ A net inflow of students before higher education in combination with a net outflow thereafter negatively influences the budget of a Bundesland. In some way this is similar to the mobility of students on the European level. The topic of European student mobility is picked up in Chapter 4, which focuses on the benefits and costs of student mobility using a two-country model and the case of The Netherlands and Germany.

\subsubsection{Differences in Rental Prices}

The migration of students right before higher education indicates the preferences of students. Furthermore, if a location receives a large inflow of students this should lead to an increase in the rents of student housing.

\footnotetext{
${ }^{23}$ Public institutions of higher education collect no tuition fees from students.
} 


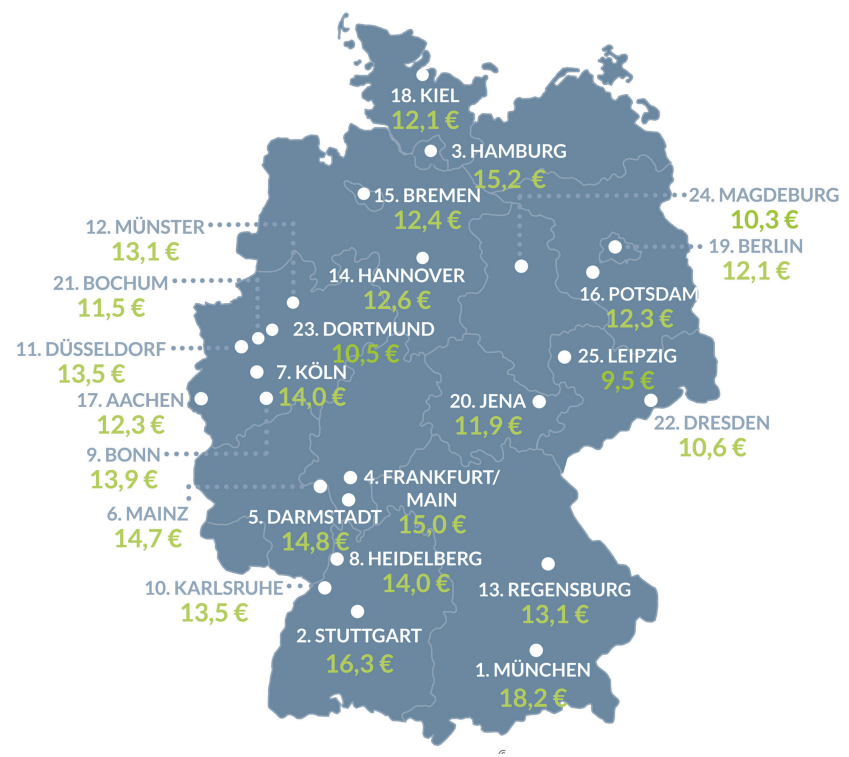

Figure 2.3: Monthly rent per square meter (including utilities) in the 25 largest German student cities.

\begin{tabular}{lccc}
\hline \hline Bundesland & Monthly Rent & Hourly wage & Working hours needed \\
\hline $\mathrm{TH}$ & $€ 269$ & $€ 8.44$ & 31.9 \\
$\mathrm{SN}$ & $€ 270$ & $€ 8,39$ & 32.2 \\
$\mathrm{SL}$ & $€ 309$ & $€ 9,58$ & 32.3 \\
$\mathrm{SH}$ & $€ 305$ & $€ 9,27$ & 32.9 \\
$\mathrm{ST}$ & $€ 267$ & $€ 8,02$ & 33.3 \\
$\mathrm{MV}$ & $€ 285$ & $€ 8,51$ & 33.5 \\
$\mathrm{BW}$ & $€ 326$ & $€ 9,51$ & 34.3 \\
$\mathrm{NI}$ & $€ 309$ & $€ 8,97$ & 34.4 \\
$\mathrm{BB}$ & $€ 309$ & $€ 8,91$ & 34.7 \\
$\mathrm{HE}$ & $€ 330$ & $€ 9,50$ & 34.7 \\
$\mathrm{NW}$ & $€ 331$ & $€ 9,29$ & 35.6 \\
$\mathrm{RP}$ & $€ 327$ & $€ 9,12$ & 35.9 \\
$\mathrm{BE}$ & $€ 346$ & $€ 9,47$ & 36.5 \\
$\mathrm{BA}$ & $€ 349$ & $€ 9,54$ & 36.6 \\
$\mathrm{HB}$ & $€ 324$ & $€ 8,77$ & 36.9 \\
$\mathrm{HH}$ & $€ 378$ & $€ 9,78$ & 38.7 \\
\hline \hline
\end{tabular}

Table 2.5: Monthly rent (including utilities), hourly wage in a student job and the resulting working hours needed to pay the rent in each German Bundesland. 
Figure 2.3 shows average rents per square meter and month (including utilities) for the 25 largest German student cities. ${ }^{24}$ A comparison with the descriptive results of student mobility within Germany gives mixed results. Munich, Stuttgart and Hamburg are at the top of the list and these cities are large net receivers of students. However, Berlin and Bremen are also associated with large inflows, while the rents in these cities remain at a much lower level. Similar evidence can be found for Sachsen. As a state it is highly popular among students, but rents in its two major cities, Dresden and Leipzig, remain at a very low level. In fact, the relationship may be reversed, so that the popularity could result from the low costs of student housing. Altogether, between round three and six of the Fachkraft data collections the rent per square meter (including utilities) shows neither an upward nor a downward trend. ${ }^{25}$

Using information on the wages students earn in their part-time job allows to calculate something which is closer to the real price of student housing. The ratio of hours of work needed to pay the monthly rate complements the previous picture. Table 2.5 illustrates that while the difference in rent from the cheapest to the most expensive German state is 42 percent, the hourly wages earned in a student job only differ by 22 percent from the minimum to the maximum. ${ }^{26}$ Hence, not all differences in rents can be taken up by a higher level of wage and some Bundesländer remain more expensive than others.

Moreover, adjusting for wage alters the ranking. Taking into consideration their high earnings students from Baden-Württemberg drop in terms of the real cost of student housing. Similarly, some East German and West German states become more alike. In terms of the hours of work needed to pay the rent there is hardly any difference between Thüringen, Sachsen, Sachsen-Anhalt and Mecklenburg-Vorpommern on one hand and the Saarland and Schleswig-Holstein on the other.

\subsubsection{Timing of Student Jobs}

Information on hourly wages is one aspect of the work life of students. Others questions from the Fachkraft data complement this image. One example is the coordination of study and work. Figure 2.4 and 2.5 give the weekly work schedule of students both during the semester when education takes place every day as well as during the semester break when only exams come about. ${ }^{27}$ The numbers refer to the share of all working students that are active within a certain time slot.

During the semester the largest shares of working students are observed in the afternoon. It appears that students have problems fitting full work

\footnotetext{
${ }^{24}$ The Figure uses information from the third Fachkraft data collection.

${ }^{25}$ The first two data collections do not allow to analyse rent on a square meter level.

${ }^{26}$ The Table uses information from the third Fachkraft data collection.

${ }^{27}$ The Figures use information from the second Fachkraft data collection.
} 


\begin{tabular}{|c|c|c|c|c|c|c|c|}
\hline TIME-SLOT & MONDAY & TUESDAY & WEDNESDAY & THURSDAY & FRIDAY & SATURDAY & SUNDAY \\
\hline $0: 00-5: 00$ & 2 & 2 & 2 & 2 & 4 & 7 & 5 \\
\hline 5:00-8:00 & 4 & 4 & 3 & 3 & 5 & & 4 \\
\hline \multicolumn{8}{|l|}{$8: 00-11: 00$} \\
\hline \multicolumn{8}{|l|}{$11: 00-14: 00$} \\
\hline $14: 00-17: 00$ & 24 & 23 & 22 & 23 & 28 & 26 & \\
\hline \multicolumn{8}{|l|}{ 17:00-20:00 } \\
\hline 20:00-24:00 & & & & & & & \\
\hline
\end{tabular}

Figure 2.4: Share of all students (\%) with a part-time job that work during a certain time-slot on a certain day during the semester.

\begin{tabular}{|c|c|c|c|c|c|c|c|}
\hline TIME-SLOT & MONDAY & TUESDAY & WEDNESDAY & THURSDAY & FRIDAY & SATURDAY & SUNDAY \\
\hline $0: 00-5: 00$ & 3 & 3 & 3 & 2 & 4 & 6 & 4 \\
\hline 5:00-8:00 & & & 8 & 8 & 8 & 7 & 4 \\
\hline 8:00-11:00 & & 52 & 3 & & & 1 & (8) \\
\hline 11:00-14:00 & & & & 30 & 34 & 22 & 12 \\
\hline 14:00-17:00 & 31 & & 5) & & & 23 & 13 \\
\hline 17:00-20:00 & & & & & & & 12 \\
\hline 20:00-24:00 & (10) & (9) & $(16$ & (11) & & & (8) \\
\hline
\end{tabular}

Figure 2.5: Share of all students (\%) with a part-time job that work during a certain time-slot on a certain day during the semester break.

days into their education schedule. Moreover, Monday and Friday show more working students than Tuesday, Wednesday and Thursday. Therefore students seem to focus more on their education in the "core" of the week and use the days just before or after the weekend to work. The drop on Sundays is most likely not a result of students being unavailable but more of low demand by employers. In Germany most businesses, including also retail and services, are normally closed on Sundays.

The picture strongly changes during the semester break. In the months of February and March as well as from mid July to mid October no education takes place at most German universities. As a result, students decide to 
work longer hours. Contrary to this overall trend, relatively less work takes place on Friday and Saturday nights as well as during weekends.

\subsubsection{First Results on Job Preferences}

Another question concerning student jobs is what job characteristics are important to students. The Fachkraft data contains ranking questions on job preferences. Participants were asked to rank the job attributes work climate, salary, promotion prospects, responsibility, job security and work - life balance against each other.

The results, as displayed in Figure 2.6, reveal that, students care mainly about salary and work - life balance. ${ }^{28}$ A good student job needs to fit the schedule and provide a sufficient amount of pay. Work climate is ranked third. Job security and responsibility are seen as being less important. Promotional prospects are least relevant.

The ranking of job attributes is likely to change after graduation. Consquently, participants were asked to rank the same set of job characteristics in regard of a future graduate job. The box plot of the results is shown in Figure 2.7. ${ }^{29}$ German students rank job security as the most important attribute of their future graduate job. Salary and the work climate rank thereafter. The median of promotional prospects is equal to that of work / life balance, however, the variation in preferences between students is much larger for the latter. Responsibility on the job ranks last in comparison to the other characteristics.

The present descriptive analysis already points out that preferences for student and graduate jobs are distinctly different. With the help of vignette questions more depth can be added to this analysis, as done in Chapter 6 . Besides, the results on the importance of work - life balance already suggest a strong heterogeneity in the preferences of students. Chapter 7 focuses on the preference for leisure and the heterogeneity in this measure with respect to a future graduate job.

\footnotetext{
${ }^{28}$ The Figure uses information from the second Fachkraft data collection.
}

${ }^{29}$ The Figure uses information from the second Fachkraft data collection. 


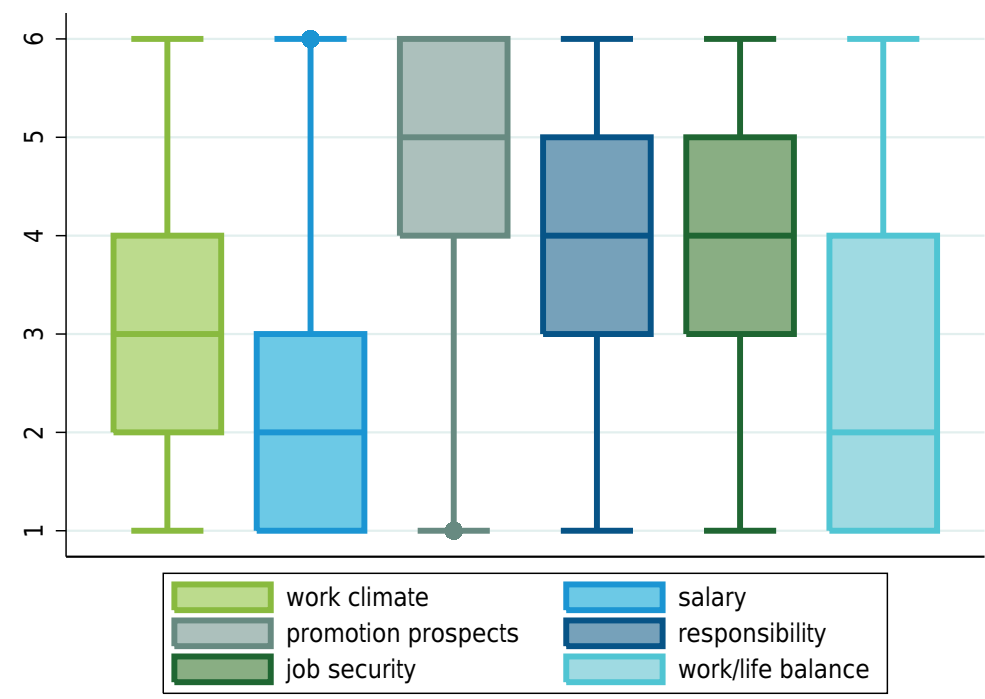

Figure 2.6: Box Plot of the results of a ranking question concerning the attributes of a student job from 1 (first priority) to 6 (last priority).

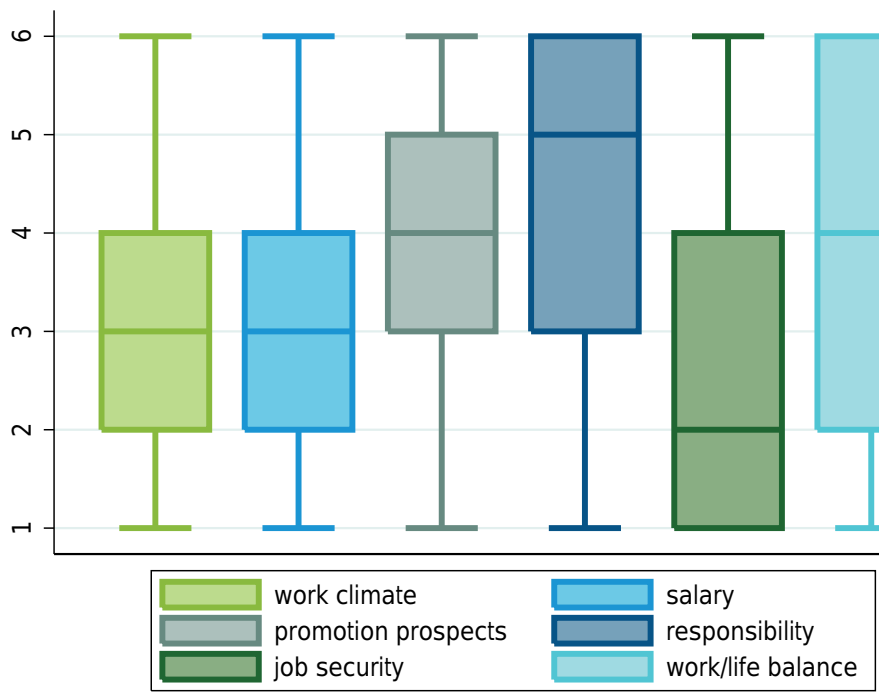

Figure 2.7: Box Plot of the results of a ranking question concerning the attributes of a graduate job from 1 (first priority) to 6 (last priority). 


\title{
Chapter 3
}

\section{Study Choice and Personality}

\author{
With Jan Bergerhoff
}

Choosing to study a particular subject at university considerably changes the set of employment possibilities later in life. Personal preferences and interests could, therefore, be expected to drive subject choice initially, but they could also change as a result of the specialisation. Using new data from over 23, 000 German students we find that study choice is influenced by personality differences. We find significant selection into study fields along the Big 5 personality traits and a comprehensive set of economic preferences. However, the personality measures do not show mean or standard deviation changes as a result of studying a certain subject. If personality plays a role in subject choice and students stick to that choice due to the opportunity costs of switching, a sizeable portion of personality based job sorting may take place just before entering university.

\subsection{Introduction}

The choice of a university subject has important implications for later life. Students often find it attractive to look for a job linked to their subject specialisation, either because a university specialisation increases their productivity in that area or (at least) because it signals interest, commitment and maybe talent for it. Once on the job they acquire more specific human capital making it even less attractive to switch to other areas. The skills that are obtained at university through specialisation are an entry card to professions in which many people choose to stay for all their working life, as the cost of switching becomes too high. This makes the choice of a university subject, that is arguably at the beginning of the described trajectory, a significant personal decision. 
Electing a field is a free choice that is yet subject to financial, regional and personal constraints. In a world with perfect information and foresight, high school graduates would compare all subjects' costs and benefits given their specific capabilities and a large vector of personal preferences. A decision without such perfect information must be based on perceptions, both of oneself and of the subject, that are also likely to be influenced by personal characteristics. Thus, if personality plays a role in subject choice and students tend to stick to that choice due to the opportunity costs of switching, a sizeable portion of personality based job sorting may take place not right after, but just before entering university.

In this Chapter, we investigate the link between personality and field of study. We want to know whether students majoring in different university subjects have different personality profiles and whether profiles change over the course of study. We investigate these questions using a new data set that consists of more than 23,000 German students who took part in the study "Fachkraft 2020". Students were asked to provide details on their study field and took a comprehensive personality tests. They answered fifty questions from the International Personality Item Pool (IPIP), of which ten at a time were used to construct the Big 5 character traits Openness, Conscientiousness, Extraversion, Agreeableness and Emotional Stability (Goldberg et al., 2006). ${ }^{12}$ Moreover, we elicited the economic traits Impatience, Risk Aversion, Trust, Altruism and Positive and Negative Reciprocity through a set of survey items that were designed by Falk et al. (2014) to most closely track the results of incentivised experiments. In our analysis we compare students at the start of their university career to students further down the road. We find that both, the Big 5 and the economic traits, play an important role when students choose their subject, but that the initial selection of personality profiles within fields remains unaffected by the length of study. This is true for the average personality profile of a study as well as the spread of personality profiles within one study field.

While previous studies have estimated the impact of personality on variables like the optimal length of education, the actual choice of study is mostly left out. The few studies that try to estimate the effect exclusively focus on either the selection into study programs or the change in personality due to studying a specific subject (Rutkowski and Domino (1975); Boone, van Olffen, and Roijakkers (2004); Lüdtke, Roberts, Trautwein, and Nagy (2011); Schurer, Kassenboehmer, and Leung (2015)). If these studies find significant effects, the causality between the field of study and personality remains unclear. The selection into a certain study track can be influenced by the personality of students. Once enrolled, the study track might then change the personality of students. It is, therefore, essential

\footnotetext{
${ }^{1}$ Emotional Stability is the inverse of the trait Neuroticism, which is an item of other versions of the Big 5.

${ }^{2} \mathrm{~A}$ more detailed description of the Big 5 personality traits can be found in the section "Personality Measures" in Chapter 5.
} 
to model these two effects simultaneously to get an understanding of the inter-linkages between personality and study field. Moreover, these studies are also limited to either the Big 5 personality scores or economic personality traits. Jackson, Thoemmes, Jonkmann, Lüdtke, and Trautwein (2012) investigate both selection and personality change for military training in Germany. They find little change, but considerable selection.

Frey and Meier (2005) find in a large sample that economics students contribute less to a good course than students of other faculties independent of whether they were freshmen at university. From this Frey and Meier (2005) conclude that the more selfish character traits of economics students were likely to be the outcome of a selection process. Our evidence supports this viewpoint. We find that business and economics students differ significantly in almost all domains compared to the broad average of students: They show less Trust and Altruism, less Positive and more Negative Reciprocity. They are less risk averse and more patient, are less aggreeable and open while being more conscientious and extraverse. On the effect of studying economics the only change we find is actually an increase in Altruism and (weakly significant) in Agreeableness. ${ }^{3}$ The strongest individual selection result is on the positive relationship between studying Pedagogy or Psychology and being agreeable.

Psychologists offer a range of explanations for why students might select into subjects which fit their personality. Rutkowski and Domino (1975) find a link between personality and study skills. With a certain set of study skills students might, then, choose subjects in which they can benefit from their specific set of skills. More generally, the tendency to select environments which suit ones personality is well known in psychology and referred to as a proactive person-environment transaction. Along these lines Balsamo, Lauriola, and Saggino (2012) find evidence for a link between two Big 5 personality scores and major choice. Similarly, locus of control has been related to study field selection (Boone et al., 2004).

With respect to changes in personality psychologists differentiate between four different types. On a person level, intra-individual changes refer to changes in the personality scores, while ipsative changes are defined as changes in the relative weights of the different domains. On a group level, mean-level changes refer to a shifting of the group mean and rank order changes refer to a change in the ranking of different participants with respect to their personality (Roberts \& DelVecchio, 2000). Group-level changes are our first criterion to determine the link between personality and study fields in this Chapter. An ongoing shift of the distribution of personality scores of a certain subject, as a result of studying this subject, would be equivalent to changes in the mean level. Additionally, we propose a second measure for change in personality as the dispersion of the distribution of personality scores within one subject may change over time. This effect is not widely

\footnotetext{
${ }^{3}$ For details please refer to Table 3.3.
} 
described in the psychology literature. Theoretically it can occur without a change in the mean or the rank order. As a result, the average personality does not change, but the longer students study, for example, the closer they could move to the mean personality of their study field. A combination of the two effects is also possible.

The next section outlines the data used. Thereafter, we explain the methodology used in this Chapter and present the various results. Finally, a last section concludes.

\subsection{Data}

The data originates from the German student study Fachkraft 2020. In this Chapter we use data from the second and the fourth round. Since participation in the personality test was made explicitly voluntary ${ }^{4}$ and some observations had to be excluded ${ }^{5}$ the analysis uses 10, 155 observations from round two and 12,985 from round four. Most students participate in only one round so that the panel dimension of the dataset is small. For this study we will ignore the panel dimension and treat the data as a repeated cross-sectional set. ${ }^{6}$ For further information on this data set please refer to Chapter 2.

As noted, the personality test included the fifty item IPIP Big 5 personality test as well as a module for economic personality traits developed by Falk et al. (2014). The IPIP test is scored on the five dimensions: Openness, Conscientiousness, Extraversion, Agreeableness and Emotional Stability (Goldberg et al., 2006). The economic traits included in the module are Impatience, Risk Aversion, Trust, Altruism and Positive and Negative Reciprocity. All different personality scores are standardised for the analysis. Study fields are clustered into ten categories: Business and Economics, Communication and Media, Engineering, Language and Culture, Law, Math and Computer Science, Medical Science, Natural Sciences, Pedagogy and Psychology as well as Social Sciences. These fields cover all students that participated in the survey except those studying Sport or Theology, which were dropped due to a small sample size.

\subsection{Methodology}

With a total of eleven different personality traits and ten study tracks which we use in our analysis it is highly likely to obtain significant associations by

\footnotetext{
${ }^{4}$ The personality test came in an extra section after the core questionnaire. Students were informed that they had finished, but that they would help research and double their chances to win the lottery if they went on to do the personality test.

${ }^{5}$ Study field with a too small sample size, age below 16 or above 30, age at entry into higher education larger 25 years or semesters studied larger 20.

${ }^{6}$ A total of 2455 students participated in both questionnaires.
} 
chance. To avoid misinterpretations, we do not study each of the possible links between study tracks and personality traits separately, but focus on the share of the significant coefficients and the distribution of the p-values instead. If the results were only obtained due to sampling variation, the distribution of p-values would asymptotically converge to a uniform distribution. Hence, finding a distribution with a higher density for lower p-values suggests an effect of the respective explanatory variables.

To shed more light on the direction of causality, the personality based selection into study tracks as well changes in personality due to the study track are estimated simultaneously. If personality change caused by a particular study field happens over time, it should be the case that students at the very beginning of their study have not yet changed. Comparing such students across study fields, then, allows to look at selection effects. Next, as long as the different student cohorts are sufficiently similar, students in higher semesters can be compared to students in earlier semesters within the same subject. We attribute the differences between these students to a change in personality as a result of studying a certain subject.

A problem arises when trying to estimate three effects simultaneously: Age at entry into higher education, getting older and studying longer. Ideally, one would like to differentiate between the effect of a student getting older and that of a student studying a certain subject. However, age at entry into higher education is an important control variable for two reasons. First, if personality changes over time it is vital to control for the starting age. Second, age at university entry carries a lot of information about students. ${ }^{7}$ Keeping age at university entry means that the model can no longer differentiate between getting older and studying longer. ${ }^{8}$ Therefore, we define the age effect as the average effect of studying longer across all subjects. If a subject deviates from this age effect one can argue for study field specific personality change.

We propose a model in equation 3.1 in which personality $(P)$ is explained by study field dummy terms $(F)$ and interaction terms between study field dummies and the semesters studied $(S)$. Note that the constant as well as a general semester effect is left out. Hence, the procedure is equivalent to estimating separate regression models for each study field. Additionally, we use control variables $(C)$ to test for stability. These are gender, age at entry into higher education ${ }^{9}$, the grade point average of the student as well as the highest parental degree for social status ${ }^{10}$. Individuals and study fields are labeled $i$, and $j$ respectively. The regression is repeated for each of the Big 5 and six economic traits.

\footnotetext{
${ }^{7}$ Conscientious students, for example, are likely to start studying earlier.

${ }^{8}$ Every variable is a linear combination of the other two.

${ }^{9}$ Age at entry into higher education is demeaned as the constant would otherwise measure the personality of a student with a hypothetical entry age of zero years.

${ }^{10}$ The variable is included in the models in quantitative terms, but consists of four ordinal categories: higher education, meister degree, vocational education and no (known) education after compulsory schooling.
} 


$$
P_{i j}=\sum_{j} \beta_{j} F_{i j}+\sum_{j} \gamma_{j} F_{i j} S_{i}+C_{i j}+\epsilon_{i j}
$$

The dummy terms measure personality if semesters studied is equal to zero. Therefore, we can speak about a significant selection effect if the coefficient of the study field dummy $\left(\beta_{j}\right)$ is significantly different from the weighted average $(\mu)$ of the dummy terms of all other study fields $(k \neq j)$. Equivalently, a study field leads to a change in personality if its interaction effect between field and semesters studied is significantly different from the weighted average interaction effect. To decide about the significance we construct a t-statistic as follows:

$$
t=\frac{\beta_{j}-\mu(\beta)_{\text {all } k \neq j}}{\sqrt{s e_{j}^{2}+\mu(s e)_{a l l ~}^{2} \neq \neq j}}=\frac{\beta_{j}-\sum_{k \neq j} \frac{\beta_{k} n_{k}}{n-n_{j}}}{\sqrt{s e_{j}^{2}+\sum_{k \neq j}\left(\frac{s e_{k} n_{k}}{n-n_{j}}\right)^{2}}}
$$

Additional to mean level changes in the personality of a certain study field the spread distribution of personality can change. Even if average personality stays the same throughout the course of a study it could be true that the standard deviation changes. A decrease in its dispersion, for example, could result from students getting closer to the mean personality of their field by studying longer. To see whether this effect can be found we formulate a new model in terms of squared differences between individual and average study field personality rather than only personality itself. By definition this difference is dependent on the study field. However, the effect of studying longer on this mean deviations does not need to be the same for different study fields. Therefore, we estimate equation 3.3 in which this effect is as well dependent on the study field. The same set of control variables as before is used. ${ }^{11}$

$$
\left(P_{i j}-\bar{P}_{j}\right)^{2}=\sum_{j} \delta_{j} F_{i j}+\sum_{j} \phi_{j} F_{i j} S_{i}+C_{i j}+\epsilon_{i j}
$$

\subsection{Results}

\subsubsection{Selection and Mean Level Change}

Using the full set of control variables and estimating the regression in equation 3.1 for each of the eleven traits shows that 53 out of the 110 study field dummy terms are significantly different from the weighted average of the remaining dummy terms. Moreover, only eight out of 110 interaction terms between study field and semesters studied show significant deviations from the weighted average of the interactions. Hence, there is strong evidence

\footnotetext{
${ }^{11}$ Gender, age at entry into higher education, grade point average of the student and highest parental degree for social status.
} 
in favour of selection into study tracks based on personality. Given the significance level of $5 \%$, however, the few significant findings where study fields change personality are likely to have emerged by sampling chance. Therefore, we cannot find evidence that differences in personality between study fields are generally changing during the course of a study program. Our results, thus, indicate that the differences in personality originate from the selection of students into study fields.

This finding is robust across different specifications of the model. Table 3.1 reports the number of significant deviations for the selection and change effect in different model specifications. Type I models use the full set of control variables, while type II models use age at entry into higher education as the only control variable. Models of specification III include no control variables at all. From the table it can be seen that leaving out some of the control variables increases the share of significant findings. However, the increase in the number of significant change effects is too small to argue for a general effect. Table 3.1 also reports the significance of the control variables. Note that each of the eleven traits is regressed separately. Each control variable appears, therefore, in eleven regressions per model specification.

Similar conclusions can be drawn based on the distribution of p-values that result from testing one coefficient against the weighted average of all other coefficients. Figure 3.1 shows a histogram of the p-values of both, the selection as well as change effect for different model specifications. Note that if scores are drawn randomly from a t-distribution their p-values follow a uniform distribution. Hence, the strong clustering of points supports selection into study fields, while the rather uniform pattern rejects the idea of study field specific personality change. This is supported by the results of testing for a uniform distribution explicitly. ${ }^{12}$ Still, the distributions for the change effects are somewhat denser at lower p-values and indeed for specification III $58 \%$ of the p-values are lower than $50 \%$. Moreover, half of the significant change effects can be found in Altruism and Openness throughout all specifications. Nevertheless, we do not want to argue that the data allows to detect a general pattern in favour of study field based personality change.

Overall, it can be said that the Big 5 personality traits inform a little more on the personality based selection of study fields than the economic traits. However, it should be noted that each of the Big 5 domains carried information from ten separate questions, while each economic trait only comprised two. Depending on the model specification the ranking of significant effects differs. Still, Agreeableness and Conscientiousness seem to be most important for the selection of study fields. Extraversion and Open-

\footnotetext{
${ }^{12}$ Categorizing the p-values in 50 categories of equal size allows the application of a chisquare test for homogeneity to test whether the distributions are indeed uniform. For the distributions of the p-values in the selection case all specifications lead to a rejection of a uniform distribution with p-values below 0.01. In the change case a uniform distribution in specifications I to III cannot be rejected at p-values of $0.86,0.52,0.87$, respectively.
} 
ness show significant selection parameters for at least half of the study fields. The importance of Emotional Stability vanishes as more control variables are added. In the group of economic traits Altruism, Impatience and Trust are most decisive. Risk aversion, Negative and Positive Reciprocity are significant less than $40 \%$ of the time. The differences in the selection effects for these traits are picked up strongly by the control variables.

\begin{tabular}{|c|c|c|c|c|c|c|}
\hline \multirow[t]{2}{*}{ Trait } & \multicolumn{2}{|c|}{ Specification I } & \multicolumn{2}{|c|}{ Specification II } & \multicolumn{2}{|c|}{ Specification III } \\
\hline & Selection & Change & Selection & Change & Selection & Change \\
\hline Altruism & $6 / 10$ & $2 / 10$ & $7 / 10$ & $2 / 10$ & $7 / 10$ & $2 / 10$ \\
\hline Impatience & $6 / 10$ & $0 / 10$ & $5 / 10$ & $0 / 10$ & $6 / 10$ & $0 / 10$ \\
\hline Neg. Reciprocity & $2 / 10$ & $0 / 10$ & $4 / 10$ & $0 / 10$ & $4 / 10$ & $0 / 10$ \\
\hline Pos. Reciprocity & $3 / 10$ & $1 / 10$ & $5 / 10$ & $1 / 10$ & $5 / 10$ & $1 / 10$ \\
\hline Risk Aversion & $3 / 10$ & $1 / 10$ & $5 / 10$ & $2 / 10$ & $6 / 10$ & $2 / 10$ \\
\hline Trust & $6 / 10$ & $0 / 10$ & $6 / 10$ & $1 / 10$ & $6 / 10$ & $1 / 10$ \\
\hline Agreeableness & $7 / 10$ & $1 / 10$ & $10 / 10$ & $1 / 10$ & $9 / 10$ & $1 / 10$ \\
\hline Conscientiousness & $7 / 10$ & $0 / 10$ & $7 / 10$ & $1 / 10$ & $7 / 10$ & $1 / 10$ \\
\hline Extraversion & $6 / 10$ & $1 / 10$ & $6 / 10$ & $1 / 10$ & $6 / 10$ & $1 / 10$ \\
\hline Emotional Stability & $2 / 10$ & $0 / 10$ & $6 / 10$ & $0 / 10$ & $7 / 10$ & $0 / 10$ \\
\hline Openness & $5 / 10$ & $2 / 10$ & $5 / 10$ & $3 / 10$ & $5 / 10$ & $3 / 10$ \\
\hline Total & $53 / 110$ & $8 / 110$ & $66 / 110$ & $12 / 110$ & $68 / 110$ & $12 / 110$ \\
\hline Control Variables & \multicolumn{2}{|c|}{ Specification I } & \multicolumn{2}{|c|}{ Specification II } & \multicolumn{2}{|c|}{ Specification III } \\
\hline Entry Age H.E. & \multicolumn{2}{|c|}{$6 / 11$} & \multicolumn{2}{|c|}{$7 / 11$} & \multicolumn{2}{|c|}{-} \\
\hline Gender & \multicolumn{2}{|c|}{$9 / 11$} & \multicolumn{2}{|c|}{-} & \multicolumn{2}{|c|}{-} \\
\hline GPA & \multicolumn{2}{|c|}{$6 / 11$} & \multicolumn{2}{|c|}{-} & \multicolumn{2}{|c|}{-} \\
\hline Parental Edu. & \multicolumn{2}{|c|}{$9 / 11$} & \multicolumn{2}{|c|}{-} & \multicolumn{2}{|c|}{-} \\
\hline
\end{tabular}

Table 3.1: Share of significant deviations $(\alpha=0.05)$ of the selection and change effects as well as share of significant control variables for different model specifications.

\subsubsection{Personality Profiles}

Next, we investigate which personality traits are important for which study field. Here, we use the model specification with the full set of control variables. Table 3.2 and 3.3 show the t-scores of the selection and change effects respectively for all combinations of study fields and personality traits. We suggest caution when interpreting the change effects as the few significant results are likely to have been obtained by chance. Therefore, we will not elaborate on them and they are merely shown for completeness. With respect to selection, we see more significant effects. Students who decide to study Pedagogy or Psychology differ from the average student in that they show greater Positive Reciprocity, are more impatient, risk averse, trusting, 

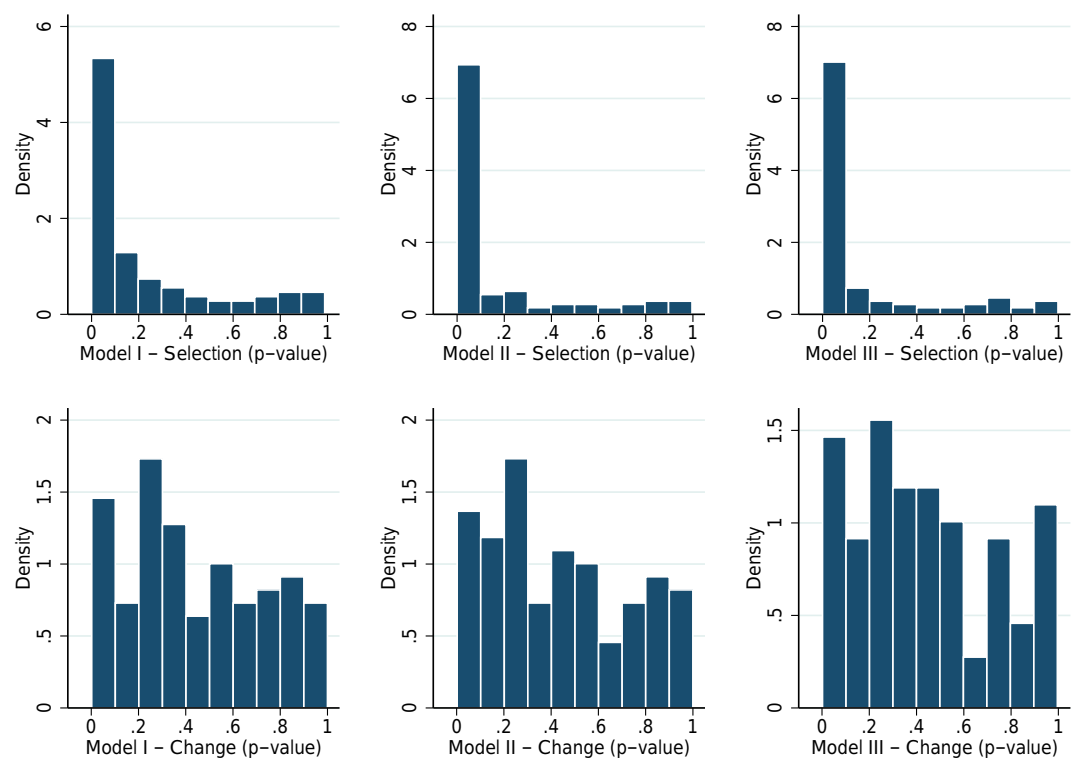

Figure 3.1: Distribution of the p-values of the selection and change effects for different model specifications.

agreeable and open, but less conscientious. Social Sciences attract students who are more altruistic, impatient, trusting, agreeable and use more Positive Reciprocity, but are less conscientious than the average student. Students with positive mean deviations for Altruism, Conscientiousness and Emotional Stability and negative mean deviations for Impatience, Agreeableness and Extraversion select into Engineering. Law students can be characterized by significantly negative t-scores for Altruism, Trust and Agreeableness as well as significantly positive t-scores for Negative Reciprocity, Conscientiousness and Extraversion. Communication and Media students are more extraverse and open, but less altruistic and risk averse. Selection effects for students in Math and Computer Science show negative deviations in Impatience, Agreeableness and Extraversion. Future medical scientists select into their field based on high Altruism, Trust and Conscientiousness. Natural Sciences are chosen by students who are trusting, but not agreeable, conscientious or extraverse. The study field Language and Culture shows positive mean deviations for Impatience and Openness and negative mean deviations for Conscientiousness and Emotional Stability. Finally, Business and Economics students are low on Altruism, Impatience, Positive Reciprocity, Risk Aversion, Trust, Agreeableness and Openness and high on Negative Reciprocity, Conscientiousness and Extraversion. We want to stress that 


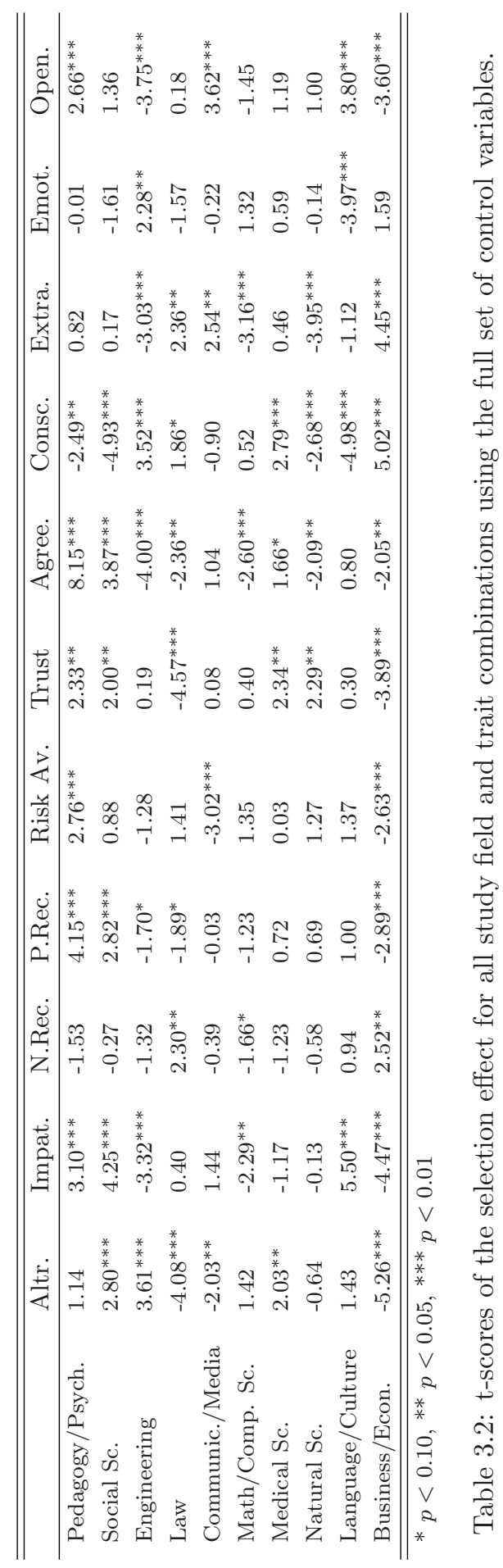




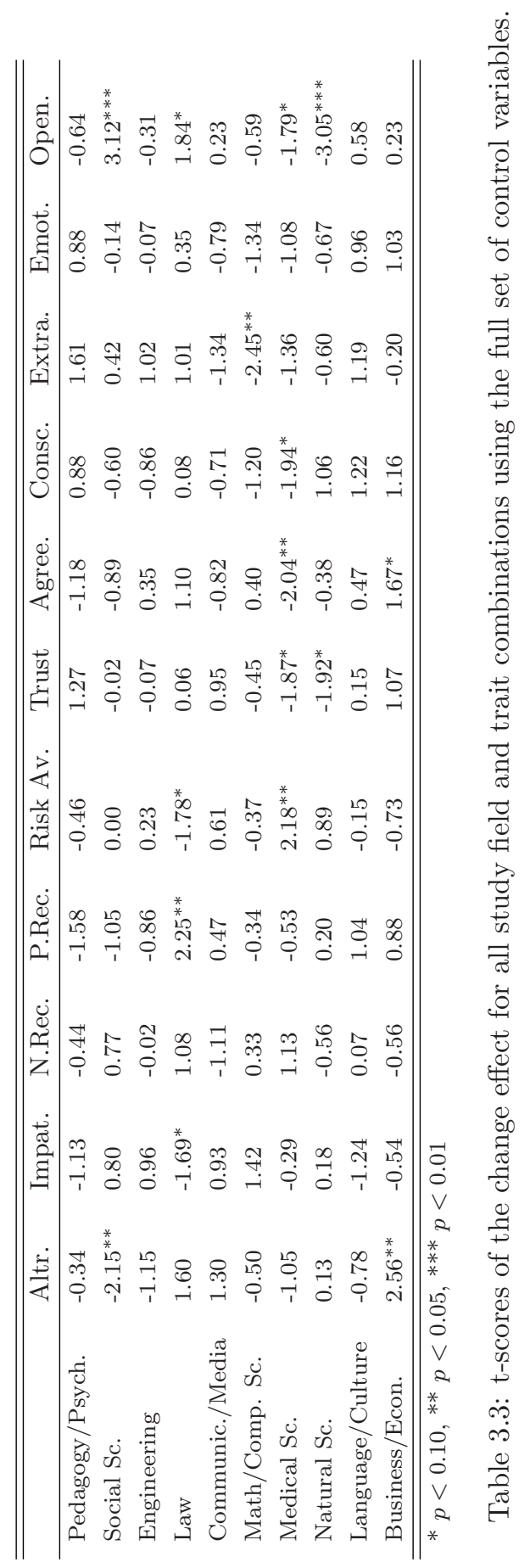


while these effects are significant they are mean effects. Personality per se is a not a very strong predictor of an individual's choice of study field. ${ }^{13}$

Counting the overlaps between study fields in terms of significant positive, significant negative and no significant deviation also allows us to analyse whether students selecting into them are similar. However, this only considers the direction, but not the size of the effect. Table 3.4 shows the amount of overlaps for the different study field combinations. With eight agreements respectively, Pedagogy / Psychology and Social Sciences as well as Math / Computer Science and Natural Sciences are most similar. The least overlap exists between Language / Culture and Business / Economics for which none of the effects point in the same direction.

\begin{tabular}{lcccccccccc}
\hline \hline & PP & SS & EN & LA & CM & MC & MS & NS & LC & BE \\
\hline Pedagogy / Psych. & $*$ & 8 & 1 & 1 & 3 & 3 & 4 & 5 & 6 & 1 \\
Social Sc. & & $*$ & 3 & 3 & 2 & 4 & 7 & 6 & 5 & 1 \\
Engineering & & & $*$ & 3 & 3 & 7 & 5 & 5 & 4 & 4 \\
Law & & & & $*$ & 6 & 6 & 5 & 6 & 2 & 6 \\
Communic. / Media & & & & & $*$ & 5 & 5 & 4 & 5 & 4 \\
Math / Comp. Sc. & & & & & & $*$ & 5 & 8 & 5 & 3 \\
Medical Sc. & & & & & & & $*$ & 7 & 5 & 2 \\
Natural Sc. & & & & & & & $*$ & 5 & 2 \\
Language / Culture & & & & & & & & $*$ & 0 \\
Business / Economics & & & & & & & & & $*$ \\
\hline \hline
\end{tabular}

Table 3.4: Overlap in effect direction (negative, positive, no significant difference) for the eleven traits between study fields.

\subsubsection{Change in Dispersion}

In the preceding analysis no mean change in personality as a result of studying could be found, but it could be that the distribution of traits changes in other ways. For example, students could become more similar over the course of their study. We estimate equation 3.3 type regression models in which the deviation between an individuals personality and the average personality of the respective study field is explained by studying longer. Again, this regression is repeated for the Big 5 personality traits and the six economic traits. To test for stability we vary the set of control variables that are included in the two models. Once more this leads to three different types of models. Type I models use the full set of control variables, type II models uses entry age as the only control variable and type III models use no controls.

\footnotetext{
${ }^{13}$ A multinomial logit regression estimating the chosen study field given only the Big 5 and six economic personality traits leads to a correct prediction in $24 \%$ of the cases.
} 

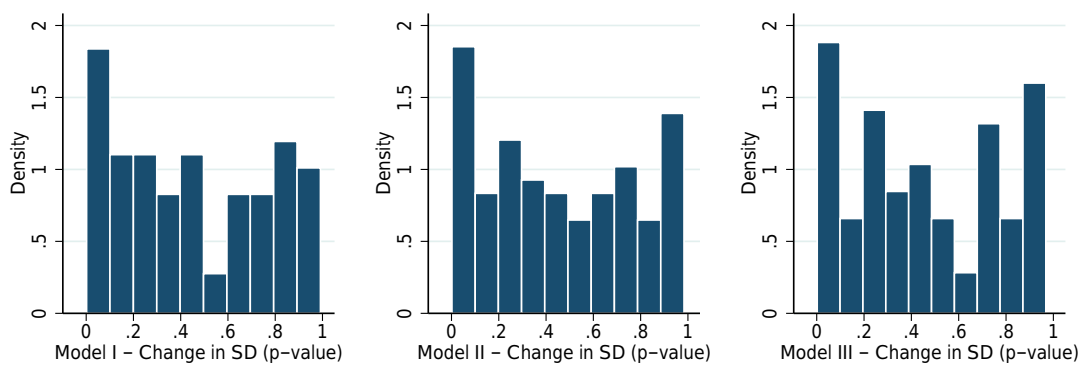

Figure 3.2: Distribution of the p-values of the deviations between individual and study field mean personality.

There are no signs of a general trend in the deviation between individual and study field mean personality. Across type I models only eleven out of 110 coefficients reveal significant changes in the standard deviation of the personality distribution over time. Moreover, from those eleven significant

\begin{tabular}{|c|c|c|c|c|c|c|}
\hline \multirow[t]{2}{*}{ Trait } & \multicolumn{2}{|c|}{ Specification I } & \multicolumn{2}{|c|}{ Specification II } & \multicolumn{2}{|c|}{ Specification III } \\
\hline & Significant & $\mathrm{R}: \mathrm{I}$ & Significant & $\mathrm{R}: \mathrm{I}$ & Significant & $\mathrm{R}: \mathrm{I}$ \\
\hline Altruism & $3 / 10$ & $3: 0$ & $3 / 10$ & $3: 0$ & $3 / 10$ & $3: 0$ \\
\hline Impatience & $0 / 10$ & $0: 0$ & $0 / 10$ & $0: 0$ & $0 / 10$ & $0: 0$ \\
\hline Neg. Reciprocity & $2 / 10$ & $0: 2$ & $2 / 10$ & $0: 2$ & $2 / 10$ & $0: 2$ \\
\hline Pos. Reciprocity & $0 / 10$ & $0: 0$ & $0 / 10$ & $0: 0$ & $0 / 10$ & $0: 0$ \\
\hline Risk Aversion & $1 / 10$ & $0: 1$ & $2 / 10$ & $0: 2$ & $2 / 10$ & $0: 2$ \\
\hline Trust & $0 / 10$ & $0: 0$ & $0 / 10$ & $0: 0$ & $0 / 10$ & 0:0 \\
\hline Agreeableness & $0 / 10$ & $0: 0$ & $0 / 10$ & $0: 0$ & $0 / 10$ & $0: 0$ \\
\hline Conscientiousness & $0 / 10$ & $0: 0$ & $0 / 10$ & $0: 0$ & $0 / 10$ & $0: 0$ \\
\hline Extraversion & $0 / 10$ & $0: 0$ & $1 / 10$ & $0: 1$ & $0 / 10$ & $0: 0$ \\
\hline Emotional Stability & $4 / 10$ & $0: 4$ & $4 / 10$ & $0: 4$ & $4 / 10$ & $0: 4$ \\
\hline Openness & $1 / 10$ & $1: 0$ & $1 / 10$ & $1: 0$ & $1 / 10$ & 1:0 \\
\hline Total & $11 / 110$ & $4: 7$ & $13 / 110$ & $4: 9$ & $12 / 110$ & $4: 8$ \\
\hline Control Variables & \multicolumn{2}{|c|}{ Specification I } & \multicolumn{2}{|c|}{ Specification II } & \multicolumn{2}{|c|}{ Specification III } \\
\hline Entry Age H.E. & \multicolumn{2}{|c|}{$4 / 11$} & \multicolumn{2}{|c|}{$5 / 11$} & \multicolumn{2}{|c|}{-} \\
\hline Gender & \multicolumn{2}{|c|}{$6 / 11$} & \multicolumn{2}{|c|}{-} & \multicolumn{2}{|l|}{-} \\
\hline GPA & \multicolumn{2}{|l|}{$5 / 11$} & \multicolumn{2}{|l|}{-} & \multicolumn{2}{|l|}{-} \\
\hline Parental Edu. & \multicolumn{2}{|l|}{$5 / 11$} & \multicolumn{2}{|l|}{-} & \multicolumn{2}{|l|}{-} \\
\hline
\end{tabular}

Table 3.5: Share of significant changes $(\alpha=0.05)$ in the deviations between individual and study field mean personality including the direction $(\mathrm{R}$ reduction, I - increase) for different model specifications. 
coefficients four point towards a reduction in standard deviation while seven show a significant increase. This picture is also robust across different formulations of the models as shown in Table 3.5. We can also see from Figure 3.2 that the p-values show no clear clustering and seem to follow a uniform distribution. ${ }^{14}$

Nevertheless, it should be noted that for each of the traits respectively the coefficients point in the same direction. For no trait both a reduction in the standard deviation of some fields and an increase for other fields could be observed. For Altruism and Emotional Stability the results are above what one would expect at the $5 \%$ significance level, with three out of ten study fields showing a lower standard deviation in Altruism and four out of ten study fields showing a larger standard deviation in Emotional Stability for later semesters. Generally, however, there is little evidence that students approach to or depart from the personality mean of their subject over the course of their study.

\subsection{Conclusion}

Personality is an important driver of labour market outcomes. Past research has focused on the effect of personality on job sorting (Dohmen \& Falk, 2010). This decision, however, is driven by the earlier subject choice. Understanding the link between personality and study field is therefore crucial in understanding job sorting. Moreover, it is conceivable that studying a certain subject affects the personality of students. If this was the case it would be valuable to know whether such changes are favourable with respect to the students' future in the labour market. The personality of an agent defines the environment under which he can operate comfortably. If a certain subject appeals to students with specific personality traits this may be because of its particular combination of teaching style, level of abstractness or degree of human interaction. Knowing about student personalities could therefore also help to improve current education programs by designing them to accommodate their particular group of students or by explicitly targeting new groups of students. For example, study programs attracting extravert students may benefit from greater interactiveness. Countries aiming at increasing the share of students in the natural sciences may devise new programs targeting different student pools.

In this Chapter we study the relationship between the personality of students and their field of study. Personality is measured by the Big 5 personality traits as well as six economic traits. A simultaneous analysis allows to disentangle the selection into a study field due to a certain personality from the effect of studying a certain subject on the personality. We find strong evidence for selection into study tracks based on personality,

\footnotetext{
${ }^{14}$ The null hypothesis of a uniform distribution cannot be rejected for each of the three models at p-values of $0.76,0.48$ and 0.13 respectively.
} 
where in the estimated models 53 out of 110 selection coefficients deviate significantly from the weighted average. We cannot confirm a change in personality as a result of studying a specific subject. Only eight out of 110 change coefficients differ significantly from the weighted mean. Moreover, we also do not find a change in the standard deviation of personality as a result of studying a certain field. Out of 110 coefficients only four point towards a reduction in standard deviation while only seven point towards an increase. The findings are robust with respect to various control variables. 



\section{Chapter 4}

\section{International Education and Economic Growth}

With Jan Bergerhoff, Lex Borghans and Tom van Veen. Published as Bergerhoff, Borghans, Seegers, and van Veen (2013).

In recent years international student mobility increased. While net hosting countries are in a better position to win highly educated students for their labour force, they face the additional cost of providing the education. In much of continental Europe these costs are not levied on students, but are borne by the national tax payers, making them an active topic of debate. Borrowing some fundamental equations from the Lucas growth model, this Chapter addresses the question whether countries benefit from educating international students. We derive conditions under which international education has a positive effect on economic growth, overall and in each specific country. Based on empirically motivated parameter values to calibrate our two-country model we find that international student mobility increases steady state growth for both countries on average by 0.013 percentage points. A small country that is favoured by the inflows of a larger country could experience an extra growth of 0.049 percentage points. The benefits from international education increase when a country tunes its education and migration policy.

\subsection{Introduction}

Education is generally viewed as an important determinant for economic growth. In recent years, international mobility of students in higher education has increased substantially and further growth is expected. This raises the question how the international flows of students will affect economic growth in general and in particular in those countries that either receive or send many students. 
The aim of this Chapter is to develop an endogenous growth model that incorporates the international mobility of students and to calibrate the model to investigate potential growth effects of internationalisation in higher education. We do this by building a two-country model, in which a fraction of the students in higher education studies abroad, around the human capital accumulation equation from Lucas (1988). We assume that the host country pays the direct costs of the university. Based on the literature we look for plausible values for the parameters in the model and the uncertainty in these estimates. Based on this we simulate potential growth profiles for countries that send or receive students. Our main findings are that total growth of both countries together always increases in steady state. Countries that receive a large group of foreign students who stay after their study will have a larger than average steady state growth rate. At the same time countries that receive a net surplus of students face an immediate negative shock in income when internationalisation increases. Receiving a large share of international students, thus, leads to a lower income at first but will benefit the country in the long run. This payback period is shorter if the fraction of foreign students that stay is larger. An international labour market that easily adopts home-educated foreign students therefore complements access for international students to the universities.

The question how internationalisation in higher education affects economic growth has important policy implications in the debate about the European market for higher education. While in countries like Australia, the US and the UK foreign students pay a fee that covers the costs of higher education, this is not true for European students that want to study in another European country. The Bologna agreement has created a common market for higher education in Europe comparable to the common market that already exists in the Anglo-Saxon World. There is, however, one main difference between the two models. Whereas in Anglo-Saxon countries tuition fees differ between locals/nationals and foreigners (in the US they even differ between in-state and out-of-state students and in addition between US and foreign students), this difference does not exist in Europe. Freedom of settlement in Europe implies that all European students must be treated the same and hence pay the same tuition fees as domestic students. For the Netherlands, for example, this implies that all European students pay the Dutch tuition fee of about 1.800 Euros per year. For Germany this means that all European students can study for free at a number of German universities. Governments are therefore confronted with the question whether they should promote the inflow of foreign European students or should make it less attractive for foreign European students to study in their country, and perhaps encourage their own students to study abroad.

This Chapter is related to literature about the returns to education and endogenous growth. Economists have been capturing the effect of education on economic growth into a series of growth models, which go back to the Solow growth model. These models manage to capture a broad range of the 
features associated with education, such as positive externalities and opportunity costs included in Lucas (1988) or the necessary monetary investment in (Mankiw, Romer, \& Weil, 1992). Research shows that an investment in education is a profitable investment: in his overview of empirical research McMahon (2004) finds that the private rate of return on education is around 10 percent while the social rate of return is around 17 percent for OECD countries. Empirical evidence confirms the positive effect of education on economic growth. The key driver of this relation is the positive relation between education and productivity.

The Chapter also relates to the literature on student mobility. Existing endogenous growth models assume that graduates stay in the country after finishing their studies. But with increasing globalisation and increasing (student) mobility, graduates do not automatically stay in the country in which they have been educated. This does not only hold for European students: in particular the $\mathrm{BRIC}^{1}$ countries have been very active in changing the brain drain into a brain gain by attracting natives who have been educated abroad, back to their home-country. On the other hand, part of the international student population is expected to stay in the host country. This changes human capital as well as the labour force in a given country and consequently leads to interesting growth effects. What happens when the net flow of students for a country is negative? Do all countries benefit from educational globalisation? These questions can be answered from the analysis of this Chapter. Similarly, countries subsidising many foreign students query whether the expected benefits exceed the cost of providing the education. With many students able to move to their desired place of study, educational protectionism could soon be a matter of debate. We focus on the relation between educating foreign students and economic growth and take two specifics of international education into account: first the costs that are involved if graduates leave the country after graduation and second the mobility of graduates.

The analyses in this Chapter are based on the assumption that studying abroad may benefit some students. This could be either because the quality of universities in another country is better in general, or because the match between student and university may improve. Internationalisation could also enhance economic productivity because of the cultural experience that students obtain in foreign education as argued by Mechtenberg and Strausz (2008): "The development of multi-cultural skills are seen as indispensable in a European Union that strives for full economic integration while preserving the diversity of its cultures" (Mechtenberg and Strausz, p. 110). We contribute to this literature by showing the relevance of the added value of international education for economic growth. In addition we take both the sending and the receiving country into account and discuss the relation between internationalisation of education and internationalisation

\footnotetext{
${ }^{1} \mathrm{BRIC}$ is short for Brazil, Russia, India and China.
} 
of the labour market via migration.

This Chapter is organised as follows. Section 2 presents the model. In section 3 we discuss the parameter values that we use to simulate the model. The results of the simulation are presented in section 4 . Section 5 concludes.

\subsection{The Model}

\subsubsection{Basic Equations}

Our model represents a "Solow style" simplification of the Lucas model ${ }^{2}$ (Lucas, 1988). To model international flows of students we extent the model by introducing a second country called Foreign, whose variables are marked by asterisks. Our domestic county is called Home. Production in the model takes place in a similar fashion as in the original Lucas Model where output $(Y)$ depends on capital $(K)$ and effective workers. The latter consist of the total labour force $L$ times the share of workers $v$ and the stock of human capital $h$

$$
Y=K^{\alpha}(v h L)^{(1-\alpha)}
$$

Investment into physical capital is derived from a constant savings rate $s$ and depreciates at a constant rate $\delta$

$$
\dot{K}=s Y-\delta K
$$

As in the Lucas model, education is necessary for the creation of human capital. Imagine a world where there exist three different types of individuals: Workers $(v L)$, students $(u L)$ and teachers $((1-u-v) L)$. Students can either receive their education domestically with productivity $\rho$, or they can go abroad and receive foreign education. The productivity of such international education $\phi$ is the sum of the domestic productivity in the foreign country $\rho^{*}$ and an international premium $\epsilon$. Similarly, $\phi^{*}$ is the sum of the domestic productivity $\rho$ and the international premium for foreign students $\epsilon^{*}$. The term productivity in this context refers to the rate at which students accumulate new human capital. This parameter could be heterogeneous among students. If the productivity of foreign education together with the international premium is below the productivity of domestic education it makes no sense for a student to study abroad.

We assume that the productivities of education are exogenous. This is a limitation to the model as the rate of internationalisation could have an effect on the productivities. The direction of this effect, however, is so far

\footnotetext{
${ }^{2}$ Lucas (1988) calculates the savings rate endogenously. We assume a constant savings rate as in Solow (1956).
} 
not determined and could be positive as well as negative. For this reason and to keep the model simple we assume the productivities to be fixed. The growth of human capital can be described as:

$$
\begin{aligned}
& \dot{h}=h u\left((1-i) \rho+i(1-\lambda) \phi+R i^{*} \lambda^{*} \phi^{*}\right), \\
& \text { where } R=\frac{u^{*} L^{*}}{u L} ; \phi=\rho^{*}+\epsilon \text { and } \phi^{*}=\rho+\epsilon^{*} .
\end{aligned}
$$

The structure of this equation is same as in Lucas. In fact, when setting the percentage of students that study abroad $i$ equal to zero, the equation gives back Lucas' equation where $\dot{h}=h u \rho$. The difference to Lucas here is the term in the parentheses, which is a weighted average of the different educational productivities. The first element $(1-i) \rho$ weights the domestic productivity of education by the percentage of Home students enrolling in domestic education. The second term $i(1-\lambda) \phi$ looks at the percentage of Home students that decide to obtain education in the foreign country at productivity $\phi$ and return to the Home. Since it can be expected that students will only study abroad when they benefit from this we assume that $\phi=\rho^{*}+\epsilon>\rho$ and $\phi^{*}=\rho+\epsilon^{*}>\rho^{*}$. It is a feature of our model that students who obtain education in the other country might not return to their country of origin. The parameter $\lambda$ captures this probability to stay. The second term, therefore, only includes those international students in Home's human capital growth that also return to the country. The last element considers the international students from the foreign country that decide to study and stay in Home. It is additionally weighted by the relative size of the two countries student populations $R=\frac{u^{*} L^{*}}{u L}$. This is important because if, for example, Foreign was four times the size of Home and had the same values for $i$ and $u$, Home would see four times more students coming into the country than leaving it for education. Overall, this equation introduces productivity differences and the concept of brain drain and brain gain to human capital formation.

The original Lucas model does not explicitly distinguish between teachers and students. A fraction $u$ of the workforce is not working in the productive sector but puts effort in learning. This fraction $u$ includes both students and teachers, while $\rho$ is the productivity of teachers and students together. In our extension we need to distinguish students from teachers, since we assume that teachers always come from the Home country, while students might also come from the Foreign country. Our fraction $u$ therefore only refers to the fraction of students in the population and is thus lower than $u$ in the Lucas model. Moreover, our $\rho$ refers to the productivity of students in learning and will therefore be larger than $\rho$ in the Lucas model which refers to students and teachers. ${ }^{3}$

\footnotetext{
${ }^{3}$ All labour that is required to build and maintain the universities has to be counted as teachers in this model.
} 
A necessary condition for students to accumulate any human capital is the availability of teachers. While students and teachers produce human capital together, we assume that only students can store human capital. Moreover, we take as given that at any point in time there exists the same ratio between teachers and students $\theta$ in both countries. This assumption enables us to effectively account for the costs of education and to leave out teachers from the human capital accumulation equation. Note that the introduction of teachers was not necessary to account for the cost of producing human capital in the original model as there were no international students. Moreover, the teacher student ratio should also have an impact on educational quality. This relation is skipped for simplicity as both the student teacher ratio and the productivity of education are exogenous. Assuming that both countries have the same teacher student ratio, $\theta$, we define the share of workers as anybody who is neither a student nor a teacher. As a result, the costs of education per student will be very similar in the two countries. The share of workers in the population is then given by

$$
v=1-u-u \theta\left(1-i+R i^{*}\right) .
$$

Student migration has a direct effect on the population size in both countries. We look at two different scenarios with respect to the balancing of migration flows. In the first scenario we assume that the population size of both countries is constant. Consequently, the growth in the population through channels other than student migration (the birth rate or migration of unskilled workers) has to counterbalance the student migration flows. In the second scenario we will assume that student mobility will cause changes in the population size of the two countries. Here we assume all other causes of population growth to be absent. Consequently the country that net receives most students will face a population growth while the other country will face a reduction in its population.

\subsubsection{Solution}

To be in steady state, capital per effective capita needs to be constant.

$$
\begin{aligned}
\frac{\dot{K}}{h L} & =0 \\
& \Rightarrow s \frac{Y}{h L}=\frac{K}{h L}\left(\delta+g_{h}+g_{L}\right) .
\end{aligned}
$$

This leads to:

$$
\frac{Y}{L}=h\left(\frac{s\left(1-u-u \theta\left(1-i+R i^{*}\right)\right)^{\frac{1-\alpha}{\alpha}}}{\delta+u\left((1-i) \rho+i(1-\lambda) \phi+R i^{*} \lambda^{*} \phi^{*}\right)}\right)^{\frac{\alpha}{1-\alpha}}
$$


Even though this expression may seem complex at first sight its interpretation is simple. All items which are listed in parentheses are constant. Therefore, output per capita grows at the same rate as the human capital stock given by

$$
g_{h}=u\left((1-i) \rho+i(1-\lambda) \phi+R i^{*} \lambda^{*} \phi^{*}\right) .
$$

Restricting student migration to balance in steady state requires an additional steady state condition. Ignoring other types of migration, the change in the Home labour force is the difference between the inflow of international foreign students who decide to stay in Home after education and the outflow of the respective Home international students who decide to stay in Foreign:

$$
\dot{L}=L^{*} u^{*} i^{*} \lambda^{*}-L u i \lambda
$$

Since in the steady state the labour force is required to be constant it follows that

$$
L^{*}=\frac{L u i \lambda}{u^{*} i^{*} \lambda^{*}}
$$

Plugging this condition into the equations above allows us to solve for the steady state level and growth of Home if student migration is in balance.

\subsubsection{The Effects of International Education}

Ultimately, this Chapter seeks to analyse under what conditions international education is beneficial for a country using steady state output per capita without internationalisation in higher education as a benchmark. Generally, two types of effects are conceivable. In the long run, growth effects that lead to a change in growth of output per capita in steady state are of greatest interest. They generally follow from changes in the human capital accumulation equation. In the short run, level effects also affect growth rates, resulting in a lower steady state of capital per effective capita, but their impact on the growth rate is not permanent. In that spirit, level effects lead to short term increases or decreases in the growth rate while growth effects prevail in steady state. To investigate both we compare the steady state levels and growth without international education with those which include international education.

Starting with the case in which migration flows balance as a whole we can derive necessary conditions for internationalisation in higher education to be beneficial. We reproduce each country's steady state growth equation for convenience. Then, Home and Foreign respectively, will experience steady state growth equal to: 


$$
\begin{aligned}
& g_{h}=u\left((1-i) \rho+i(1-\lambda) \phi+R i^{*} \lambda^{*} \phi^{*}\right) \\
& g_{h}^{*}=u^{*}\left(\left(1-i^{*}\right) \rho^{*}+i^{*}\left(1-\lambda^{*}\right) \phi^{*}+\frac{1}{R} i \lambda \phi\right) .
\end{aligned}
$$

To examine how international education affects the overall growth rate in both countries we can aggregate the growth rates. Assuming that output per capita in both countries is comparable, their respective population sizes can be used as weights. International education increases total growth in the countries if the following holds:

$$
\begin{aligned}
\frac{L u \rho+L^{*} u^{*} \rho^{*}}{L+L^{*}}<\frac{L u g_{h}+L^{*} u^{*} g_{h}^{*}}{L+L^{*}} & \\
& \Rightarrow i \rho+i^{*} R \rho^{*}<i \phi+i^{*} R \phi^{*} .
\end{aligned}
$$

Economic theory would predict that students only go abroad if it is more productive. If this assumption holds, it is beneficial for both countries together to open up for international students. The question remains, however, whether both countries separately benefit from internationalisation. Home will experience an increase in its growth rate if:

$$
u \rho<u\left((1-i) \rho+i(1-\lambda) \phi+R i^{*} \lambda^{*} \phi^{*}\right) .
$$

$R i^{*} \lambda^{*} \phi^{*}$ is always positive. This is not necessarily true for $(-i) \rho+i(1-$ $\lambda) \phi$ which is positive only if

$$
\rho<(1-\lambda) \phi
$$

Hence, the domestic productivity must be lower than the international productivity times the share of students that returns to Home. If this term is negative it has to be sufficiently small to make the steady state growth rate positive. A negative growth rate is only possible in either Home or Foreign, but not in both. In general, the country that receives and keeps the smaller share of foreign students faces a lower growth rate.

The steady state growth rates determine the effects of internationalisation in the long run. In the short run, however, matters can turn out very differently. Immediately after the introduction of international student flows, the only effect is that the country that receives more students needs more teachers, while the other country needs fewer teachers. Since we assume the same teacher to student ratio in both countries, this implies that the aggregate short run effect is zero. For each country individually, however, this direct effect might be positive or negative depending on whether more or less members of the labour force are required for teaching. 


$$
\begin{aligned}
s(1-u-u \theta)^{\frac{1-\alpha}{\alpha}}<s\left(1-u-u \theta\left(1-i+R i^{*}\right)\right)^{\frac{1-\alpha}{\alpha}} & \\
& \Rightarrow i<R i^{*} .
\end{aligned}
$$

To investigate the effects of internationalisation on growth if students migration leads to changes in the population of both countries a similar analysis is informative. The steady state growth rate in the home country is now equal to

$$
g_{h}=u\left((1-i) \rho+i(1-\lambda) \phi+i \lambda \phi^{*}\right)
$$

Growth in both countries together is higher with international education if the following holds true.

$$
\begin{aligned}
& \frac{L u \rho+L^{*} u^{*} \rho^{*}}{L+L^{*}}<\frac{L u g_{h}+L^{*} u^{*} g_{h}^{*}}{L+L^{*}} \\
& \Rightarrow \rho+\frac{\lambda}{\lambda^{*}} \rho^{*}<\phi+\frac{\lambda}{\lambda^{*}} \phi^{*} .
\end{aligned}
$$

Again, this assumes that output per capita is comparable in the two countries so that population sizes can be used as weights. The term will always be positive if international students are rational and hence $\rho<\phi$. Moreover, a country is able to benefit individually from internationalisation in higher education if it holds that.

$$
\begin{aligned}
& u \rho<u\left((1-i) \rho+i(1-\lambda) \phi+i \lambda \phi^{*}\right) \\
& \quad \Rightarrow \rho<\phi+\frac{\lambda}{1-\lambda} \epsilon .
\end{aligned}
$$

This condition is always met if $\rho<\phi$. Moreover, we can see that in the long run, when migration is balanced, the growth rate increases with the productivity of education of domestic students in the foreign country. A certain share of these students returns to Home after graduation. Additionally, Home benefits by the international premium that Home students in Foreign gain. This effect increases if more foreign students decide to stay in Home after education.

Finally, we can have a look at the level effects in the case where student migration balances.

$$
\begin{aligned}
& s(1-u-u \theta)^{\frac{1-\alpha}{\alpha}}<s\left(1-u-u \theta\left(1-i+\frac{\lambda}{\lambda^{*}} i\right)\right)^{\frac{1-\alpha}{\alpha}} ; \\
& \Rightarrow \lambda<\lambda^{*}
\end{aligned}
$$


This means that if student flows balance the level effect is no longer dependent on the actual student inflow but on the probability that those students stay in the country. If the probability that home students stay abroad is smaller than the probability that foreign students stay in Home, the level effect is positive in the home country.

\subsection{Empirics}

\subsubsection{Parameter Calibration}

In order to apply the model it is essential to evaluate its parameters empirically. The exact share of international students depends on the country at hand. Within the model the internationalisation rate $i$ is measured in terms of the share of students which are educated in a foreign country. A broad comparison of those rates of internationalisation is possible with the help of a yearly assessment by Eurostat. According to their measurement, internationalisation within Europe averages 2.9 percent (Statistical Office of the European Communities, 2012). However, given that not all international students register in the foreign country, the Eurostat figures are likely to be under-reported. This becomes visible at the example of the Netherlands, for which Nuffic collects data on a university level. While Eurostat reports that 2.3 percent of the Dutch students go abroad, Nuffic (2011) reports a rate of internationalisation of 7.1 percent. Since the Netherlands are below the European average in terms of outgoing students in (Statistical Office of the European Communities, 2012), the simulations are done for international shares between 5 and 10 percent.

Data quality is weaker when it comes to the probability to stay in a foreign country after graduation. In a recent paper, Bijwaard (2010), suggest that male study related migrants have a chance of 19 percent to stay in the Netherlands. For female students the chance is estimated at 26 percent. The values fluctuate strongly between different countries of origin. Moreover, these figures might be over reported. The data includes only students who register in the Netherlands and these have a higher probability to stay than students who do not even register in the first place. Hence the probability to stay used in the simulations is 15 percent.

To estimate the share of students in the labour force as measured by the model we consider the working population only. Eurostat data shows that men in Europe work between 40 and 46 years over their lifetime, while women work 36 to 44 years (Brugiavini \& Peracchi, 2005). Moreover, university education is supposed to require three to four years for a Bachelor and four to six years for a Master degree. In reality even more time may be needed to finish university. Combining this information with the European target that 40 percent of the population should hold a university degree allows to calculate scores for the share of students. These range between 
roughly 2.5 percent and 7.5 percent, and hence, 5 percent will be used in the simulations.

Values for the teacher to student ratio $\theta$ can be found on the basis of data published by the European Commission. Currently, there is a total of roughly 19 million students in Europe, while higher education institutions employ 1.5 million staff members. Hence, $\theta$ should be close to 8 percent. This number neglects workers that work on buildings and equipment for the university sector.

Suppose there was no international education. Setting $i=i^{*}=0$, the human capital accumulation equation would reduce to $\dot{h}=h u \rho$ as in the original Lucas model. The parameter $\rho$, then, represents the growth of the human capital stock. In a sense, it is the return on human capital for every unit of human capital each time period. To evaluate plausible values for $\rho$ we make use of the vast literature estimating real returns to education. In their influential review paper, Psacharopoulos and Patrinos (2004) estimate the social return on investments into education to be 10.8 percent. In the context of our model every unit invested in human capital grows with rate $\rho$ and every one percent increase in human capital results in a $(1-\alpha)$ percent increase in output. ${ }^{4}$ To obtain an estimate for $\rho$ we hence use that

$$
r_{e d u} \approx \rho(1-\alpha)
$$

Setting $r_{\text {edu }}=10.8$ and $\alpha=\frac{1}{3}$ gives an estimate for $\rho$ at 15.75 percent. The return in human capital that is specific to international education is given by $\epsilon$. This variable is important as it determines the extra learning gains from international education. Unfortunately, not much conclusive evidence exists on whether international education holds a return premium. However, several empirical studies have shown that students spending time abroad have benefited in terms of improved language skills and better cultural understanding (Sutton \& Rubin, 2004; Freed, 1995). Many verbal accounts, moreover, suggest that students undergo some personal development when going abroad. International experience, indeed, catches a wage premium in the labour market, but currently it is uncertain how much of it is attributable to selection (Oosterbeek \& Webbink, 2006). Applying the same approximation as above $\epsilon=0.02$ implies a rate of return premium of about 1.3 percent.

\subsubsection{Simulations}

The model as formulated can be calibrated to fit many different pairs of countries. Whenever we compare our findings to an economy with purely domestic higher education, we name this economy "Lucas"'. Whenever we do this, we mean that we are comparing our results to the simplified version

\footnotetext{
${ }^{4} \alpha$ is the capital share in the production function.
} 
of the Lucas model rather than with the original. In the following section we will consider a pair that has the same parameter values except for size, where we assume that the labour force of the foreign country is initially four times larger. This setup roughly resembles the cases of Germany and the Netherlands. All parameter values used lie within the ranges established in the previous section. Thus, we let

$$
\begin{aligned}
& \alpha=\frac{1}{3}, \\
& s=\delta=0.1, \\
& \theta=0.08, \\
& u=0.05, \\
& i=0.1, \\
& \rho=0.15, \\
& \lambda=0.15 .
\end{aligned}
$$

Imagine this two-country world and suppose that international education does not carry any premium. Given that all parameters are identical with the exception of population size, we should expect to see a great surplus of students entering the small country every period of time. Since all students have the same probability to stay, the small country then faces a positive migration of well-qualified students as compensation for the initial increase in the cost of education. Figure 4.1 plots the development of both countries' income per capita relative to what it would have been without international education. The left panel assumes that the population size of both countries remains the same, and thus that student migration is offset by exogenous factors. The small country represented by the thick line initially starts off at a lower income per capita level. This decrease in GDP per capita equals -0.084 percent. However, since it enjoys a larger growth rate, it reaches the no-internationalisation level of income within only four periods. Thereafter, brain gain leads to constantly higher levels of income than under the noninternational "'Lucas regime"' and to 0.034 percent faster growth in steady state.

Table 4.1 gives additional comparative statics for this scenario relative to the domestic education economy, which, under our parameters for $u$ and $\rho$, grows at 0.75 percent in steady state.

If more students of the home country study abroad $(i=0.15)$ the extra steady state GDP-growth decreases. When the mobility of foreign students increases $\left(i^{*}=0.15\right)$ the steady state growth rate increases. A simultaneous increase in both mobility rates is more advantageous for the smaller than for the larger country. The same is true for the percentage students that stay in the country of study. An increase of the fraction of students that remain abroad negatively influences the growth rate, but the smaller country benefits more from a higher percentage of stayers than the larger country. 
The right panel of Figure 4.1 shows what happens if the population size of both countries starts to change due to student mobility. Since for the Home country GDP growth is now accompanied by a population growth Home needs much more time to recover from its initial drop, and GDP per capita will grow slower. The reason for this is that the capital stock only adjusts gradually to the increased population size. If the increase in the number of workers would be accompanied by an extra investment in capital, the growth patterns would look more like in the first panel. Figure 4.2 shows what happens in the very long run. With a constant increase in population the smaller country becomes larger and larger. This means that the mobility flows become more equal. The smaller country has more students and, therefore, also more students will study abroad. Eventually, the differences in population size will disappear and the growth effects vanish. It should be stressed that this result is a consequence of having constant and equal parameter values for $u, i, \lambda$ and $\rho$. If one country, for example, has a higher internationalisation rate, country sizes will not fully equalise in the long run.

Thus far, in the Figures we have only considered the purely distributional effects of international education. Figure 4.3 repeats the simulation assuming an international premium of two percent corresponding to about 1.3 percent greater returns to education. This corresponds to the penultimate row in Table 4.1. Relative growth rates of both countries increase across scenarios such that in either scenario both countries benefit from international education. Economic growth in the home country increases from 0.034 percentage points to 0.049 while for the foreign country a lower growth of -.0085 turn into a faster growth of 0.0044 . Based on these parameters economic growth in the smaller country would increase with 0.049 percentage points while GDP per capita would increase with 0.0044 percentage points. The average annual extra growth in both countries therefore equals 0.013 percentage points.

This shows that at the most plausible values of the parameters interna-
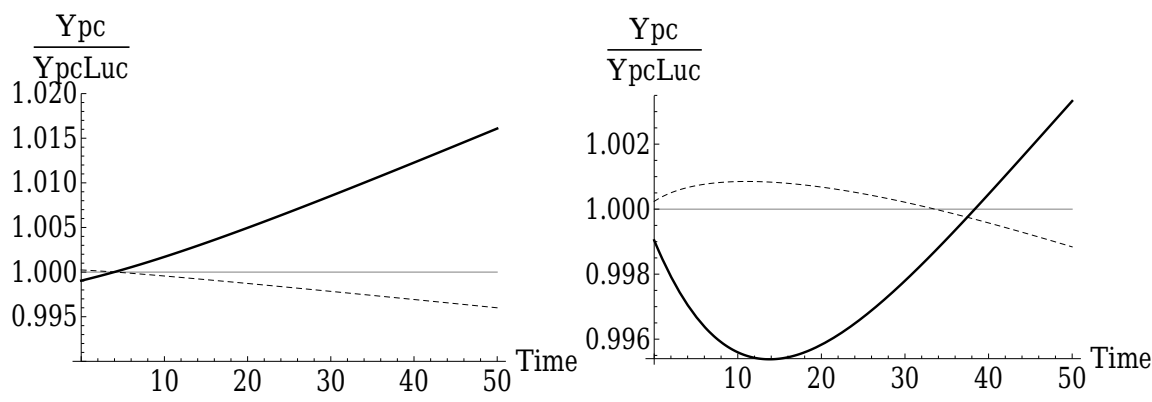

Figure 4.1: Base Scenario without Labour Adjustments (Left), with Labour Adjustment (Right). 


\begin{tabular}{l|lll|ll}
\hline \hline & \multicolumn{3}{|c|}{ NL } & \multicolumn{2}{c}{ DE } \\
\hline Rel. to Lucas & Init. $\Delta(\%)$ & Recov. in (t) & SS Gr.(\%) & Init. $\Delta$ & SS Gr. \\
\hline Base L. exog. & -0.084 & 4.00 & 0.034 & 0.021 & -0.0085 \\
\hline$i=0.15$ & -0.070 & 4.00 & 0.028 & 0.017 & -0.0071 \\
$i^{*}=0.5$ & -0.141 & 4.00 & 0.056 & 0.035 & -0.014 \\
$i=i^{*}=0.15$ & -0.126 & 4.00 & 0.051 & 0.032 & -0.013 \\
\hline$\lambda=0.2$ & -0.085 & 4.50 & 0.030 & 0.021 & -0.0075 \\
$\lambda^{*}=0.2$ & -0.085 & 2.75 & 0.049 & 0.021 & -0.012 \\
$\lambda=\lambda^{*}=0.2$ & -0.085 & 3.00 & 0.045 & 0.021 & -0.011 \\
\hline$\rho=\rho^{*}=0.2$ & -0.085 & 3.00 & 0.034 & 0.021 & -0.0085 \\
$\rho=\rho^{*}=0.1$ & -0.085 & 6.00 & 0.034 & 0.021 & -0.0085 \\
$\epsilon=\epsilon^{*}=0.02$ & -0.085 & 2.75 & 0.049 & 0.021 & 0.0044 \\
$\epsilon=\epsilon^{*}=0.05$ & -0.085 & 1.75 & 0.070 & 0.021 & 0.014 \\
\hline \hline
\end{tabular}

Table 4.1: Comparative Statics for the left panel of Figure 4.1. The first column gives the Initial Change of Output per Capita relative to Lucas. In the second column we give the time it needs to reach the Lucas' level of output per capita again. The third column has the changes in the steady state growth rate due to internationalisation in percentage points.

tional education is beneficial for both countries. Naturally, policy makers can attempt to increase their share of the overall gains, by targeting variables like the probability to stay through migration policy or by making it easier for foreign students to start studying. Even if no international premium exists, international education may be mutually beneficial. This is, for example, the case when one country has a higher productivity in educating students than the other country; a relationship we may see between a more and a less developed country. Under the assumption that only students from the less developed country want to study and stay in the more developed country, international education is universally beneficial as shown in Figure 4.4. Here, the less developed country benefits as the higher human capital of the students returning from the developed country outweighs the human capital loss from brain drain. The developed country loses in the short run due to the higher costs of education, but quickly recovers and gains from the inflow of talented students later on.

\subsection{Conclusions}

In this Chapter we developed an endogenous growth model to investigate the effects of internationalisation in higher education on economic growth. In aggregate, assuming that individual students only go abroad when that is beneficial to them, in the long run internationalisation is always beneficial for the two countries together. The distribution of the gains, however, 

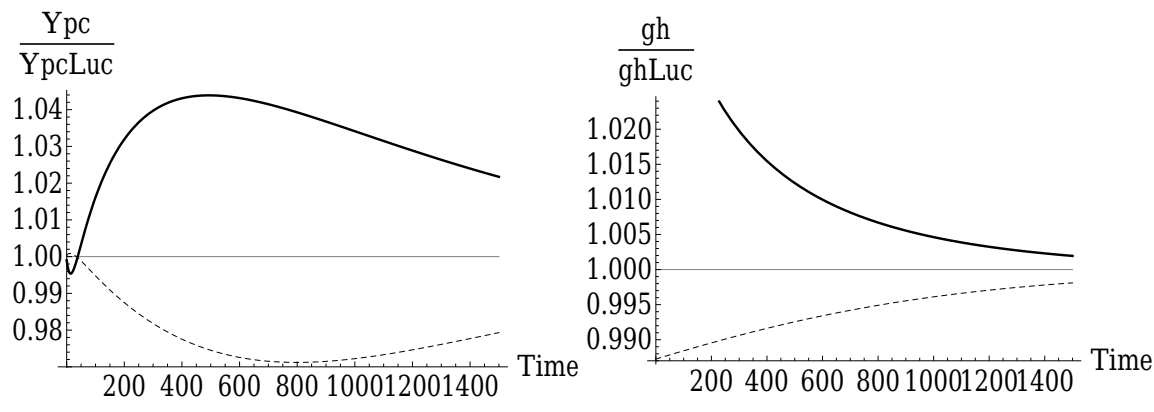

Figure 4.2: Long Run adjustment of per Capita Income and Human Capital relative to Lucas when Labour is Endogenous.
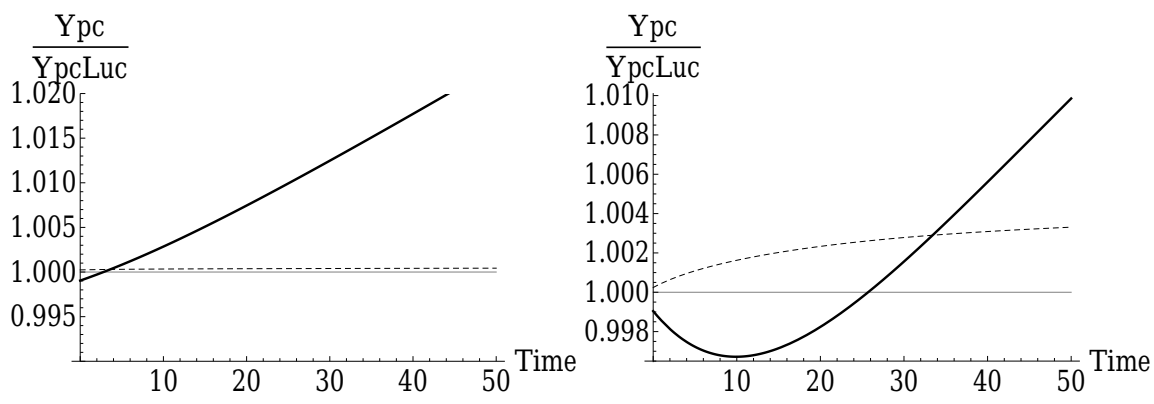

Figure 4.3: Scenario with $\epsilon^{*}=0.02$ without Labour Adjustments (Left), with Labour Adjustment (Right).
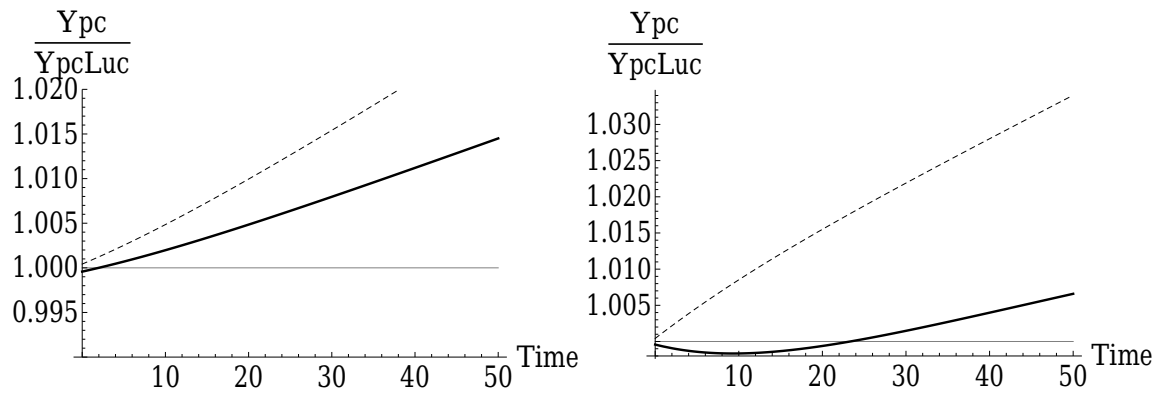

Figure 4.4: Case where countries are unsymmetric in most parameters except size: $\rho=0.2, \rho^{*}=0.1 ; i=0, i^{*}=0.2 ; \lambda^{*}=0.2$. 
depends on a variety of parameters like the rate of internationalisation and the probability to stay in a foreign country. While there are cases in which both countries gain, it is also possible that one country loses.

This implies that there can be two obstacles for the internationalisation of university education. First, countries that emphasise short run effects in their decision making might try to limit access for foreign students. The reason for this lies in the costs of education which lower short term output. Second, an unequal division of the benefits of internationalisation might hamper international agreements about international cooperation. Since it will be hard for countries to stop students from studying abroad it will especially be difficult to benefit from internationalisation when the countries that receive students do not benefit from this, because a large fraction of the graduates leaves the country after the study. In a situation of high labour mobility a prisoner's dilemma might therefore occur. In the opposite extreme, if a substantial fraction of the students stays in the country of study, it will be attractive for each individual country to promote foreign students to study in their country. This could lead to a rat race in which countries attempt to get an as large as possible share of the flow of international students. Considering long-term growth, a country benefits if it attracts many foreign students who stay in the country. A policy to open up universities for foreign students is therefore complementary to a policy to make the labour market attractive for these foreign students. 


\title{
Chapter 5
}

\section{Investing in Personality? The impact of international education on non-cognitive abilities}

\author{
With Jan Bergerhoff
}

Adapting to new challenges and environments can change the knowledge and skill set of an individual, but it may also have an impact on personal preferences and interests. While such traits seem to be important determinants of labour market outcomes, health and subjective well-being, they are regarded as relatively stable. In this study we test whether Big 5 and Locus of Control personality traits can be changed through an international experience at university. We find that university students who go abroad return with lower Neuroticism and a more inward Locus of Control. Other studies and our own estimates from the German Socio Economic Panel suggest that these changes carry a premium in the labour market.

\subsection{Introduction}

Personality, like cognitive ability, has been suggested to determine a wide range of life outcomes. Several studies have linked it to educational attainment, occupational choice, job performance and health. An implicit consensus from this research is that certain personality profiles generate better outcomes than others. If personality was somehow transformable, for example through experience, the question would emerge whether it is possible to invest in it directly.

The aim of this Chapter is to test whether personality can be affected by an educational policy. To this end we evaluate an international education programme that offers students an international experience during their time at university, an area that can be easily targeted by policies. We ask participants of the student exchange programme at Maastricht University to fill in personality questionnaires at three points in time, where a small timing asymmetry is used to create a treatment and a control group. We find that students who go abroad experience changes in two personality domains, 
which, among others, are associated with greater productivity in the labour market. Our evidence suggests that the changes could be persistent.

To study the average treatment effect of international education on any given person, one would require randomly selected subjects, that are randomly divided into a going-abroad treatment and staying-home control group. In the context of international education such data is not easy to come by, especially since some portion of the population does not want to go abroad. If we wanted to evaluate policies that would force people into international education, this would be problematic. Moreover, all programmes known to us are rather opt-in by nature including study programmes with mandatory study abroad that have a form of voluntary 'early' selection by students. We, hence, focus on the treatment effect on the treated, knowing that the effect on somebody who did not select into such a programme might be different.

For our study we make use of a timing asymmetry resulting from the fact that it is more economical for a university if not too many students go abroad at the same time. At Maastricht University's School of Business and Economics (SBE), where all Bachelor students take a mandatory semester abroad in their third year, this means that some students go in the first semester of their third year, while others go in the second semester, but all of them go eventually. Students were asked to fill in questionnaires at the beginning, the middle, and the end of the academic year. The design is summarised in Figure 5.1 and provides us with variation across and within subjects. We follow a differences-in-differences identification strategy comparing the changes from those who went abroad to those who stayed in Maastricht. This distinguishes us from earlier psychological work by Zimmermann and Neyer (2013), who carefully analyse possible channels of personality change in response to a study abroad, but only control by using students who decided not to go abroad. The data allows to study both the initial effect of studying abroad and its persistence after an equally long period in Maastricht.

We find that going abroad has a significant and lasting impact on Locus of Control, which measures to what extend a person feels in control of life events, and on Neuroticism. On the 23 point Locus of Control scale students become more than 2 points (or 0.38 standard deviations) more inward after having gone abroad compared to the control group of students staying in Maastricht. An internal Locus of Control is associated with the believe that own decisions and effort have a decisive impact on individual life events, and according to Heckman, Stixrud, and Urzua (2006) is linked to improved labour-market outcomes. The result is robust irrespective of whether the groups going in the two semesters are pooled and significant across specifications. For the smaller sample, where it was possible to observe long term effects the hypothesis that mean reversion does not exist could not be rejected at a significance level of more than eighty percent. For the Big 5 personality traits, the results are mixed. We find significant 


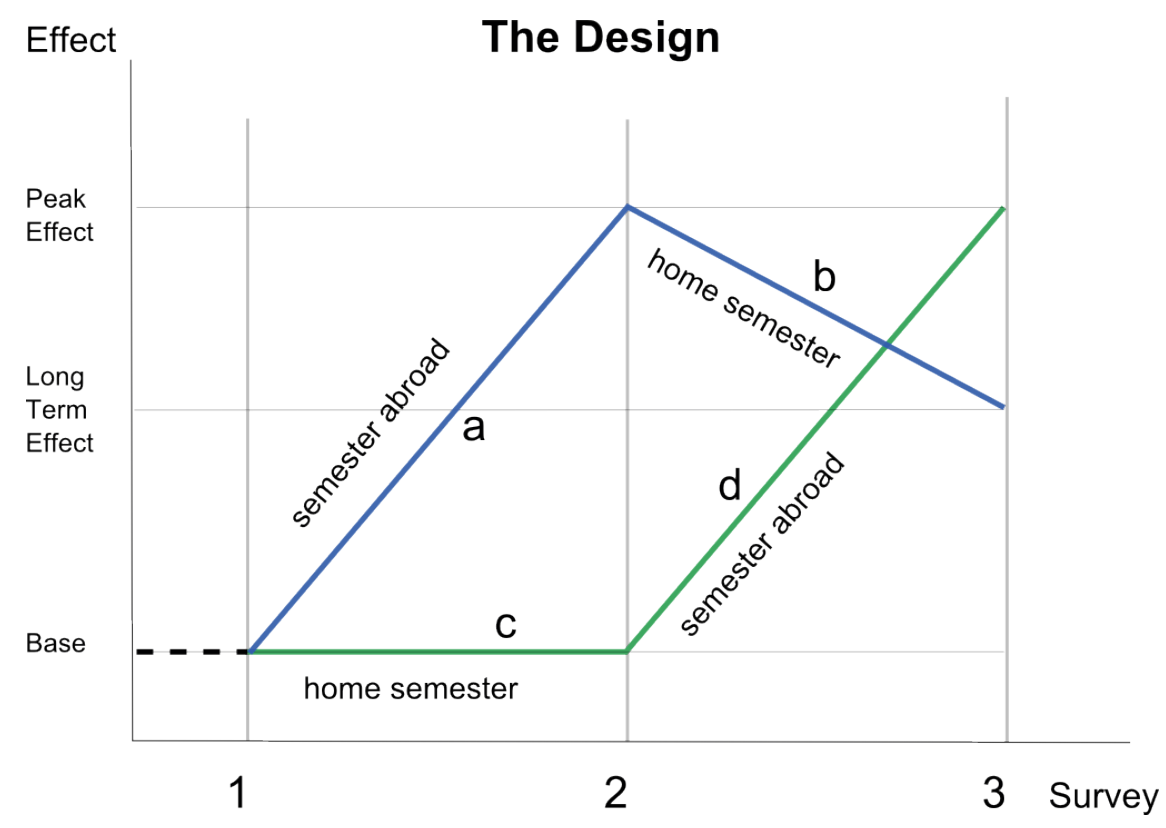

Figure 5.1: A three survey design: $\mathrm{a}=$ Change after being abroad in autumn (group A), b= Change after staying the spring in Maastricht (group A), $c=$ Change after staying the autumn In Maastricht (group B), d=Change after being abroad in spring (group B).

decreases of Neuroticism, the trait capturing low self esteem and tendencies for experiencing anxiety and depression. For the remaining traits, no stable patterns are detected.

Overall, our results suggest that studying abroad has an impact on a student's personality. A back-of-the-envelope calculation that uses correlations between wages and personality traits from the German Socio Economic Panel (GSOEP, (Schupp \& Wagner, 2002)) suggests that the productivity increase from the mean-level personality changes we measured could be around 2.4 percent. Under some assumptions this would be equivalent to a net present value in monetary terms of $€ 21,525 .{ }^{1}$ Naturally, such a result should be applied with caution since, for example, it is not proven that the effect will persist over a longer time horizon.

A more inward Locus of Control and lower Neuroticism are also said to be related positively to health and subjective well-being. In their metastudy DeNeve and Cooper (1998) find that Locus of Control and emotional stability (the inverse of Neuroticism) correlate most strongly with subjective well-being. The correlation between Locus of Control and health was so

\footnotetext{
${ }^{1}$ The assumptions are: average starting wage of $€ 42,000$, zero wage growth, a 3.5 percent discount rate and a forty year working life.
} 
apparent that specific health Locus of Control scales have been developed (see for example Wallston, Wallston, and DeVellis (1978)). Besides these studies and our own estimations a large literature on personality helps to interpret our results.

We devote one section of the Chapter to review the meanings and roles played by the different personality constructs. Almlund et al. (2011) interpret personality as a "strategy function for responding to life situations" (p. 8). To deal with the large pool of life situations humans pick from an even larger pool of strategies; the fact that their choices are correlated makes it possible to aggregate them into personality traits: Those who enjoy art, for example, are also more likely to try out foreign food, those who value punctuality tend to also prefer hierarchical structures and strive for achievement.

Several papers have highlighted the importance of such preference clusters. Especially Conscientiousness (Salgado (1997); Barrick and Mount (1991)), Neuroticism (Nyhus and Pons (2005), Salgado (1997)) and Locus of Control (Heckman et al., 2006) correlate with labour market outcomes. Depending on the outcome variable, correlations with other domains are reported. Rothmann and Coetzer (2003), for example, find a strong positive correlation between Openness and management performance in a pharmaceutical company. Heckman et al. (2006) estimate that through direct and indirect channels (like educational attainment) non-cognitive abilities account for as much variation in adult earnings as cognitive ability. A. Becker et al. (2012) argue that personality traits complement the classical economic measures like trust or risk aversion in explaining economic behaviour.

Our results also contribute to the literature on the stability of personality traits and personality change. Roberts, Walton, and Viechtbauer (2006) argue that while personality traits are fundamentally consistent across time and age ${ }^{2}$ mean-level changes occur and are triggered by certain experiences such as leaving the parental home or starting a career. Our results support this viewpoint.

In the economics literature, by contrast, personality has been regarded as relatively stable. As an assumption this allows studying the impact of personality on economic outcomes, but if it is not fulfilled it can lead to biased conclusions (Cobb-Clark \& Schurer, 2012). Using the Australian Household, Income and Labour survey (HILDA), Cobb-Clark and Schurer (2013) do not find large mean-level changes for the Big 5 and Locus of Control (Cobb-Clark \& Schurer, 2012) in response to adverse life events over a period of four years. Sahm (2012) uses the American Health and Retirement Study (HRS) to investigate risk tolerance over a period of ten years (1992-2002) and finds that individual life events only play a minor role. The literature on the effectiveness of early childhood intervention, however,

\footnotetext{
${ }^{2}$ Roberts and DelVecchio (2000) show that rank-order-consistency, measuring changes of the individual rankings in the population wide distribution of a trait, increases from 0.31 in children to 0.54 during the college years to 0.74 between the ages of 50 and 70 .
} 
recognizes personality changes as an important channel (Heckman, Pinto, \& Savelyev, 2012) of such programs. So far, to the best of our knowledge, there is no evidence on the stability of personality following a more experimental approach in the economics literature.

Our results may also explain why international education has become increasingly popular both with students and policy makers. Universities have invested in student exchange-programmes, and institutions like the European Union have implemented policies that offer students organisational and financial support to go abroad. ${ }^{3}$ Our empirical findings, therefore, contribute to the literature on education by providing evidence on a specific merit of international education which is important for policy evaluations or to calibrate structural parameters in models like the one in Chapter 4 that model human capital formation through education.

The structure of the Chapter is as follows. The next section discusses the measures of personality which are used in this study as well as our data. Thereafter, we present the results in two sections. For this we analyse the changes in personality and thereafter the magnitude of such changes in terms of labour market returns. A last section concludes.

\subsection{Personality Measures and Data}

Personality measures can be seen as clusters that comprise many individual traits which are elicited by individual questions. The type of questions used by psychologists to elicit the Big 5 and Locus of Control differ substantially. To elicit Locus of Control students needed pick the - sometimes controversial - statement they agreed relatively more with from a battery of 29 statement couples. For each domain of the Big 5 inventory participants needed to indicate how much they agree with 12 statements about themselves on a five-point Likert Scale. Psychologists have assorted these preferences into separate clusters of traits that correlate strongly with one another (convergent validity) and little with components from other clusters (discriminatory validity). While there are various competing frameworks, many psychologists nowadays use the Big 5, a set of traits including Openness to Experience, Conscientiousness, Extraversion, Agreeableness and Neuroticism, developed by Costa Jr and McCrae (1989).

Please see Chapter 2 for a description of the Big 5 personality traits. Locus of Control assesses to what extent subjects feel in control of events in life and how much they attribute to chance, fate, or circumstances. It originally received attention by economists because of its appearance in the National Longitudinal Survey (NLSY), where it was used by Heckman et

\footnotetext{
${ }^{3}$ Indeed, Vossensteyn, Lanzendorf, and Souto-Otero (2008) in a report for the European Commission evaluating the ERASMUS Programme summarise: "At the individual level previous studies indicated that the ERASMUS experience has had an effect on the nature of graduate careers [...]. The effect on academic development is detected, but particularly personal development [...] is recognised by participants." (p. 10)
} 
al. (2006) as a measure for non-cognitive skills. While it was developed separately from the Big 5 , it has been found to correlate with Neuroticism (especially with its sub-construct anxiety) (Judge, Erez, Bono, \& Thoresen, 2002). Using data from the German Socio Economic panel, A. Becker et al. (2012) find that Locus of Control correlates more strongly with wages than any of the Big 5 domains.

The Bachelor students at Maastricht University's School of Business and Economics (SBE) take a mandatory semester abroad. They choose their preferred destinations from a long list of possible exchange partners from all over the world, and depending on their first year average grade their preferences are fulfilled. Students select to go abroad during the first or the second semester of their last year. A market like allocation system for exchange destinations based on first year average grades ensures that semesters are roughly equally popular. ${ }^{4}$

The students can choose from the same list of over a hundred SBE partner universities in 38 different countries. To allocate the places all students are ranked according to their first-year grade point average and are asked to submit their top three preferences. If the top preference cannot be fulfilled because all places at the destination were occupied by students with a higher ranking, the second preference becomes the new top preference. If this cannot be satisfied either, the focus shifts to the third preference. Only when none of the preferred destinations could be offered, the student is pooled with others without allocation and asked to choose out of the remaining places using the same procedure as before.

The data was collected over the academic year 2012/2013 via an online survey to which all economics and business students who were identified as going abroad by the university's International Relations Office (IRO) in that year were invited to. Emails were sent via an official IRO email account to attract attention, but no information about the purpose of the study was released. Students were asked to fill in three separate questionnaires at the start, the middle, and at the end of the year. Every participant who completed all three surveys was awarded a ten Euro shopping voucher and was given the opportunity to request a personality profile in the final questionnaire.

\section{$5.3 \quad$ Results}

Under the assumption that the treatment assignment is random or only linked to fixed effects, this data allows us to study mean-level personality changes sparked by the experience of the going-abroad programme. The

\footnotetext{
${ }^{4}$ Since our design allows us to take first differences and compare them within and across both groups, we are not that concerned about minor differences between both groups. While Maastricht University has not disclosed the full grade distribution to us, we were informed that the difference of both groups in terms of grades is insignificant, that is to say, smaller than 0.5 on a grading scale from 1 to 10 .
} 
responses from students staying a semester longer in Maastricht before their abroad experience are held as a benchmark against the study abroad effect of the group which went abroad first. Definitios of the different changes can be found in Table 5.1. This is different from Zimmermann and Neyer (2013), whose control group consists of students who indicated that they do not go abroad in the next twelve months. Zimmermann and Neyer (2013) find that these students differ from the going-abroad group systematically in the domains Openness, Conscientiousness and Extraversion. By avoiding such systematic differences our control group resembles the hypothetical counter-factual $^{5}$ more closely. Zimmermann and Neyer (2013) do not elicit Locus of Control.

Figure 5.2 reports the mean values for each personality trait as measured by the different surveys for each group. We can see some pattern for Neuroticism and Locus of Control in the bottom of the panel. The average value of Neuroticism decreases for both groups during their study-abroad experience and increases to a lesser degree during the semester in Maastricht. Furthermore, students on average report a more inward Locus of Control after their semester abroad. The relation between a more inward Locus of Control and lower Neuroticism has also been found in other studies (Almlund et al., 2011). ${ }^{6}$

\begin{tabular}{rrr}
\hline \hline Short & Long & Description \\
\hline a & Trait $_{A 2}-$ Trait $_{A 1}$ & $\Delta$ after being abroad in autumn \\
b & Trait $_{A 3}-$ Trait $_{A 2}$ & $\Delta$ after staying the spring in Maastricht \\
c & Trait $_{B 2}-$ Trait $_{B 1}$ & $\Delta$ after staying the autumn in Maastricht \\
d & Trait $_{B 3}-$ Trait $_{B 2}$ & $\Delta$ after being abroad in spring \\
\hline \hline
\end{tabular}

Table 5.1: The long form notation is Trait $i t$ where $i \in\{A, B\}$ and $t \in$ $\{1,2,3\}$. Students with sub-index A study abroad in autumn and stay in Maastricht during spring. Students with index B do this in reverse order. The index $t$ refers to the questionnaire where the first, second and third were administered at the start, middle and end of the academic year respectively.

Before comparing treatment and control outcomes, we check which of the changes we measured are significantly different from zero. Overall, the patterns of Figure 5.2 are confirmed by the one-sample t-tests shown in Table $5.2 .^{7}$

Students who go abroad report a more inward Locus of Control and lower Neuroticism afterwards. The change is different from zero at the 5

\footnotetext{
${ }^{5}$ What would have happened to the personality of students had they not gone abroad at that time.

${ }^{6}$ The correlation between Neuroticism and Locus of Control is not obvious as the metrics used to construct both measures are quite different.

${ }^{7}$ Throughout the Chapter all p-values given are two-sided. To avoid confusion with the short-hand notations a, b, c and d, it is easiest to refer to Figure 5.1 or to Table 5.1 for the formal definitions.
} 

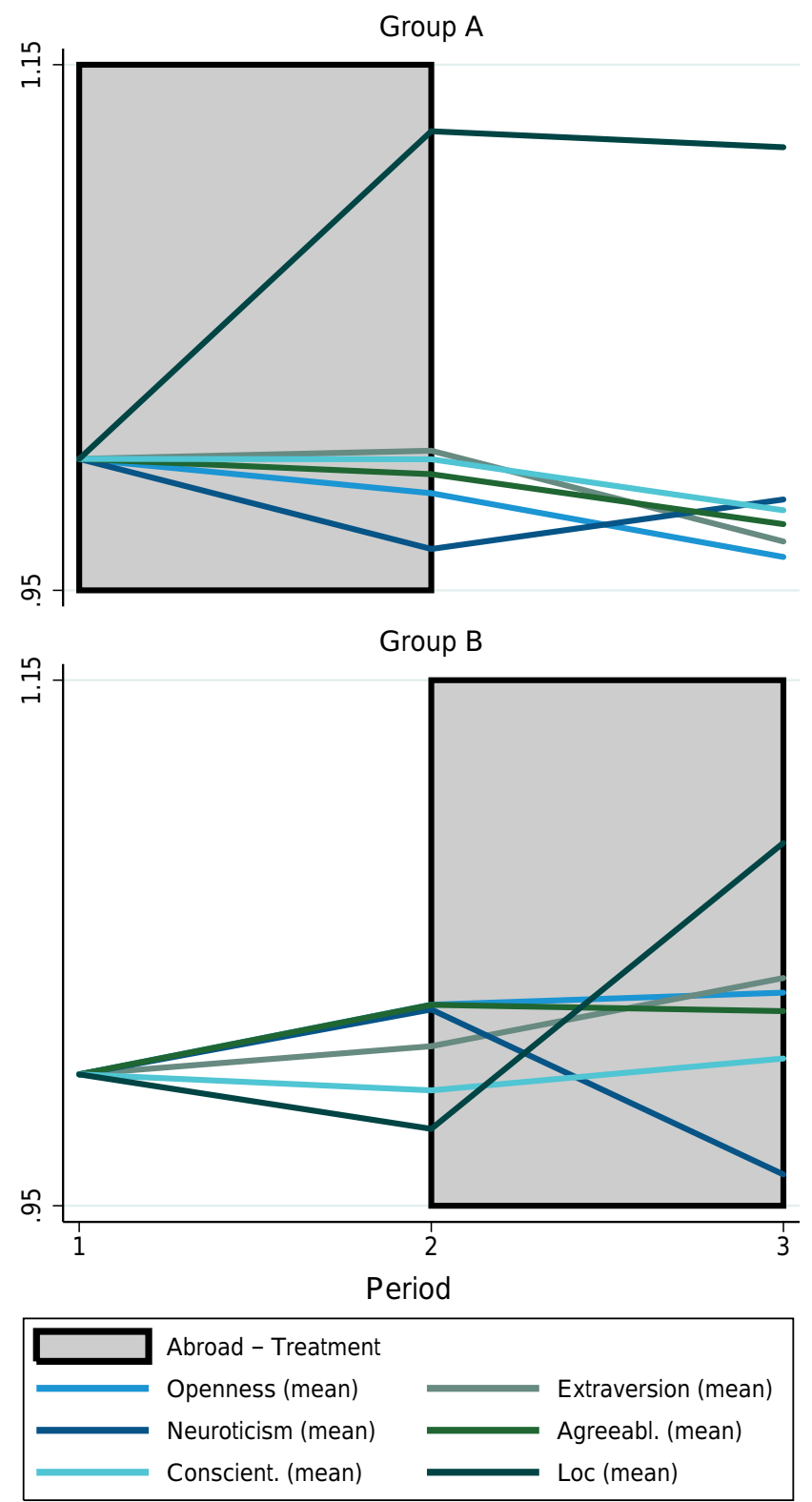

Figure 5.2: Average personality traits at each survey. All values are scaled by their first period mean, such that all lines start at the value one. 


\begin{tabular}{l|lll|lll|lll}
\hline \hline & \multicolumn{3}{|l|}{ Test: $\mathrm{a} \& \mathrm{~d}=0$} & & \multicolumn{3}{|c|}{ Test: $\mathrm{b}=0$} & \multicolumn{3}{|c}{ Test: $\mathrm{c}=0$} \\
\hline Trait & $n$ & $\mathrm{p}$ & $\mu$ & $n$ & $\mathrm{p}$ & $\mu$ & $n$ & $\mathrm{p}$ & $\mu$ \\
\hline open & 78 & 0.753 & -0.13 & 42 & $0.070^{*}$ & -0.98 & 34 & 0.140 & 0.97 \\
consc & 80 & 0.661 & 0.21 & 41 & $0.099^{*}$ & -0.90 & 34 & 0.900 & -0.09 \\
extra & 80 & 0.220 & 0.60 & 42 & $0.044^{* *}$ & -1.02 & 35 & 0.525 & 0.43 \\
agree & 78 & 0.883 & -0.06 & 42 & 0.924 & -0.05 & 34 & 0.211 & 0.82 \\
neuro & 79 & $0.045^{* *}$ & -1.14 & 40 & 0.919 & 0.08 & 35 & 0.301 & 0.80 \\
loc & 80 & $0.001^{* * *}$ & 1.33 & 42 & 0.245 & -0.48 & 35 & 0.663 & -0.23 \\
\hline \hline
\end{tabular}

${ }^{*} p<0.10,{ }^{* *} p<0.05, * * * p<0.01$

Table 5.2: Tests whether effects between the two surveys are significantly different from zero. All p-values given are two-sided. To avoid confusion with the short-hand notations a, b, c it is easiest to refer to Figure 5.1 or to Table 5.1 for the formal definitions.

percent level of significance for Neuroticism and below 1 percent for Locus of Control as shown in the left panel of Table 5.2. The students staying in Maastricht after their abroad experience are used to analyse the long-term impact of going abroad. The test for $b=0$ in the middle of Table 5.2 cannot reject that these changes are persistent. During their semester back in Maastricht following the study abroad semester, Neuroticism for group A increases a little and Locus of Control becomes slightly less inward. The effect sizes, however, are not that large and none of them is statistically indistinguishable from zero. The third panel of Table 5.2 investigates whether staying in Maastricht for a semester has any effect in itself. As the outcome of non-assignment it is the empirical benchmark against which the studyabroad treatment will be evaluated. It does not hint at any systematic effects.

For the treatment-control comparison we formulate the following hypothesis:

\begin{tabular}{ll}
\hline \hline Hypotheses & The test assesses the ... \\
\hline H1: $a=c$ & abroad effect across students at the same time. \\
H2: $c=d$ & abroad effect within students over time. \\
H3: $a \& d=c$ & pooled, across and within going abroad effect. \\
H4: $b=c$ & persistance of going abroad effect within students. \\
H5: $a \& d=b \& c$ & pooled, across and within going abroad effect. \\
\hline \hline
\end{tabular}

Table 5.3: Summary of the main hypotheses.

What distinguishes this Chapter from previous work is the possibility to construct a treatment with a control group. We test five hypotheses 
which are summarised in Table 5.3 while the results are presented in Table 5.4. Hypothesis $H 1: a=c$ focuses on the first semester and compares the average changes in the study abroad group with the changes in the staying in Maastricht group. In the top panel of Table 5.4 using an unpaired, twosample t-test, we see a similar pattern and effect size for Neuroticism and Locus of Control, but little other systematic variation.

The same is found when testing the hypothesis $H 2: c=d$ which only uses the within subject variation. While effect sizes are similar, they lose some statistical significance which may be the result of the relatively small sample size (below 40) in Group B. We again use an unpaired, two-sample test, as we are working with first differences. Fixed effects between identical individuals, therefore do not interfere with the independence of both samples. To rule out interference of higher order effects we later perform paired and partially paired tests. The results do not change.

In hypothesis $H 3: a \& d=c$ we pool both going abroad semesters and compare them against the effect of staying in Maastricht in the first semester. Since the effects $d$ and $c$ are derived from the same set of individuals some, but not all students studied in $a \& d$ and $c$ are identical. The t-test signals a significant reduction of Neuroticism and an inward moving Locus of Control in the going abroad treatment group.

Given this pattern, hypothesis $H 4: b=c$ tests whether these effects are persistent. More precisely, it investigates whether the changes felt by group $\mathrm{A}$ in the semester after the study abroad experience are different from the changes felt by group B in the semester before their study abroad experience. Like the test for $b=0$ in Table 5.2, no strong patterns for Neuroticism or Locus of Control are detected. In fact, in both groups the effects have the same sign. Finally, we pool both going-abroad periods and both stayingin-Maastricht periods and test for equality in hypothesis $H 5: a \& d=b \& c$. Again, we find the same pattern with a significant reduction in Neuroticism and a significantly more inward Locus of Control in the going-abroad group.

Asking the same individuals at different points in time points towards the use of a paired test. Instead, we present unpaired tests in Table 5.4 because we are already comparing changes rather than levels. Thus, a correlation from fixed effects, a major reason for using the paired test, should no longer be present. Table 5.5, however, shows paired tests for $H 2$ and $H 5$ and a partially paired test for $H 3$, where we use a correction adjusting for the fact that only the $\mathrm{c}$ and $\mathrm{d}$ parts of the sample can be paired. The results point in the same direction with the reduction in Neuroticism losing some significance. We also asked students about their study abroad destinations. Around 61 percent were heading for a university outside of Europe, where South-America was the most popular Non-European destination with a share (among all options) of roughly 25 percent. A test whether the study abroad effect was different for students staying in Europe compared to those studying further away yielded no difference. For all traits the hypothesis that the changes were equal could not be rejected with high p-values. 


\begin{tabular}{|c|c|c|c|c|c|}
\hline Hypothesis & $n_{1}$ & $n_{2}$ & $\mathrm{p}$ & $\mu_{1}$ & $\mu_{2}$ \\
\hline \multicolumn{6}{|l|}{$\mathrm{H} 1: \mathrm{a}=\mathrm{c}$} \\
\hline open & 49 & 34 & 0.142 & -0.224 & 0.971 \\
\hline consc & 50 & 34 & 0.908 & 0.020 & -0.088 \\
\hline extra & 50 & 35 & 0.825 & 0.240 & 0.429 \\
\hline agree & 49 & 34 & 0.282 & -0.122 & 0.824 \\
\hline neuro & 49 & 35 & $0.060^{*}$ & -1.122 & 0.800 \\
\hline loc & 50 & 35 & $0.022^{* *}$ & 1.420 & -0.229 \\
\hline \multicolumn{6}{|l|}{$\mathrm{H} 2: \mathrm{c}=\mathrm{d}$} \\
\hline open & 34 & 29 & 0.339 & 0.971 & 0.034 \\
\hline consc & 34 & 30 & 0.554 & -0.088 & 0.533 \\
\hline extra & 35 & 30 & 0.509 & 0.429 & 1.200 \\
\hline agree & 34 & 29 & 0.381 & 0.824 & 0.034 \\
\hline neuro & 35 & 30 & 0.128 & 0.800 & -1.167 \\
\hline loc & 35 & 30 & $0.094^{*}$ & -0.229 & 1.167 \\
\hline \multicolumn{6}{|l|}{ H3: $a \& d=c$} \\
\hline open & 78 & 34 & 0.153 & -0.128 & 0.971 \\
\hline consc & 80 & 34 & 0.724 & 0.213 & -0.088 \\
\hline extra & 80 & 35 & 0.836 & 0.600 & 0.429 \\
\hline agree & 78 & 34 & 0.258 & -0.064 & 0.824 \\
\hline neuro & 79 & 35 & $0.044^{* *}$ & -1.139 & 0.800 \\
\hline loc & 80 & 35 & $0.018^{* *}$ & 1.325 & -0.229 \\
\hline \multicolumn{6}{|l|}{$\mathrm{H} 4: \mathrm{b}=\mathrm{c}$} \\
\hline open & 42 & 34 & $0.022^{* *}$ & -0.976 & 0.971 \\
\hline consc & 41 & 34 & 0.357 & -0.902 & -0.088 \\
\hline extra & 42 & 35 & $0.085^{*}$ & -1.024 & 0.429 \\
\hline agree & 42 & 34 & 0.289 & -0.048 & 0.824 \\
\hline neuro & 40 & 35 & 0.495 & 0.075 & 0.800 \\
\hline loc & 42 & 35 & 0.708 & -0.476 & -0.229 \\
\hline \multicolumn{6}{|l|}{ H5.: $\mathrm{a} \& d=\mathrm{b} \& \mathrm{c}$} \\
\hline open & 78 & 76 & 0.969 & -0.128 & -0.105 \\
\hline consc & 80 & 75 & 0.251 & 0.213 & -0.533 \\
\hline extra & 80 & 77 & 0.132 & 0.600 & -0.364 \\
\hline agree & 78 & 76 & 0.491 & -0.064 & 0.342 \\
\hline neuro & 79 & 75 & $0.045^{* *}$ & -1.139 & 0.413 \\
\hline loc & 80 & 77 & $0.001^{* * *}$ & 1.325 & -0.364 \\
\hline
\end{tabular}

Table 5.4: Testing the hypothesis of Table 5.3. A and B refer to groups A and B. Sample sizes $(n)$ and means $(\mu)$ are presented from left to right. For H1: $\mathrm{a}=\mathrm{c}$ this means that $n_{1}$ is the number of observations for a and $n_{2}$ is the number of observations for c. All tests are unpaired and have been performed assuming an unequal variance using Satterthwaite's estimate for the degree of freedoms. Paired and partially paired tests are presented in Table 5.5. 


\subsection{The Size of the Effect}

To assess the magnitude of these level changes, Table 5.6 provides the means and standard deviations of all traits at each point of testing. Locus of Control always has the lowest standard deviation of all traits. Taking the effect size from the first panel of Table 5.2 would imply that students on average obtained a $\Delta_{\text {loc }}=1.33$ points more inward Locus of Control which is about 38 percent of a pre-treatment standard deviation. For Neuroticism the effect size is slightly below 15 percent of one pre-treatment standard deviation.

To obtain an impression about the relevance of our results we investigate how Neuroticism and Locus of Control are jointly related to productivity

\begin{tabular}{llllll}
\hline \hline Hypothesis & $n_{1}$ & $n_{2}$ & $\mathrm{p}$ & $\mu_{1}$ & $\mu_{2}$ \\
\hline H2: c =d, a paired t-test & & & & & \\
open & 29 & 29 & 0.459 & 0.931 & 0.034 \\
consc & 29 & 29 & 0.624 & 0.034 & 0.690 \\
extra & 30 & 30 & 0.572 & 0.333 & 1.200 \\
agree & 29 & 29 & 0.776 & 0.310 & 0.034 \\
neuro & 30 & 30 & 0.280 & 0.567 & -1.167 \\
loc & 30 & 30 & 0.201 & -0.167 & 1.167 \\
\hline H3: a\&d=c, a partially paired t-test & & & & & \\
open & 78 & 34 & 0.144 & -0.128 & 0.971 \\
consc & 80 & 34 & 0.749 & 0.213 & -0.088 \\
extra & 80 & 35 & 0.862 & 0.600 & 0.429 \\
agree & 78 & 34 & 0.182 & -0.064 & 0.824 \\
neuro & 79 & 35 & 0.100 & -1.139 & 0.800 \\
loc & 80 & 35 & $0.005^{* * *}$ & 1.325 & -0.229 \\
\hline H5: a\&d=b\&c, a paired t-test & & & & & \\
open & 70 & 70 & 0.890 & -0.171 & -0.271 \\
consc & 70 & 70 & 0.393 & 0.214 & -0.514 \\
extra & 72 & 72 & 0.139 & 0.792 & -0.458 \\
agree & 70 & 70 & 0.674 & -0.143 & 0.143 \\
neuro & 69 & 69 & 0.155 & -1.101 & 0.290 \\
loc & 72 & 72 & $0.005^{* * *}$ & 1.417 & -0.347 \\
\hline \hline
\end{tabular}

$* p<0.10,{ }^{* *} p<0.05,{ }^{* * *} p<0.01$

Table 5.5: This Table presents paired and partially paired t-tests. A paired t-test can be applied to account for the dependence between observations from the same individuals at different points in time. However, we do not compare individual characteristics, but changes in these. Thus, the dependence one would expect from fixed effects has already been extracted. We present the paired t-tests as a robustness check against non-linear dependencies. 


\begin{tabular}{lcccccc}
\hline \hline & open & consc & extra & agree & neuro & loc \\
\hline $\mathbf{1}$ & & & & & & \\
Male & 40.89 & 43.42 & 41.28 & 39.44 & 30.11 & 11.22 \\
& $(6.06)$ & $(6.73)$ & $(5.79)$ & $(6.16)$ & $(7.79)$ & $(3.48)$ \\
Fem. & 41.00 & 45.64 & 41.41 & 42.69 & 34.18 & 10.26 \\
& $(5.95)$ & $(5.69)$ & $(6.50)$ & $(6.52)$ & $(8.58)$ & $(3.51)$ \\
$\mathbf{2}$ & & & & & & \\
Male & 40.74 & 43.24 & 40.93 & 39.62 & 30.50 & 12.20 \\
& $(5.85)$ & $(7.47)$ & $(6.16)$ & $(5.00)$ & $(7.51)$ & $(3.90)$ \\
Fem. & 41.58 & 45.64 & 42.51 & 43.18 & 33.00 & 10.72 \\
& $(5.22)$ & $(5.84)$ & $(6.58)$ & $(5.10)$ & $(8.82)$ & $(3.98)$ \\
$\mathbf{3}$ & & & & & & \\
Male & 40.38 & 42.62 & 40.88 & 38.86 & 30.73 & 12.38 \\
& $(5.74)$ & $(6.31)$ & $(5.69)$ & $(5.44)$ & $(7.98)$ & $(4.78)$ \\
Fem. & 40.83 & 46.03 & 41.57 & 43.40 & 31.86 & 11.27 \\
& $(5.88)$ & $(5.84)$ & $(7.31)$ & $(6.12)$ & $(8.17)$ & $(4.50)$ \\
\hline \hline
\end{tabular}

Table 5.6: Reports the average values for the different personality domains and standard deviations (in parentheses) for all three surveys.

in the work place. We use data from the German Socio Economic Panel $(\text { GSOEP })^{8}$ which includes information on the Big 5 and Locus of Control as well as on wages which we use as a proxy for productivity and several other socio demographic characteristics. It also captures economic preferences like risk aversion, patience, trust, altruism and reciprocity. ${ }^{9}$ We estimate the following regression model:

$$
\operatorname{hourlywage}_{i}=\beta_{0}+\beta_{1} \operatorname{loc}_{i}+\beta_{2} \operatorname{big} 5_{i}+\beta_{3} \text { controls }_{i}+\epsilon_{i} \text {. }
$$

The estimation results are summarised in Table 5.7. In the first three models we estimate Equation 5.1 with varying controls. Model 1, the model with the largest effect sizes, simply regresses hourly wages on the six traits without further controls. ${ }^{10} \mathrm{~A}$ more inward Locus of Control and low Neuroticism are associated with higher hourly wages. Controlling for cognitive ability $^{11}$, economic preferences and demographics reduces most individual

\footnotetext{
${ }^{8}$ The GSOEP is a large panel data set that is representative of the German adult population (Schupp \& Wagner, 2002).

${ }^{9}$ The relationship between the Big 5 and these economic preferences in the GSOEP was investigated by A. Becker et al. (2012). We use the same data (waves 2003 to 2009) as A. Becker et al. (2012) restricting the sample to individuals where information about each trait is available. The sample size is further reduced by missing data on wages and work hours. All traits are standardised.

${ }^{10}$ With the exception of Extraversion the direction of all effects is preserved when more control variables are included.

${ }^{11}$ Cognitive ability is measured by a word fluency test (respondents had to name as
} 
coefficients in model 2 , but the overall pattern remains unchanged. This is also true when we include educational attainment in model 3 , which is seen as an important mediator between personality and labour market outcomes by Almlund et al. (2011).

\begin{tabular}{|c|c|c|c|c|}
\hline & $\begin{array}{c}\text { (1) } \\
\text { hourly wage }\end{array}$ & $\begin{array}{c}\text { (2) } \\
\text { hourly wage }\end{array}$ & $\begin{array}{c}\text { (3) } \\
\text { hourly wage }\end{array}$ & $\begin{array}{c}(4) \\
\text { hourly wage }\end{array}$ \\
\hline loc & $\begin{array}{c}2.119^{* * *} \\
(16.07)\end{array}$ & $\begin{array}{c}1.428^{* * *} \\
(4.88)\end{array}$ & $\begin{array}{c}1.080^{* * *} \\
(3.75)\end{array}$ & $\begin{array}{l}1.524^{*} \\
(1.82)\end{array}$ \\
\hline open & $\begin{array}{c}1.163^{* * *} \\
(7.96)\end{array}$ & $\begin{array}{c}1.276^{* * *} \\
(3.87)\end{array}$ & $\begin{array}{c}0.719^{* *} \\
(2.20)\end{array}$ & $\begin{array}{l}0.192 \\
(0.21)\end{array}$ \\
\hline consc & $\begin{array}{c}0.247^{*} \\
(1.70)\end{array}$ & $\begin{array}{c}0.0454 \\
(0.14)\end{array}$ & $\begin{array}{l}0.293 \\
(0.93)\end{array}$ & $\begin{array}{l}0.124 \\
(0.15)\end{array}$ \\
\hline extra & $\begin{array}{c}-1.158^{* * *} \\
(-8.32)\end{array}$ & $\begin{array}{l}-0.272 \\
(-0.84)\end{array}$ & $\begin{array}{l}0.103 \\
(0.32)\end{array}$ & $\begin{array}{l}0.431 \\
(0.47)\end{array}$ \\
\hline agree & $\begin{array}{c}-1.258^{* * *} \\
(-9.26)\end{array}$ & $\begin{array}{c}-0.671^{* *} \\
(-2.05)\end{array}$ & $\begin{array}{c}-0.681^{* *} \\
(-2.12)\end{array}$ & $\begin{array}{l}-1.560 \\
(-1.62)\end{array}$ \\
\hline neuro & $\begin{array}{c}-1.353^{* * *} \\
(-9.55)\end{array}$ & $\begin{array}{c}-0.987^{* * *} \\
(-3.19)\end{array}$ & $\begin{array}{c}-0.751^{* *} \\
(-2.48)\end{array}$ & $\begin{array}{l}-0.197 \\
(-0.22)\end{array}$ \\
\hline iq & & $\begin{array}{c}1.353^{* * *} \\
(3.25)\end{array}$ & $\begin{array}{c}0.822^{* *} \\
(2.00)\end{array}$ & $\begin{array}{l}0.914 \\
(0.82)\end{array}$ \\
\hline constant & $\begin{array}{l}15.28^{* * *} \\
(126.77)\end{array}$ & $\begin{array}{l}-4.463 \\
(-1.32)\end{array}$ & $\begin{array}{c}-15.52^{* * *} \\
(-4.26)\end{array}$ & $\begin{array}{l}-1.217 \\
(-0.10)\end{array}$ \\
\hline economic traits & $\mathrm{No}$ & Yes & Yes & Yes \\
\hline other controls & No & Yes & Yes & Yes \\
\hline schooling & No & No & Yes & No \\
\hline$N$ & 6023 & 1155 & 1121 & 289 \\
\hline
\end{tabular}

Table 5.7: Regression table relating hourly wage and personality using data from the German Socio Economic Panel.

To increase comparability to the Maastricht student population in model 4 we restrict the sample to respondents holding a university or technical college degree. ${ }^{12}$ Due to the lower sample size, standard errors are pushed up and much significance seems to have been lost. Only Locus of Control remains weakly significant.

Using the coefficients from model 4 we perform a simple calculation to translate the changes in Locus of Control and Neuroticism which we at-

many animals as possible in 90 seconds) and by a symbol correspondence test (participants had to match numbers to as many sings as possible in 90 seconds according to a codebook).

${ }^{12} \mathrm{We}$ do this since the large majority of students that is granted permission to go abroad at SBE also completes their degree. 
tribute to the study abroad experience into working productivity. Since all trait measures in the regression were standardised, we assess the productivity change as follows:

$$
\Delta_{\text {producitiy }}=\frac{\Delta_{\text {loc }}}{s d_{\text {loc }}} * \beta_{\text {loc }}+\frac{\Delta_{\text {neuro }}}{s d_{\text {neuro }}} * \beta_{\text {neuro }} .
$$

The calculation suggests that the personality change following from a half year study-abroad experience may improve the productivity of the participating individuals in the magnitude of 2.4 percent. With an average starting wage of $€ 42,000$, zero growth and a discount rate of 3.5 percent this would amount to a present monetary value of $€ 21,525$ over the course of a forty year working life. If the effect vanished after five years this number would decrease to $€ 4,551$.

\subsection{Conclusion}

In this Chapter we presented evidence that suggests that investment in personality is possible. We find that a going-abroad experience changes the personality of university students by comparing two student groups from the same programme who go abroad in different semesters. We find that going abroad leads to a 38 percent standard deviations more inward Locus of Control and to 15 percent of a standard deviation lower Neuroticism. Both, a more inward Locus of Control and lower Neuroticism, in the literature are associated with higher subjective well being and better health with some studies suggesting that, of all traits, Locus of Control and Neuroticism have the highest correlation with these outcomes. Using GSOEP data we confirm previous findings that a more inward Locus of Control and lower Neuroticism are positively related to earnings. For a sample of university graduates in the GSOEP we find that the personality changes measured on average in our treatment groups would imply an increase in gross wages of about 2.4 percent. Under some assumptions this suggests a present monetary value of $€ 21,525$. The number would be lower if the study abroad would eventually fade out. While this number is not in any way exact, it provides some guidance for the potential economic impact of a change in non-cognitive abilities that could be achieved by an educational policy.

There are some limitations to our findings. An important concern would be the sample size in the individual groups. Especially, in the group that stays in Maastricht before going abroad that serves as a control group the lowest observations available for a given trait is 34 . While the main result that going abroad groups obtain a more inward Locus of Control and lower Neuroticism appears to be strong despite the low sample size, more subtle points might have been lost. For example, it would have been interesting to see how students with different personality profiles ex-ante were affected by the treatment. The study focused on a treatment effect for a group who 
committed themselves to go abroad and, thus, does not comment on the effect of international education for groups that do not want to go abroad.

The results help to explain why international education has become increasingly popular as it has become more easily attainable. It also suggests an explanation for the observed international-experience wage premium (Oosterbeek \& Webbink, 2006) that goes beyond a pure signaling effect. This is also relevant for international communities like the European Union who encourage students to go abroad hoping to a achieve more integration between its members. The results may hint that there is an economic dividend to policies enabling students to such policies. Our analysis also suggests that studying in another European country has the same effect on student personality than going away even further.

Non-cognitive abilities have received much attention in recent years. If cognitive and non-cognitive abilities are indeed important complements and non-cognitive skills can be affected by public policy, then, investment into cognitive as well as non-cognitive abilities would be a logical step. Going abroad seems to have an effect on the personal development of young adults and, thus, may be a way of investing in personality. 


\section{Chapter 6}

\section{Job Preferences of Students}

Learning the preferences of students is crucial to understand why they pick certain jobs. Using more than 30,000 replies to two different vignette-type questions this Chapter explains what job characteristics are important to students, both in regard to current part-time and future graduate jobs. Due to the design of the vignette questions, the value of changes in job attributes can be expressed in terms of a wage. For example, students dislike mobility, while they are willing to give up parts of their wage for increased flexibility (part-time jobs) or job security (graduate jobs). This information can be used by companies to design more efficient pay schemes or to gain an advantage when competing for employees.

\subsection{Introduction}

In a simple economic model of the labour market the wage of a certain job is determined by a combination of its attractiveness and its requirements. Jobs that are unattractive or require specific skills should pay more. Within this framework we can ask how labour supply reacts to certain changes in job attractiveness. Moreover, we can consider the wage a job characteristic by itself. In order to boost the attractiveness of a job higher pay is then only one option. Other job attributes such as weekly working hours, job mobility or the type of work could also be altered to enhance attractiveness. In some cases this might be cheaper for the company than increasing the wage.

This Chapter gives a mapping of the job preferences of students, both for part-time jobs during the studies and for graduate jobs thereafter. For this two different vignette questions with, in total, more than 30,000 participants are used. We find that German students show a clear negative response 
to job mobility. Each additional minute of travelling time to a student job should be compensated by an increase in the hourly wage of $€ 0.16$. Moving to another German state (Bundesland) for a first graduate job requires an additional $€ 349$ in monthly salary after taxes. Other job characteristics can have similar, strong effects on job attractiveness. In a part-time job students are willing to forgo $€ 2.18$ per hour if they are allowed to pick their working times independently. Graduates are willing to give up $€ 320$ in monthly salary after taxes to switch from a temporary job position to an open-ended one.

Companies can use this information on compensating differentials to design more attractive jobs. This is especially important for employers who have problems to compete for talent in a purely monetary fashion. Some job characteristics are easy to change and have a strong impact. Graduates put a large weight on job security and like family friendly employers. Similarly, students in a part-time job greatly value flexible working hours. Other job characteristics may take longer to be altered. For example, students have a strong distaste of companies with a bad reputation. While this applies to both part-time and graduate jobs, the corporate image is nothing that can be changed quickly.

The decision of a company whether or not to change a certain job design depends on two things. On the one hand, this Chapter determines how much employees value certain changes in job attributes. On the other hand, these changes are costly (Lazear \& Shaw, 2007). Whether the benefits of a certain change outweigh the costs can only be determined on a company level. There is, however, evidence that at least with respect to certain job attributes the benefits are larger (Lazear \& Oyer, 2012).

The preferences of students are hard to study using market data. In reality it is probably true that graduates who are offered an open-ended job position will also earn a higher salary. In an early paper, for example, Ehrenberg (1980) finds a positive relationship between wages and retirement benefits. To obtain the true, and as we show negative, trade-off between job amenities and wage requires to restrict the analysis to very similar individuals. Unfortunately many important variables that measure differences between individuals are unobservable. There are different ways to solve this problem in the existing literature. Olson (2002) uses an instrumental variable approach to access the trade-off between health insurance and wage. Using different job offers for the same scientist S. Stern (2004) is able to find the willingness to forgo wages to be able to engage in more scientific work. These approaches are, however, limited to one specific job characteristic.

To study the job preferences of students we conduct two choice experiments in the form of two different vignette-type questions. Round three of the Fachkraft data asked respondents to choose between three different part-time jobs for students. Three different graduate jobs to choose from were included in round four. In both cases the wage of a job is included as a job characteristic. On top of this, the vignette question on part-time jobs in- 
cludes travelling time to the job, weekly working hours, time slots in which the work takes place, type and requirements of work as well as size and corporate image of the employer. For graduate jobs weekly working hours, job location, industry, type of organisation, type of contract and specific company information are included in addition to the wage. The vignette questions allow to calculate the probability that a certain job is chosen. This is a good proxy for job attractiveness. Holding it constant allows to derive the marginal changes in some job attributes that are necessary to balance a change in another job attribute.

Other papers have used similar methods to analyse labour market decisions. ${ }^{1}$ Eriksson and Kristensen (2014) use a vignette-type question design to find the trade-offs between wage, on-the-job training, health insurance and flexible working hours. In their sample of Danish workers they find negative trade-offs between the different job characteristics. However, the smaller sample size requires them to include only two jobs to choose from and less job attributes with less levels. ${ }^{2}$ More papers can be found that measure the preferences of employers. Examples of papers that analyse the hiring decision using vignette-type questions are Van Beek, Koopmans, and Van Praag (1997), Karpinska, Henkens, and Schippers (2011) or Humburg and van der Velden (2014). Bertrand and Mullainathan (2004) go one step further and send seemingly real resumes to companies that are looking to hire new employees. Vignette studies are frequently applied in other contexts. Starting off in psychology (Rossi \& Nock, 1982) the technology was used in marketing research (Green \& Srinivasan, 1990). Borghans, Romans, and Sauermann (2010) use a vignette-type question to determine which conferences appeal to labour economists.

The remainder of this Chapter is structured as follows. The next section outlines the design of the two different vignette-type questions. The estimation method is explained in the section thereafter. Section four displays the various results before a last section concludes.

\subsection{Question Design}

\subsubsection{General Vignette Design}

The Fachkraft data includes choice experiments in the form of vignette questions. Thereby round three of the data collections includes a vignette question concerning part-time jobs for students. A vignette question on graduate jobs is part of round four. The integration of these two questions in the questionnaire is very similar. The online survey hosting service used, fluidsurveys, offers a plug-in that allows to amend questions using

\footnotetext{
${ }^{1}$ The vignette technique is often referred to as a conjoint study or simply a choice experiment.

${ }^{2}$ The final sample consists of roughly 3,000 individuals.
} 
JavaScript programming. The relevant data generating process has then been implemented within the online questionnaire and the vignette questions were generated for each participant the moment the survey was taken. Also, the question design is very comparable for the part-time and graduate job vignette questions. In both cases the choice experiment is composed of three different options called vignettes. In each round a participant has to choose the most preferred one out of these three vignettes. To add power to the analysis each participant is presented with three such questions per questionnaire and consequently has to make three decisions. The three rounds and the large number of participants allow to impose very little restrictions on the composition of the vignettes. Almost all levels of each vignette are randomised. Whenever some structure is imposed this is done to rule out implausible combinations and to make the vignettes more realistic. The main difference between the vignettes on part-time jobs versus graduate jobs lies in the data generating processes and hence in the composition of the levels of the respective vignettes.

\subsubsection{Part-Time Job Vignette Design}

The question design of a specific part-time job vignette question is given in Figure 6.1. This particular question is just one of many possible examples that was generated randomly subject to a data generating process. In total answers from 14,245 students, who participated in round three of the Fachkraft data collection, can be used for the analysis. ${ }^{3}$

As can be seen in Figure 6.1 the first characteristic of each vignette is hourly wage. Hourly wage is randomly drawn from a uniform distribution between $€ 7$ and $€ 17$ using discrete steps of $€ 0.50$. The second attribute, travelling time, is measured in minutes and also drawn randomly from a discrete uniform distribution. The lowest possible travelling time is five minutes while the maximum is 90 minutes with a step size of one minute.

The next criterion defines whether a job is mentally or physically challenging. The four possible combinations are drawn with an equal chance of 25 percent each. Characteristic number four defines the size and the public image of the company to work for. Company size is measured in small and large, while the public image has three levels, bad, neutral and good. Again, the six possible combinations each receive an equal chance to be selected. The type of work is defined in line five. The levels are office, call centre inbound, call centre - outbound, retail, catering / hotel, healthcare / social, IT / EDP, physical work, promotion / hostess and scientific. Once more, each of these levels has an equal chance to be chosen.

Criterion six gives the time slot(s) during which the work takes place. Here the levels do not receive an equal chance to be picked. Morning is chosen with a chance of $1 / 6$, afternoon also with $1 / 6$, evening with $1 / 9$, night

\footnotetext{
${ }^{3}$ For more information on the data set please refer to Chapter 2.
} 


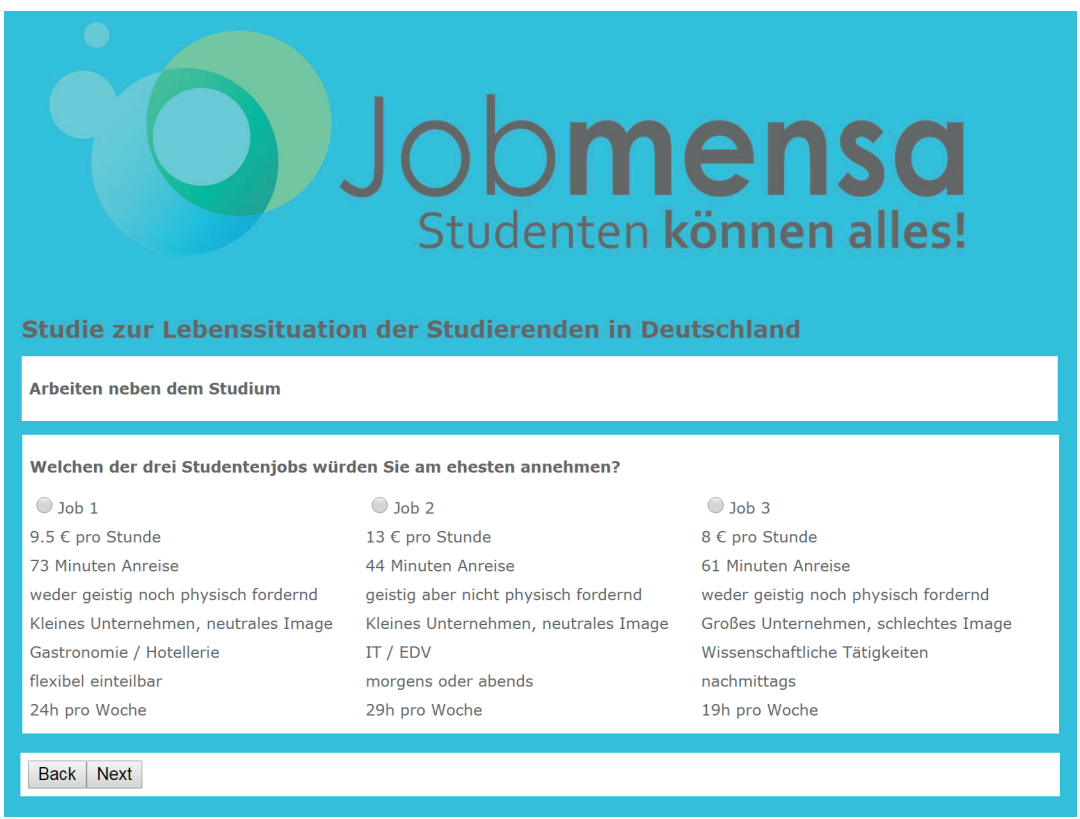

Figure 6.1: Screenshot of the part-time job vignette question. Levels are selected randomly and change for each respondent.

with $1 / 18$, a combination of morning and afternoon with $1 / 9$, a combination of morning and evening with $1 / 18$, a combination of morning and night with $1 / 18$, a combination of afternoon and evening with $1 / 18$, a combination of afternoon and night with $1 / 18$, a combination of evening and night with $1 / 18$ and completely flexible working hours with $1 / 9$. The final characteristic of the part-time job are the working hours per week. These follow a discrete uniform distribution between two and 40 with a step size of one hour. All of the seven job attributes are independent from each other.

\subsubsection{Graduate Job Vignette Design}

An example of the question design of the graduate job vignette question can be found in Figure 6.2. Note again, Figure 6.2 only displays one specific version of the many vignette questions as all characteristics can take different levels. In total 18,788 participants from round four of the Fachkraft data are used to analyse this vignette question. ${ }^{4}$

In the graduate job vignette question the first two characteristics are monthly wage after taxes and weekly working hours. These two values are

\footnotetext{
${ }^{4}$ For more information on the data set please refer to Chapter 2 .
} 
based on multiple independent uniform distributions. They are dependent on each other but independent from all other job characteristics. First, weekly working hours are generated using the following formula with each $u_{i}$ being a random draw from independent uniform distribution on the interval $[0 ; 1]$.

$$
\text { hours }=12+20\left(u_{1}+u_{2}+u_{3}\right)
$$

Next, monthly wage after taxes is generated using weekly working hours and again three random draws from independent uniform distributions on the interval $[0 ; 1]$. Thereby, the first term measures whether a job requires a lot or only a few hours per week. The second term then scales whether the work is, independent from the working hours, well paid or not. Figure 6.3 displays the distributions of the two variables as they occur in the data set.

$$
\text { wage }=\frac{\text { hours }}{40}\left(300+1000\left(u_{1}+u_{2}+u_{3}\right)\right)
$$

Criterion three and five give the location and the industry of the graduate job. The location consists of the city size and the Bundesland. Germany is a federal state and has in total 16 states called Bundesländer. ${ }^{5}$ An exception are Berlin, Bremen and Hamburg as these are city states. Hence, city size for these states is fixed to large city. For the other states city size can take four, equally likely levels which are large city, medium city, small city and rural area. ${ }^{6}$ To create a realistic set of locations, the German state in which a participant studies is set to appear twice in the three options. It may not be reasonable to assume that, for example, a student from southern Germany has to choose between three jobs that are all located in the North. The last option is then a random draw with all German states having equal odds. $^{7}$ Students that do not study in Germany get a random draw with equal odds for all three locations.

For the industry, which is the fifth job characteristic, a similar approach is used. Given the study field of a participant, some industries fit better than others. Therefore, for each study field one or two industries were selected that present a good fit for the respective subject. As this had to be decided prior to the data collection the mapping of study fields to

\footnotetext{
${ }^{5}$ The states are Baden-Württemberg, Bayern, Berlin, Brandenburg, Bremen, Hamburg, Hessen, Mecklenburg-Vorpommern, Niedersachsen, Nordrhein-Westfalen, Rheinland-Pfalz, Saarland, Sachsen, Sachsen-Anhalt, Schleswig-Holstein and Thüringen.

${ }^{6}$ In Germany a large city is defined as having 100.000 or more inhabitants, a medium city ranges from 20,000 to 100,000 , a small city from 5,000 to 20,000 and everything below 5,000 is categorised as rural area.

${ }^{7}$ The position of the vignettes is also randomised, so it could be that this last, random option appears in the left, the middle or the right vignette.
} 


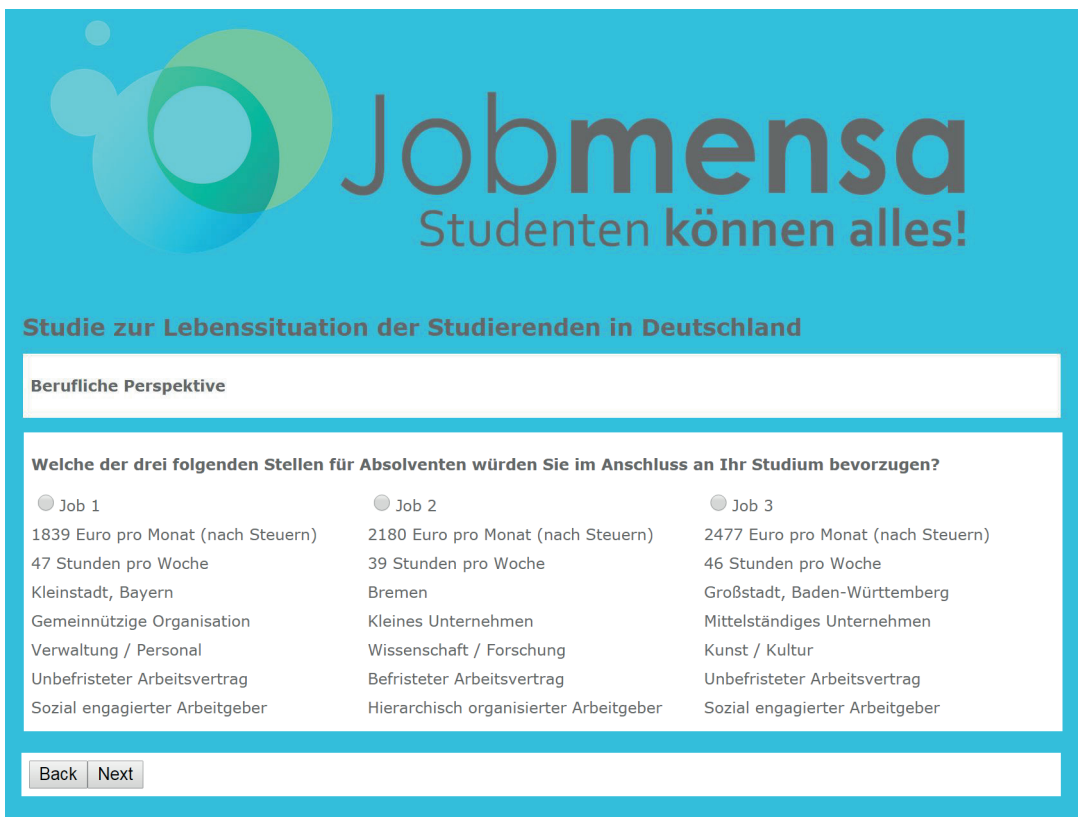

Figure 6.2: Screenshot of the graduate job vignette question. Levels are selected randomly and change for each respondent.

industries is clearly subjective. ${ }^{8}$ The data generating process is then set up to present each participant with exactly two, out of the three, options that fit to the study field. The last option is a random draw with equal odds for all industries. ${ }^{9}$ The industries used in the vignette are health / social work, art / culture, media / marketing, administration / human resources, law, production / construction, computer science / information technology, science / research, education / pedagogy and finance / accounting. By design, location and industry of a graduate job vignettes are not perfectly independent, but any correlation between the place of study and the subject might be picked up by these variables. To account for this, the two variables are studied simultaneously in the later analysis.

All other job attributes are randomly drawn and hence completely independent. The fourth one, company type, has five equally likely levels. These are large company, medium-size business, small business, public sector and non-profit organization. Graduate job characteristic six defines whether a job position is temporary or open-ended. By design, 60 percent of the vignettes show temporary and 40 percent open-ended job positions.

\footnotetext{
${ }^{8}$ The mapping used is accounted for by the analysis.

${ }^{9}$ As with the German state the location of the random option is itself randomised.
} 

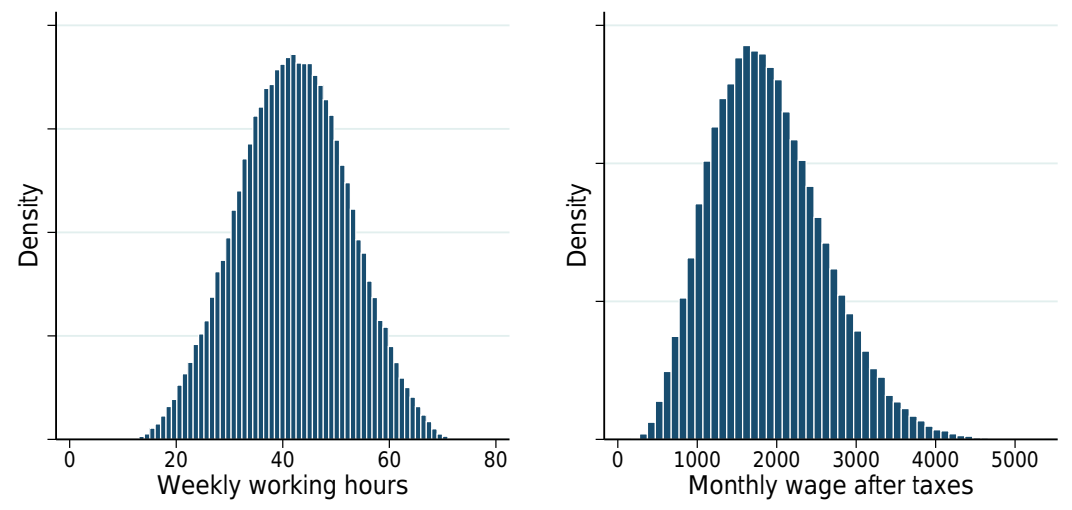

Figure 6.3: Distribution of weekly working hours (left) and monthly wage after taxes (right) from the graduate job vignette question.

Finally, the last attribute gives specific information about the employer. An employer can be labeled family friendly, environmentally friendly, socially involved, organised by a strict hierarchy, using a gender quota at the top levels, strong worker representation, high turnover or publicly criticised. For each vignette exactly one of these labels is selected with all labels having the same chance of being picked.

\subsection{Estimation Method}

For each participant the vignette question consists of three rounds with three possible choices each. The outcome variable is a choice dummy and, by definition, twice equal to zero and once equal to one per round. The job characteristics of each vignette, as described in the previous section, are then used to explain the choice of a participant. With a few exceptions it is not important whether the analysis is done simultaneously or not. Randomisation ensures that the different job characteristics are independent from and hence, do not correlate with each other. By design, omitting other job characteristics from the vignette cannot bias the coefficients of the variables included in the model.

Due to randomisation the level of attractiveness of the three options varies between different rounds of vignettes. In some rounds vignettes with low attractiveness need to be chosen as a result of the other two options being even less attractive. Equivalently, in other rounds, vignettes with high attractiveness are not chosen as another option is even better. To account 
for the varying degree of attractiveness between the different rounds requires fixed effects. A model that includes this feature is the conditional logistic regression. Still, it is not required to estimate a model that accounts for the varying level of attractiveness. On average each vignette as well as each round of vignettes are equally attractive. The only source of differences in attractiveness is the randomness imposed by the process that generates each vignette. Therefore, the conditional logistic regression surely fits the data best, however, a normal logistic regression leads, asymptotically, to the same coefficients. In the results section the logistic model is used. The reason is that it allows for a simpler analysis and an easier display of the predictions of the models. Due to the large sample size no large differences between the models can be found. ${ }^{10}$

Attractiveness itself is a somewhat abstract concept. In the vignette questions at hand it is the prediction of the choice variable or in other terms the estimated chance that a certain job gets chosen. This choice variable is on average $1 / 3$ and either equal to 0 or 1 . A far more intuitive unit of measurement can be the change in one job characteristic that exactly balances a change in another job characteristic. A natural choice for this is wage. By design, wage itself is a job characteristic, either in terms of hourly wage in the part-time job vignette or in terms of monthly wage after taxes in the graduate job vignette. Therefore a change in any other job characteristic can be expressed by the amount of wage required to compensate for it. Mathematically the wage needed to counter-balance a change in job characteristics, so that attractiveness stays constant, is given approximately by the ratio of the two coefficients and the size of the change in the job characteristic.

$$
\text { Compensation }_{i}=\frac{\Delta X_{i} \beta_{i}}{\beta_{\text {wage }}}
$$

\subsection{Results}

\subsubsection{Part-Time Job Vignette}

All job characteristics of the part-time job vignette are independent from each other. Therefore they can be analysed individually. Moreover, the large amount of observations allows to run a model without imposing any functional form. All levels of the quantitative variables can be included in dummy terms. The first variable to analyse is hourly wage. Dummy terms that differ sufficiently from the base level show significant deviations. ${ }^{11}$ Figure 6.4 plots the predictions of the model. Estimating a logit model with

\footnotetext{
${ }^{10}$ The conditional logistic regression has been applied as a robustness check.

${ }^{11}$ Setting the base level at $€ 12$ per hour only $€ 12.50$ and $€ 13.50$ show no significant deviations at a 5 percent significance level.
} 


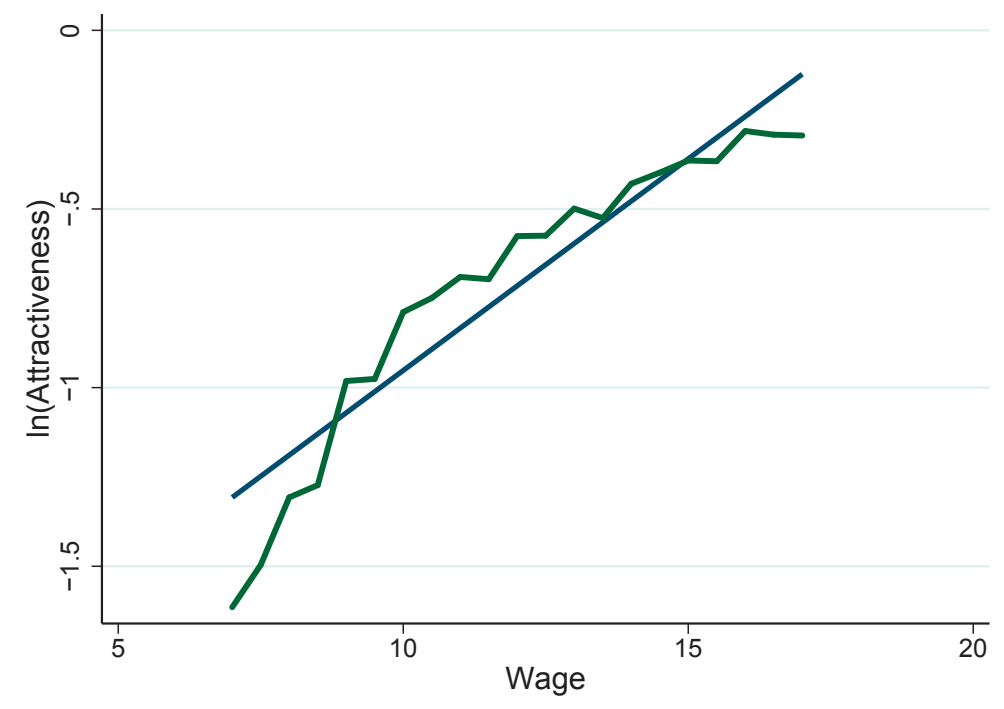

Figure 6.4: Predictions of the effect of hourly wage (in Euros) on the attractiveness of a student job using logistic regression models without any functional form as well as a linear function.

a linear wage effect shows that a one Euro increase in wage increases the attractiveness of the job by 11.8 percent. ${ }^{12}$ The linear fitted line is also plotted in Figure 6.4.

A very similar analysis can be conducted for the time a student needs to travel to the job. A model without any functional form shows that most dummies differ significantly from the base level. ${ }^{13}$ Figure 6.5 illustrates that, without imposing any structural form, the effect of travelling time in the model is very close to linear. Once more, the graph includes the predictions of a linear effect. An increase in travelling time by one minute leads to a drop in attractiveness of 1.9 percent. ${ }^{14}$. In other words, for each 6.2 minutes of travelling time students want to earn an extra Euro per hour.

The next set of characteristics that define a vignette consist of categories. The first defines the size of a company and its corporate image. For students that choose a part-time job the size of a company is no relevant criterion. The corporate image of a company, however, does lead to differences in the attractiveness of a job. From a bad to a good corporate image job attractiveness increases significantly as can be seen from Figure 6.6. In

\footnotetext{
${ }^{12}$ Hourly wage is significant with a p-value lower than 0.001 .

${ }^{13}$ With a base level of 45 minutes only $36,37,38,40,41,42,43,44,46,47,48$ and 49 minutes show no significant deviation at a significance level of 5 percent.

${ }^{14}$ In the linear logit model travelling time is a highly significant estimator of attractiveness with a p-value below 0.001 .
} 


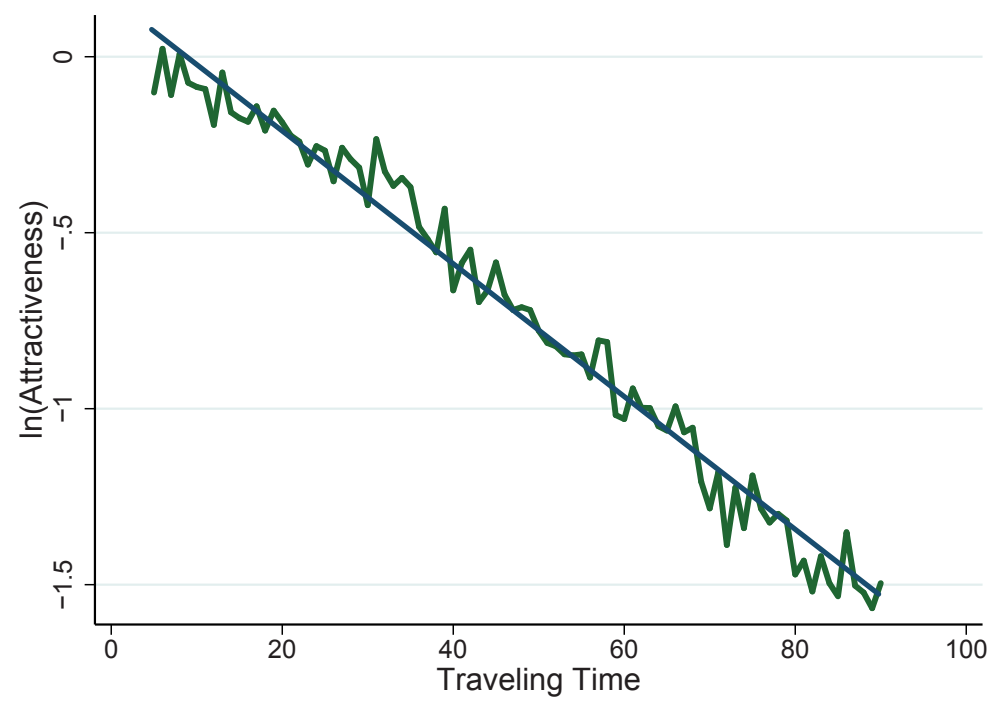

Figure 6.5: Predictions of the effect of travelling time (in minutes) on the attractiveness of a student job using logistic regression models without any functional form as well as a linear function.

monetary terms, the average student can only be convinced to work for a company with a bad image, in comparison to one with a good image, if that company pays an additional $€ 5.26$ per hour. The difference between a good image and a neutral one is much smaller. In this case students only ask for an additional $€ 1.03$ per hour.

The type of work also affects attractiveness. Students like working in jobs that are mentally challenging but not physically. Moreover, the preference for the first is stronger than the dislike of the second. Hence, jobs that are both, mentally and physically challenging, are preferred over jobs that are neither. In terms of hourly wage the gap between a mentally, but not physically challenging job and a job that is physically, but not mentally challenging is $€ 1.64$.

With regard to the time slot in which the work takes place students have a clear preference for flexibility. For once, this is derived from the high attractiveness of fully flexible jobs. Equivalently, a combination of time slots is generally preferred over only one fixed time slot. Figure 6.6 also shows that night-time work is least attractive, followed by morning, evening and then afternoon. Compared to all other jobs students are willing to earn $€ 2.18$ less per hour if they are allowed complete flexibility in choosing their working times. ${ }^{15}$ Moreover, the average student is only willing to work in

\footnotetext{
${ }^{15}$ Thereby the amount of weekly working hours stays constant.
} 

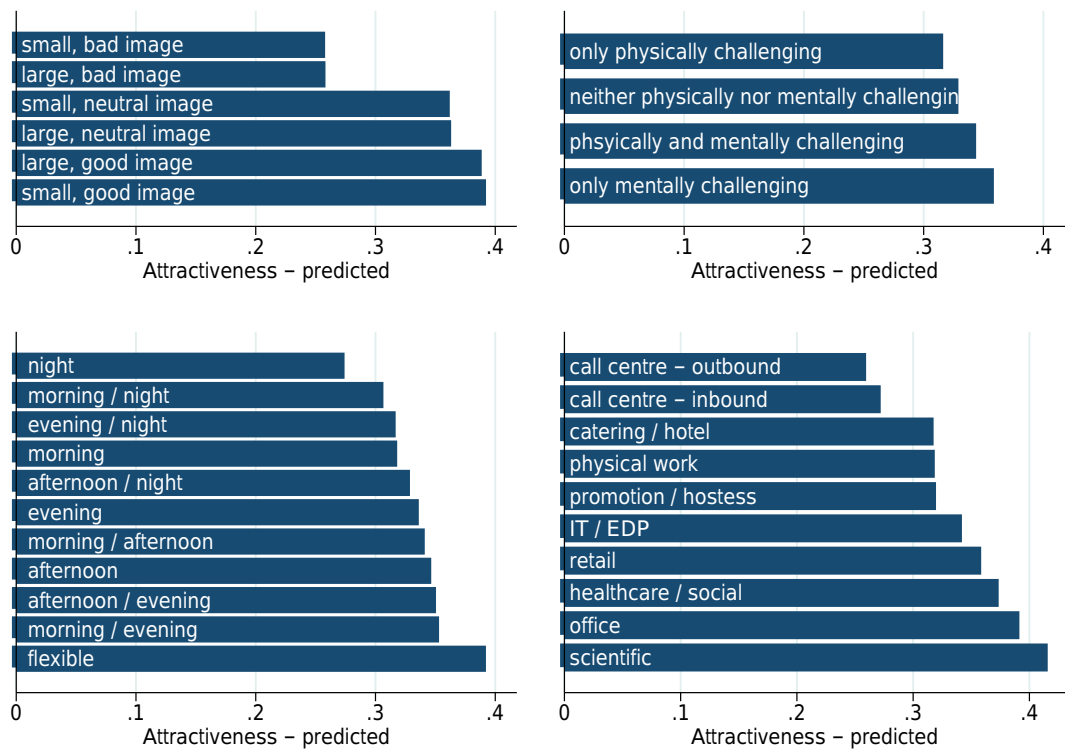

Figure 6.6: Predictions of the effect of company size and corporate image (top left), type of work (top right), time slot (bottom left) and sector (bottom right) respectively on the attractiveness of a student job using logistic regression models.

the morning, compared to the afternoon, if the wage increases by $€ 1.12$ per hour.

Finally, each vignette featured the sector of the student job. Call-centre jobs rank lowest, followed by catering / hotel jobs which are very comparable to both physical work and promotion / hostess type jobs. Jobs with higher levels of attractiveness are situated in IT / EDP, retail and healthcare / social. Office work ranks second only to scientific part-time jobs. On a monetary scale the difference between the lowest ranking call centre outbound jobs and the highest ranking scientific jobs is severe. The average student is only indifferent between the two if the hourly wage gap is equal to $€ 6.15$.

The last criterion of each vignette is the amount of weekly working hours. As can be seen in Figure 6.7 a model without any functional form predicts attractiveness to reach a maximum at a certain point. Once more, most dummy terms differ significantly from each other. ${ }^{16}$ As the shape is similar to that of a hill shaped parabola Figure 6.7 includes the predictions of a quadratic model. The quadratic model predicts that a student job with 12.6

\footnotetext{
${ }^{16}$ Setting the base level at 13 hours per week, all dummies but those of $6,7,8,9,10$, $11,12,14,15,16,17$ and 18 differ significantly.
} 


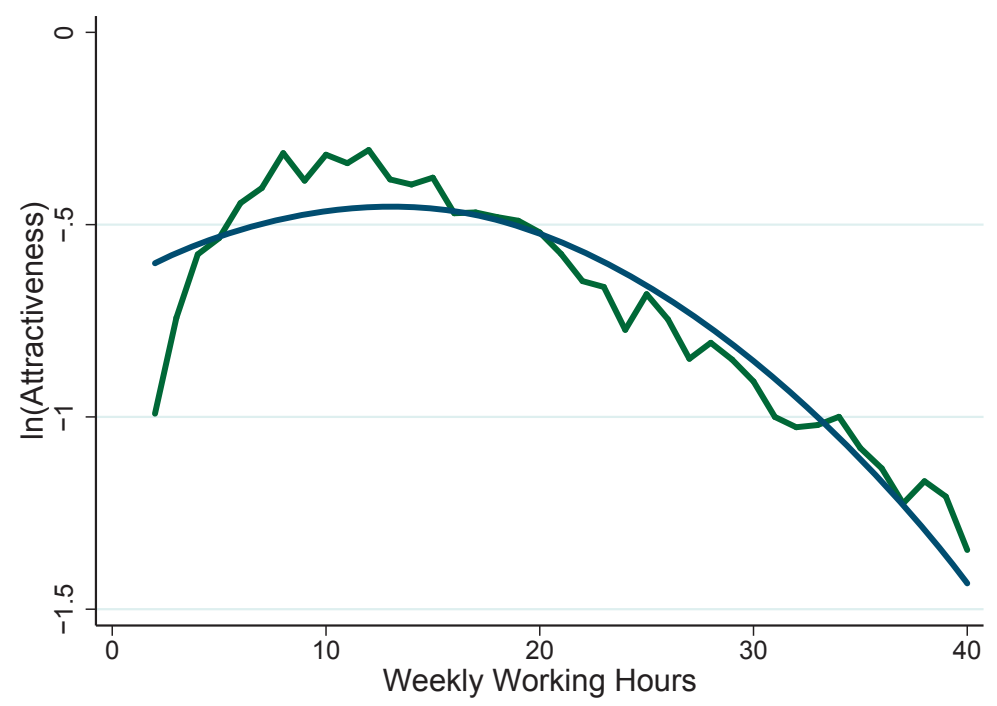

Figure 6.7: Predictions of the effect of weekly working hours on the attractiveness of a student job using logistic regression models without any functional form as well as a quadratic function.

weekly working hours will, all else constant, have the highest attractiveness. Besides, for students it is equally attractive to work either two hours or 23.1 hours per week. In terms of hourly wage students are willing to give up $€ 1.24$ to move from a job with either two or 23.1 weekly working hours to one with the optimal weekly working time of 12.6. Equivalently, forcing a student from 12.6 hours per week into full time employment (40 hours per week) requires an additional $€ 8.37$ per hour. This is probably close to the point where the wage is high enough to convince a student that quitting or at least pausing higher education has a higher value than moving on with it.

\subsubsection{Graduate Job Vignette}

The first two criteria in the graduate job vignette question are monthly wage after taxes and weekly working hours. As previously noted, these two depend on each other to enhance the plausibility of the different vignettes. As a result they can only be analysed simultaneously. All other variables, however, are independent and are therefore skipped for the moment. Estimating a model without any functional form requires both wage 


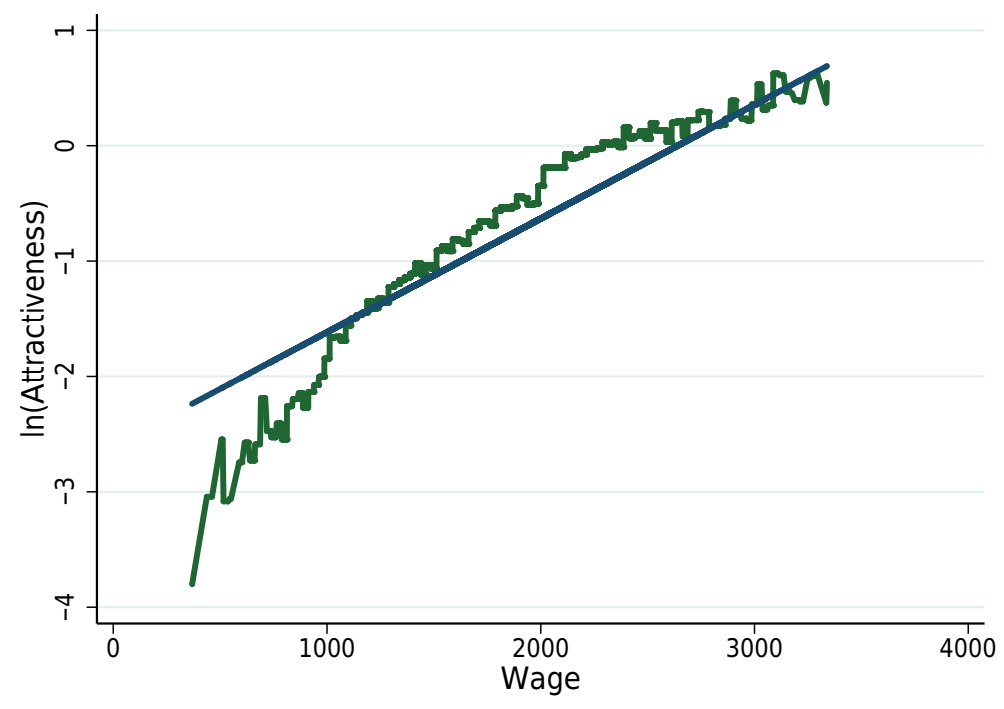

Figure 6.8: Predictions of the effect of monthly wage after taxes on the attractiveness of a graduate job using logistic regression models without any functional form as well as a linear function.

and hours to appear as dummy variables only. ${ }^{1718}$ Figure 6.8 displays the predictions of attractiveness in this model with respect to wage. Along the graph weekly working hours are held constant at their mean of 42 hours per week. Equivalently, Figure 6.9 shows the effect of weekly working hours on the attractiveness of a graduate job. In this case monthly wage after taxes is held constant at the most frequent value of $€ 1,625$. Additionally, the two graphs include the linear predictions of attractiveness resulting from changes in wage and hours, respectively. Thereby, a 1 percent increase in monthly wage after taxes, hours hold constant, raises the attractiveness of a graduate job by 0.1 percent. Analogously, an increase in weekly working hours of 1 percent, while wage is hold constant, decreases the attractiveness of a graduate job by 4.4 percent. ${ }^{19}$ The net effect of working hours and wage implies that participants want to earn roughly $€ 9.77$ more for each additional hour. Chapter 7 analyses the trade-off between working hours and wage in more detail by developing a new tool to measure preference for leisure.

\footnotetext{
${ }^{17}$ Wage is rounded into $€ 25$-groups. At a significance level of 5 percent only 15 out of 180 dummy terms do not differ significantly from the base level of $€ 1,625$.

${ }^{18}$ Only five out of 58 dummy terms do not differ significantly from the base level of 42 hours per week at a significance level of 5 percent.

${ }^{19}$ In the logit model including both wage and working hours both effects are significant at p-values below 0.001 .
} 


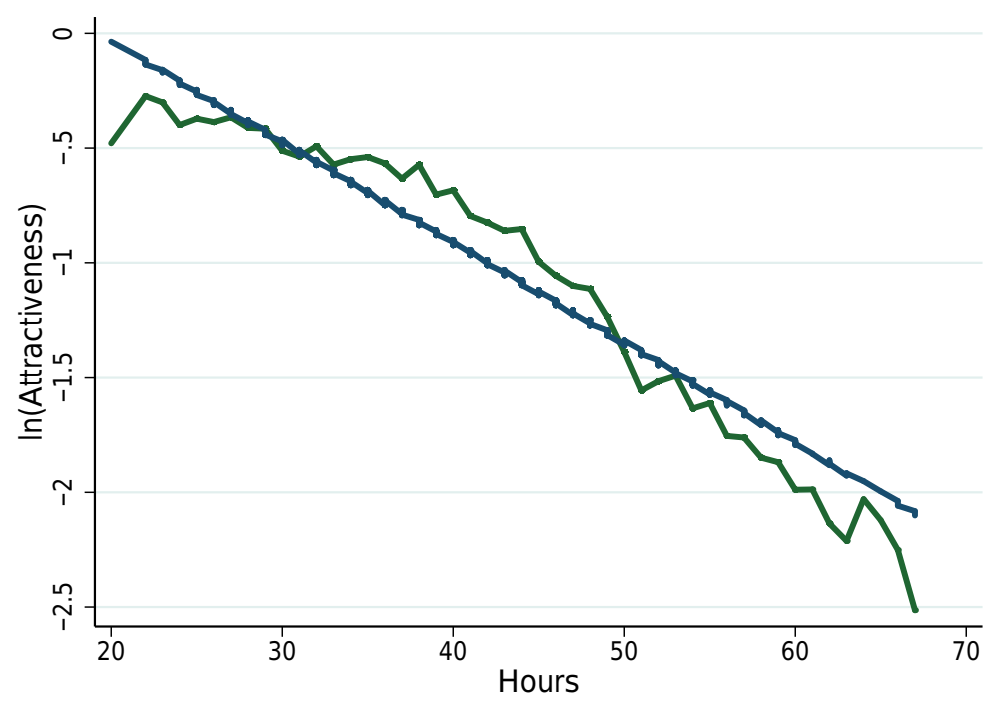

Figure 6.9: Predictions of the effect of weekly working hours on the attractiveness of a graduate job using logistic regression models without any functional form as well as a linear function.

The next two job characteristics, place of work and the industry of the job, are not independent. The industry depends on the study field while the place of work depends on the current place of study. Both is done to improve the plausibility of the vignettes that are shown to the participants. Any correlation between study field and location could, at least theoretically, be picked up by the vignettes. Even though this effect is likely to be very small the two criteria are analysed simultaneously. The logit model uses dummy terms for the location and the industry. Additional dummy terms that indicate whether the location is the same as the place of study and whether the industry fits the study field are included as well. As can be seen from Figure 6.10 and Figure 6.11 the results confirm the intuition that job offers at the current location and in a related industry are more attractive. This finding is robust across all 16 Bundesländer as well as all ten industries. Moreover, with regard to the industry mapping it gives credibility to the choice of industries that were selected to fit well with certain study fields.

The analysis allows further interesting conclusions. Figure 6.10 reveals that attractiveness varies greatly between different German states. According to the vignette question Berlin and Hamburg are by far the most attractive locations to start a graduate career, both for students already studying there and students studying elsewhere. This effect is not derived purely from the fact that they are large cities. City size is discussed in a 
later paragraph. Furthermore, some states like Bayern or Sachsen are very popular with their current inhabitants, but less so with students from other states. Generally, less densely populated states, especially in former East Germany, are at the bottom of the list. To a large extent the analysis confirms the descriptive findings about intentional migration within Germany which is featured at the end of Chapter 2. There is, however, a clear difference in the questions asked. A graduate looking for a job in Berlin would answer a question on the preferred Bundesland with Berlin. In the vignette question it could be true that none of the options feature Berlin, but that the graduate is offered a position in a large city in Brandenburg. As this is sufficiently close to Berlin the graduate is likely to accept that job. This explains why some Bundesländer receive a better ranking in the vignette question than the Figures shown at the end of Chapter 2 suggest.

The strongest finding from the analysis of the locations of the graduate jobs is that German students dislike mobility. The average student requires an additional $€ 349$ in monthly salary after taxes to be indifferent between staying in the current Bundesland and moving to another German state. This number fluctuates between different German states. Students from the Saarland and Sachsen-Anhalt are easiest to convince to move. They are willing to accept a job outside of their Bundesland if it pays an additional $€ 206$ or $€ 230$, respectively. On the contrary, students from Berlin and Hamburg are willing to forgo up to $€ 457$ or $€ 402$ in monthly salary after taxes to get a graduate job in their current state.

Focusing on the different industries reveals that, conditional on a good fit with the study field, media / marketing, art / culture, science / research and education / pedagogy are at the top of the preference ranking. As there is no perfect mapping of the fit between study fields and industries this effect can also be driven by those industries fitting better to the assigned fields. Therefore, the differences are not purely explained by varying levels of attractiveness. With respect to administration / human resources this suspicion is particularly strong. Separating students according to the fit of their subject yields no pronounced differences in preferences for this industry. The average student is willing to earn $€ 375$ less per month to switch from a job in administration / HR to a job in media / marketing.

The graduate job vignette question includes some categorical criteria. These are the size of the city at which the job is located, the type of work contract that is offered, the type of organization to work for and other characteristics of the employer. Figure 6.10 shows that, with respect to the location of a graduate job, students prefer large cities. The other levels are ranked according to this, however, the increase in attractiveness is largest when moving from a small to a medium sized city. To move to a small city, a medium city or a large city instead of a rural area students are willing to lose $€ 86$, $€ 224$ and $€ 302$ in monthly wages respectively. This highlights that while students dislike mobility in general, rural areas have a distinct additional disadvantage. 


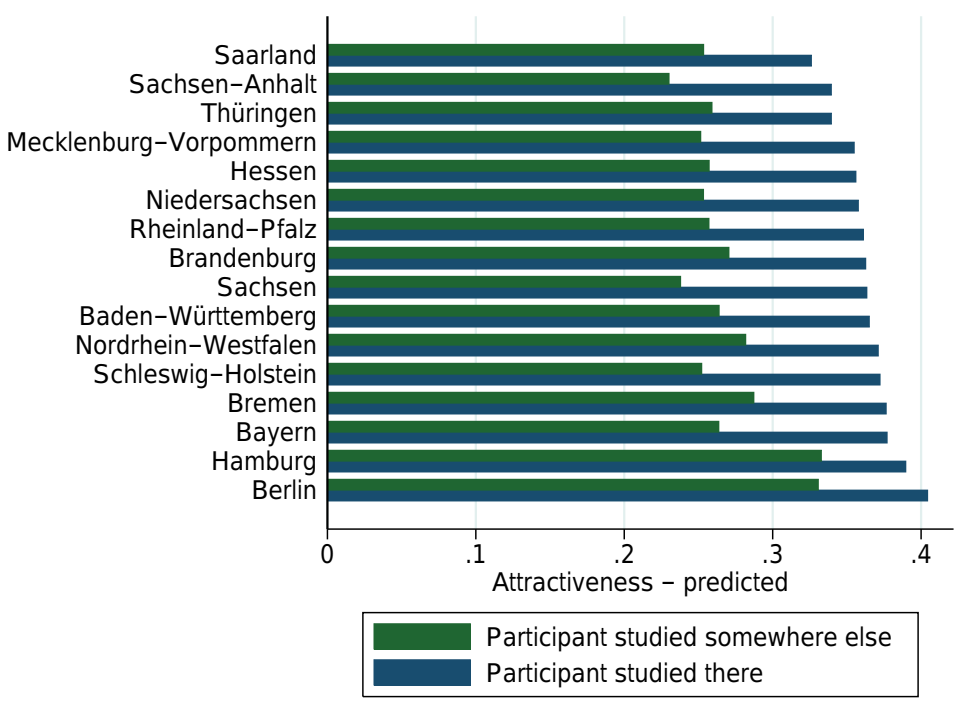

Figure 6.10: Predictions of the effect of job location and its fit to the current place of study on the attractiveness of a graduate job using logistic regression models, controlling for the industry.

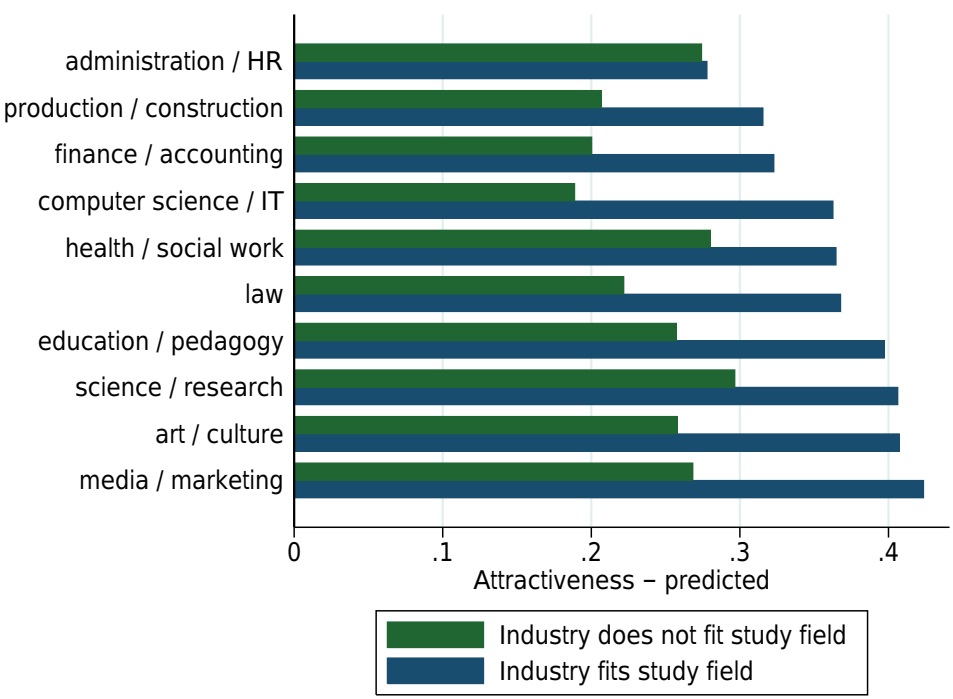

Figure 6.11: Predictions of the effect of the industry of a job and its fit to the study field on the attractiveness of a graduate job using logistic regression models, controlling for the location. 
Not surprisingly, the next criterion reveals that students favour openended work contracts over temporary ones. Still, this analysis allows to compare this preference with those for other job characteristics. Students are willing to give up $€ 320$ per month to switch from a temporary to an open-ended contract. The magnitude of this effect is larger than the difference between a large city and a rural area. This finding is in line with the descriptive analysis at the end of Chapter 2 which also revealed the importance of job security to higher education graduates.

The type of organisation also affects the attractiveness of a graduate job. The public sector is least preferred, followed by small businesses, mediumsize businesses and large companies. Top of the list are non-profit organizations. Note, however, that the differences in attractiveness are very small and hence the preferences of students with respect to this criterion are rather weak. This can also be expressed in monetary terms. To work for a non-profit organization, instead of the public sector, students are willing to accept a monthly wage after taxes that is only $€ 91$ lower.

Finally, it matters to students who they are going to work for as a graduate. Companies that are publicly criticised, have a high turnover
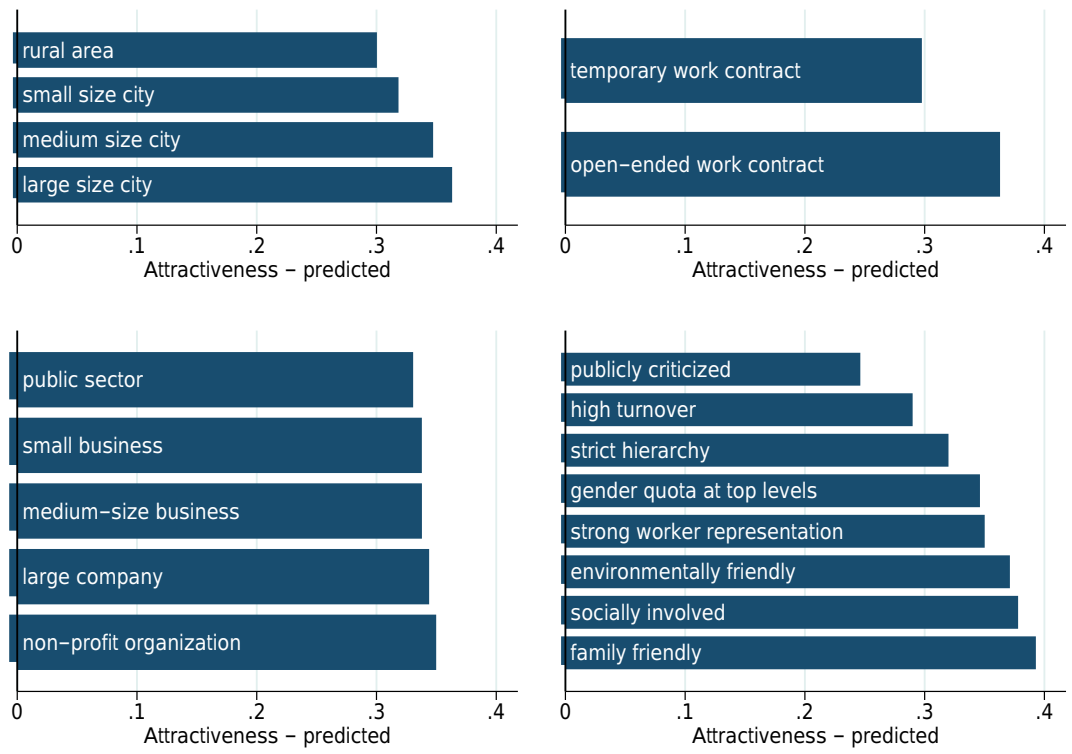

Figure 6.12: Predictions of the effect of city size (top left), type of work contract (top right), type of organization (bottom left) and other characteristics of the employer (bottom right) respectively on the attractiveness of a graduate job using logistic regression models. 
or make use of a strict hierarchy are disliked by the participants. The use of a gender quota at the top level or a strong worker representation are in the middle of the ranking. When it comes to their graduate job students like employers which are environmentally friendly, socially engaged or family friendly. Especially publicly criticised companies are like to have problems finding graduates. Compared to the attribute with the second lowest ranking, having a high turnover, they still need to pay a premium of $€ 204$. The total range from a publicly criticised company to a family friendly one is, in monetary terms, equal to $€ 685$ per month.

\subsection{Conclusion}

Using two different vignette-type questions this Chapter analyses the job preferences of students. With respect to their part-time job students have a pronounced distaste for travelling time. For each additional minute of travelling to the job they ask an additional $€ 0.16$ in hourly wage. Company size is no relevant criterion to choose jobs, while the image of the company is. Employers with a bad corporate image have to pay a premium of $€ 5.26$ per hour in comparison to those with a good image. With respect to the type of work students prefer mentally, but not physically challenging jobs. This is in line with the preference for different sectors. Working scientifically or in office occupations ranks highest. Lastly, a student job needs to be compatible with the curriculum. Optimally, students find work for close to 12 hours per week with the option to independently decide when to work. Working more or fewer hours per week is less attractive. Working 40 hours per week requires an additional $€ 8.37$ per hour compared to the optimum.

The distaste for mobility can also be seen in the graduate job vignette question. While different German states vary in attractiveness, students prefer the location of their first graduate job to be close to their place of study. Convincing a student to move requires, on average, an increase in the monthly wage after taxes by $€ 349$. On top of this students prefer to work in larger cities. Another finding concerns job security. In order to gain an open-ended work contract students are willing to give up $€ 320$ in monthly salary after taxes. This criterion is much more relevant than, for example, the type of organisation. To switch from the most preferred organisation, a non-for profit, to the least preferred one, the public sector, only requires an additional $€ 91$. With respect to the corporate image of the employer the results of both vignette questions are coherent. Companies that have a bad image, in comparison to those that are family friend, need to add $€ 685$ to the monthly salary after taxes to attract the average student.

Economically this information is valuable as it allows to enhance the efficiency of job designs and compensation schemes. This is true whenever the cost a company faces to alter a certain job attribute is below the benefit of employees. If such opportunities are present, companies should exploit 
them. Doing so enables them to compete for employees in many alternative ways. If a new job requires moving to a different German state, then this cannot only be balanced by a higher salary, but also by offering an openended instead of a temporary contract. Equivalently, companies that are located outside of student cities can balance the required travelling time by giving higher flexibility in terms of working hours. 


\title{
Chapter 7
}

\section{Preference for Leisure}

\author{
With Marion Collewet
}

This Chapter presents a tool to measure preference for leisure by eliciting the shape of individual indifference curves between leisure and consumption. We asked more than 16,000 German students to indicate which different combinations of working time and wage they would find equally satisfying for their future graduate jobs. This information reveals a big diversity in preferences and can be used to study how the utility of different individuals is likely to be affected by a given change in their working time. For instance, individuals who are planning to work longer hours are more likely to dislike increases in working time.

\subsection{Introduction}

There is a range of policies that attempts to influence the supply of labour, such as the design of social assistance, unemployment benefits, taxation, or retirement age, and policy makers are concerned with people who lose their job or face a reduction in working time. By changing incentives, these policies in most cases stimulate workers to increase their hours of work. Such policies lead to an increase in earned income. From a welfare perspective, though, it is also important to know to what extent such increases or decreases in hours worked affect the well-being of people. For that purpose, in addition to changes in earnings, information is needed about how much people value changes in working hours.

The aim of this Chapter is to measure preference for leisure, in the sense of how much people want to be compensated for changes in working hours. Using a survey among German students, we measure preference for leisure introducing a new set of questions, in which we elicit their willingness to pay for leisure time in their first graduate job. After asking participants about their desired weekly working time and expected monthly wage in their first graduate job, we ask them to state the monthly wages that they 
would require in order to be indifferent between their desired starting point and a series of alternative weekly working times. For each of the 16,000 participants, we propose an increase and a decrease by four hours relative to their desired working hours, and in two additional questions we randomly vary the proposed working hours. To check the validity of this approach we compare the results to the graduate job vignette of Chapter 6 as this constitutes an alternative way to elicit preferences. The results are in line with the findings in the others questions.

Our results indicate that, in line with the standard model of labour supply, indifference curves are convex, since their steepness increases with the number of hours proposed. This is not only true on average, but we also show that three quarters of our respondents have indifference curves which are (weakly) convex. Examining the correlates of the different types, we find, for instance, that individuals who are planning to work longer hours from the start and individuals in a stable relationship are more likely to be negatively affected by an increase in their weekly working time. Conversely, individuals who started studying later and more extrovert individuals seem to have a lower preference for leisure. Our results are valid for the population of future higher education graduates only, however they illustrate that the inclusion of our preference for leisure questions in a broader survey could have great added value for both research and policy.

The determinants of labour supply have been extensively studied and there are a correspondingly big number of studies about the elasticity of individual labour supply to changes in wage rates and taxes (see for instance reviews by Blundell and MaCurdy (1999) Keane (2011) Saez, Slemrod, and Giertz (2012)). Still, Manski (2014) concludes that economists do not know how peoples labour supply is affected by changes in tax rates. He argues that this is due to two problems in the existing labour supply research. First, economists often have to make rather strong assumptions about the shape of individuals utility functions in order to be able to estimate wage elasticities. N. Stern (1986) and Blundell and MaCurdy (1999) give overviews of the implications of different assumptions about individual preferences for the estimation of wage elasticities. Different assumptions lead to different restrictions on the elasticities to be estimated. Second, most models assume that responses are homogeneous within broadly defined demographic groups. They do not allow for heterogeneity in the parameters of the labour supply function. There are studies which try to relax assumptions about the shape of individual utility functions (Blomquist \& Newey, 2002) and which pay attention to potential heterogeneity in labour supply functions (Blundell, Bozio, and Laroque (2011); Blundell and Shephard (2012)). Empirical information about the distribution of preferences for different combinations of working time and income seems to be a logical complement to this literature. Manski (2014) advocates in favour of the collection of data about hypothetical choices in order to learn more about the preferences of the individuals in terms of labour supply. 
The study of various individual preferences has received increasing attention in the economic literature recently (e.g. Dohmen, Falk, Huffman, and Sunde (2009); Dohmen et al. (2011); Dohmen, Falk, Huffman, and Sunde (2012)), but still very little is known about preference for leisure, apart from wage elasticities (Borghans, Duckworth, Heckman, \& Ter Weel, 2008). This Chapter is a first attempt to address this gap.

The remainder of the Chapter is structured as follows. Section 2 presents the method we use to measure preference for leisure. Section 3 describes the data we collected. In section 4 , we present our main results about the distribution of preference for leisure. Section 5 studies determinants and correlates of preference for leisure. In section 6 , we check how robust the estimate for preference for leisure are. In section 7 , we present a policy simulation in order to illustrate the practical implications of our results. Section 8 concludes.

\subsection{Measuring Preference for Leisure}

\subsubsection{Preference for Leisure and Opportunity Costs of Work}

Measuring preference for leisure is a challenging task. The term "preference" seems to imply that the way an individual relatively values income and free time is part of a given set of tastes which barely changes over his life course. One thinks of a general tendency of a person to like hard work vs. lying on the beach or to like buying luxury goods vs. taking long walks in the woods. However, in the standard model of labour supply, preference for leisure is nothing else than the marginal rate of substitution between consumption and leisure, the slope of the indifference curve between these two goods. It is easy to imagine that this marginal rate of substitution, and even the whole shape of the indifference curve, can change depending on the context, and in particular if the opportunity costs of work change.

We choose to stick to the broad definition of preference for leisure as in the standard model of labour supply. In our basic measure, we take leisure to be everything that is not paid work. This means that we do not differentiate between taste for leisure and opportunity costs of working. If the opportunity costs of working increases for an individual, this will be translated into a higher preference for leisure in our setting. There are two main reasons for this choice. First, it is not clear how the difference between opportunity costs of work and preference for leisure should be made exactly. For instance, having children or grandchildren arguably increases the opportunity costs of work. But how much of the care for children should be considered home production, and how much leisure? Does the productivity at home increase when children come, or do parents or grandparents discover new things, which increase their taste for leisure? It is not straight- 
forward to give an answer to such a question in theory. And in practice, it seems hard to disentangle the two, since the separating line is likely to be different for every individual. Second, the opportunity costs faced by an individual may be dependent on his or her preference for leisure vs. paid work. An individual who loves paid work might choose for this reason not to have children, or may not invest in hobbies which would increase his or her taste for leisure. In addition, a broad definition of preference for leisure makes it easier to derive policy implications. It directly gives us information about the shape of the individual preferences about working time and income.

\subsubsection{Open hypothetical questions}

In order to measure preference for leisure, we need to obtain a number of combinations of income and leisure for each individual which provide him with the same level of well-being. This locus of points can be seen as a representation of an individual's indifference curve between consumption and leisure. An individual's preference for leisure is given by the shape of his indifference curve. The steeper the indifference curve, the more consumption an individual needs to compensate a decrease in leisure, the higher his preference for leisure. The more curved the indifference curve, the less consumption and leisure are substitutable.

In order to obtain a number of points on an individual's indifference curve, we have to use hypothetical questions, because it is very difficult to observe the same individual faced with different amounts of leisure and consumption, holding everything else, including utility, constant. The added value of such a method is that it generates several observations for a given individual, but that these observations do not follow each other in time and can therefore not be interpreted as all part of the same life-cycle optimization process. To our knowledge, Borghans, Meijers, and Ter Weel (2008) are the only ones to have presented respondents with explicit hypothetical trade-offs between income and leisure, in the context of a laboratory experiment among students. Presenting such trade-offs to a bigger sample enables us to learn about the distribution of preferences for leisure and its correlates.

We start by asking respondents how many hours they would like to work per week in their first job after they finish their studies. We then ask them which monthly wage after taxes they expect to earn for this working time. This provides us with a starting point. To derive the other points on the individual's indifference curve, we ask respondents how much their monthly net earnings should be in order for them to be indifferent to a series of four different hypothetical weekly working times. Respondents were first asked to value (1) an offer for four hours less than their desired weekly working time; (2) an offer for four hours more than their desired weekly working time. We use these answers to derive the slope of the indifference curve in 


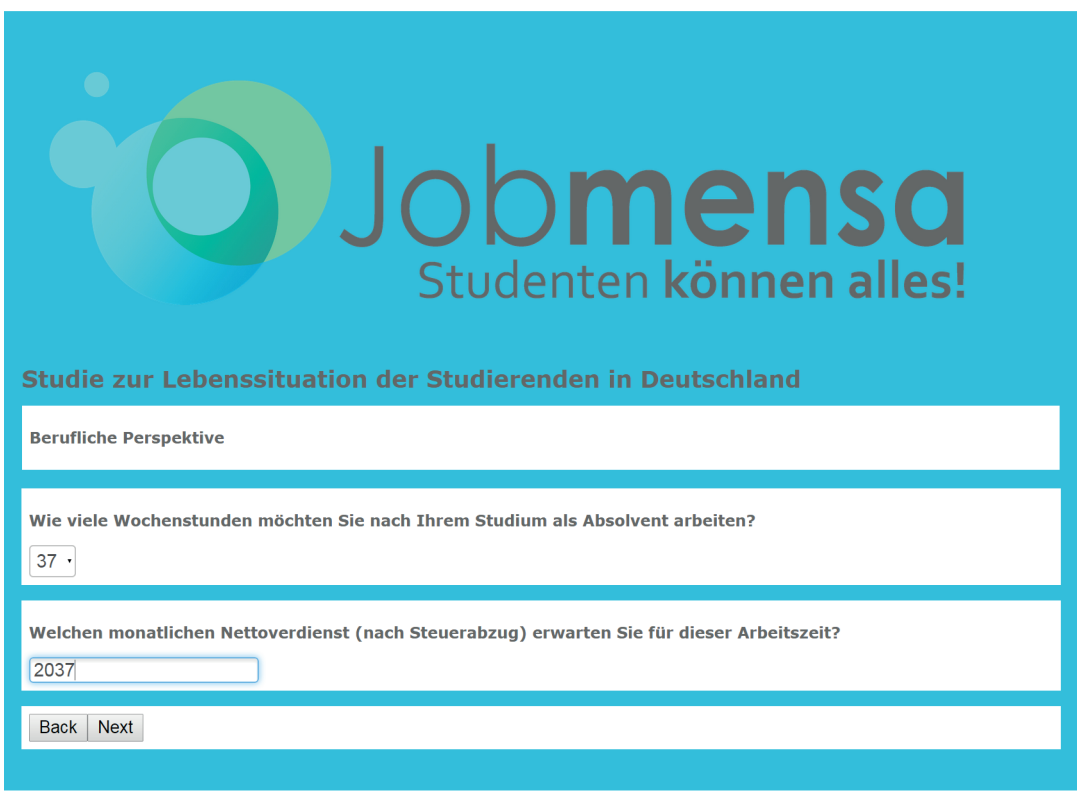

Figure 7.1: Open Question Page 1.

the neighborhood of the reference point. Having such information at the individual level can already be very useful to predict the effect of different policies.

Ideally, one would like to have such valuations over the whole working hours spectrum for each person. This is not feasible on an individual basis. We can, however, construct a preference for leisure curve at the group level, by asking each person to value two additional randomly drawn values of weekly working time. Therefore, our respondents are also presented with two working time offers (3) and (4) that are randomly selected from two different working time intervals. These two intervals get chosen in a way that prevents the offers (1) to (4) as well as the starting point to fall in the same interval. To construct the intervals we divided the spectrum 14-46 hours in four 7 -hour intervals. ${ }^{1}$ The ranges of the intervals were chosen in order to maximize the probability that the respondents' answers to the first two questions are situated in two different intervals. As a result, in many cases all four intervals can be covered by the four variations of the starting point. Screen-shots of the open questions can be found in Figure 7.1 and Figure 7.2.

The open questions we chose have several advantages compared to binary

\footnotetext{
${ }^{1}$ The intervals were defined as follows: [14-21],[22-29],[30-37],[38-46].
} 


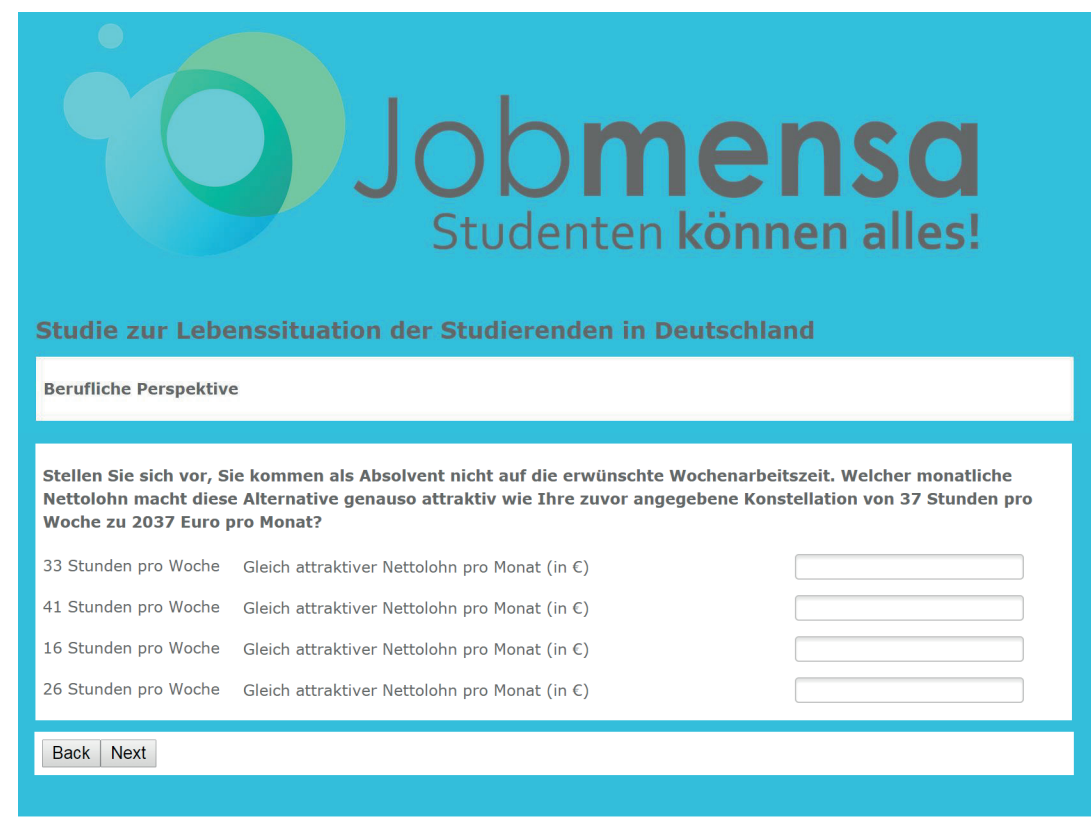

Figure 7.2: Open Question Page 2.

choices, i.e. questions for which the respondent should indicate whether a given combination of hours and earnings would be acceptable for him. First, the packages presented in binary choices could set default or priming effects, while an open question does not influence the answers. Second, a single open question is a lesser burden for the respondents, and costs less time to answer, than the series of binary choices which would be needed to determine a single point on the individual's indifference curve. Admittedly, it might be more difficult for the respondent to formulate an answer to such an open question than to think whether a given package is acceptable. We believe that this disadvantage is compensated by the reduction in burden and response time. We formulate the questions in terms of weekly working times and monthly net incomes because these measures are likely to be most familiar and meaningful for most respondents.

\subsubsection{Vignettes}

There are two potential drawbacks of using open questions. First, respondents may be tempted to exaggerate the wage they would require for a given working time. Even if strategic reasons for doing so are very limited in the context of a survey, we cannot entirely exclude this a priori. Second, we do not know whether individuals faced with a new working time offer keep all 
other attributes of the job constant when answering the question. It may well be that their idea of a 20 -hours job is quite different from their idea of a 40-hours one.

In order to test whether these factors play a role, we use a choice experiment in form of graduate job vignettes. A detailed description of this graduate job vignette question can be found in Chapter 6 . It consists of three rounds with three respective graduate job vignettes each. Every round the most preferable of the three vignettes has been selected by the participants. Each vignette is defined by eight job characteristics, two of which are monthly wage after taxes and weekly working hours. Participants cannot exaggerate their wage expectations, but only choose the most preferred graduate job. Moreover, by design these two characteristics are random and independent of the other six characteristics. ${ }^{2}$ Therefore this analysis of the vignette questions can focus exclusively on the trade-off between wage and working hours without the need to consider the other characteristics. Unlike to the open questions, however, these other job characteristics stay, on average, constant for different hour and wage profiles. Hence, the vignette question can be used to test whether the two main weaknesses of the open question play a crucial role. A screen-shot of the vignette question in our questionnaire can be found in Chapter 6, Figure 6.2.

\subsection{Data}

The data originates from the German student study Fachkraft 2020. In this Chapter we use data from the fourth round. More information on the data set can be found in Chapter 2. For this research we use the open questions on working hours and wage and the vignette questions which were described above. Additionally, we use typical demographic variables like gender, age, study field, relationship status. The questionnaire also included the fifty item IPIP personality inventory which is scored on the Big 5 domains agreeableness, conscientiousness, emotional stability, extraversion and openness.

We drop students who gave no or unfeasible information about either their age ${ }^{3}$, gender, Bundesland or field of study. We are left with answers from 16,455 students. ${ }^{4}$ We set wage to missing for answers that imply an hourly wage below 1 or above 50 euros (this is the case for only 827 observations, i.e. $2.5 \%$ of the observations). We are left with 32,007 observations on 16,042 individuals. Selected descriptive statistics on these participants can be found in Table 7.1.

\footnotetext{
${ }^{2}$ Wage and working hours are dependent on each other including random noise to make the graduate job vignettes more realistic.

${ }^{3}$ Age was set to missing when it was below 15 or above 40 .

${ }^{4}$ Results for this group do not differ from those of the larger sample.
} 


\begin{tabular}{lrrrrr}
\hline \hline Variable & Obs & Mean & Std dev. & Min & Max \\
\hline Female & 16042 & 0.58 & 0.49 & 0 & 1 \\
Age & 16042 & 23.62 & 3.33 & 15 & 40 \\
East Germany & 16042 & 0.13 & 0.34 & 0 & 1 \\
Humanities & 16042 & 0.11 & 0.31 & 0 & 1 \\
Natural sciences & 16042 & 0.40 & 0.49 & 0 & 1 \\
Social sciences & 16042 & 0.49 & 0.50 & 0 & 1 \\
Hours (start-point) & 16042 & 39.66 & 6.16 & 3 & 60 \\
Wage (start-point) & 16042 & 2285 & 749 & 100 & 10000 \\
Wage of hours-4 (1) & 16005 & 2070 & 713 & 30 & 12000 \\
Wage of hours+4 (2) & 16002 & 2528 & 839 & 60 & 12000 \\
Hours random (3) & 15906 & 23.73 & 7.29 & 14 & 45 \\
Wage random (3) & 15906 & 1570 & 664 & 76 & 9000 \\
Hours random (4) & 15876 & 23.77 & 7.30 & 14 & 45 \\
Wage random (4) & 15876 & 1594 & 688 & 100 & 8000 \\
\hline \hline
\end{tabular}

Table 7.1: Descriptive statistics.

\subsection{Main results: Distribution of Preference for Leisure}

\subsubsection{Indifference Curves: Working Time and Wage}

The main information delivered by the answers to the open questions is a series of points in the weekly working time - monthly wage space with which the individuals are equally satisfied. It is the mirror image of an indifference curve between leisure and income.

Figure 7.3 is an example of the data we obtained. It reproduces the answers of individuals who state a working time of $20,35,40,45$ or 50 hours as a starting point. Each group contains more than 1000 individuals. It displays the wages required to reach indifference to this starting point for minus four hours and plus for hours as well as for randomly selected hours from other intervals. The Figure shows that individuals require, as one would expect, higher wages for longer hours. All curves are positively sloped, seem close to linear, and there are no striking differences in slopes depending on the starting point. In the following, we examine the indifference curves and their correlates more closely.

\subsubsection{Slope of the Indifference Curve}

We now turn to studying the shape of the indifference curve. To do so, we consider the average hourly wage required by the respondent for the segment of hours between his desired hours at the starting point and the hours proposed in the question. This average hourly wage is our preferred 

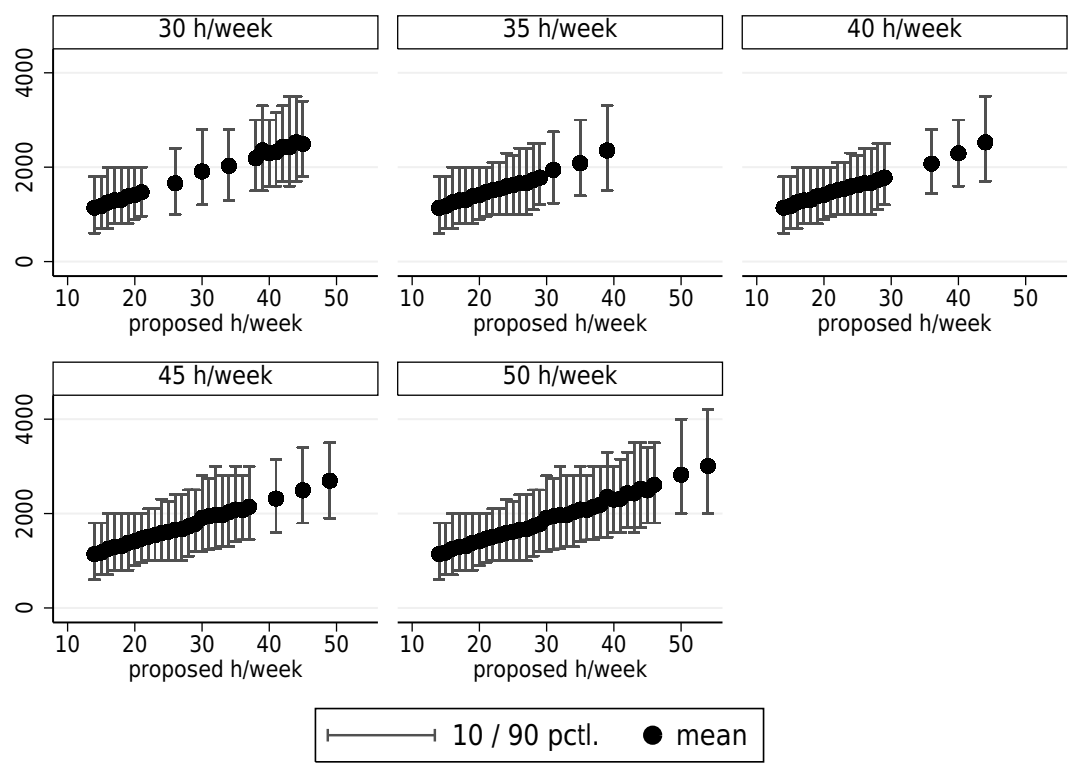

Figure 7.3: Equivalent combinations of working time and wage for different desired starting points.

measure of preference for leisure, PL.

$$
P L=\frac{\left(\text { wage }_{q}-\text { wage }_{s}\right)}{\left(\text { hours }_{q}-\text { hours }_{s}\right)}
$$

where hours $s_{s}$ and wage $_{s}$ are the weekly working time and the net monthly wage desired by the respondents at the start of their career, hour $s_{q}$ are the alternative hours proposed in the question, and wage $e_{q}$ is the wage required by the respondent to be just as satisfied with these proposed hours as he would be with his desired working time and wage. If the proposed hours are just four hours below or above the desired hours, then this measure is as close as we can come to the slope of the indifference curve for the range between the starting point and the specific proposed number of hours. For hours further away from the starting point, we still stick to the average slope of the indifference curve between the starting point and the proposed hours as our preferred measure of preference for leisure. This is because such a measure is likely to contain less measurement error than a measure relying on two proposed working times which are not the ones preferred by the respondents. Furthermore, this ensures consistency and makes interpretation easier.

If the indifference curve is convex, PL should be lower the further pro- 


\begin{tabular}{|c|c|c|c|c|c|c|}
\hline \multirow[t]{2}{*}{ Proposed hours } & \multicolumn{6}{|c|}{ Desired hours } \\
\hline & $<14$ & $14-21$ & $22-29$ & $30-37$ & $38-46$ & $>46$ \\
\hline \multirow[t]{3}{*}{$<14$} & 15.94 & 21.34 & & & & \\
\hline & $(30.55)$ & $(33.64)$ & & & & \\
\hline & 77 & 44 & & & & \\
\hline \multirow[t]{3}{*}{$14-21$} & -1.70 & 10.92 & 13.12 & 10.32 & 10.04 & 9.29 \\
\hline & $(26.14)$ & $(30.06)$ & $(17.71)$ & $(7.17)$ & $(5.00)$ & (5.33) \\
\hline & 53 & 201 & 237 & 3137 & 9966 & 805 \\
\hline \multirow[t]{3}{*}{$22-29$} & 4.87 & 9.96 & 15.76 & 12.28 & 10.60 & 9.73 \\
\hline & $(8.42)$ & $(28.86)$ & $(20.91)$ & $(13.44)$ & $(6.41)$ & $(6.14)$ \\
\hline & 47 & 188 & 238 & 3166 & 9972 & 805 \\
\hline \multirow[t]{3}{*}{ 30-37 } & 10.57 & 12.23 & 18.10 & 11.81 & 12.38 & 10.13 \\
\hline & $(9.82)$ & $(12.80)$ & $(16.81)$ & $(17.01)$ & $(13.05)$ & $(7.19)$ \\
\hline & 38 & 179 & 238 & 3175 & 10040 & 850 \\
\hline \multirow[t]{3}{*}{$38-46$} & 5.57 & 10.98 & 15.39 & 14.96 & 13.55 & 12.20 \\
\hline & $(6.64)$ & $(9.94)$ & $(11.06)$ & $(17.92)$ & $(18.02)$ & $(12.32)$ \\
\hline & 40 & 179 & 233 & 3165 & 10787 & 902 \\
\hline \multirow[t]{3}{*}{$>46$} & & & & & 14.75 & 12.97 \\
\hline & & & & & (19.65) & $(27.99)$ \\
\hline & & & & & 2248 & 2779 \\
\hline \multirow[t]{3}{*}{ Total } & 7.80 & 11.58 & 15.60 & 12.35 & 11.84 & 11.56 \\
\hline & $(22.25)$ & $(23.51)$ & (17.08) & $(14.62)$ & (12.61) & (19.87) \\
\hline & 255 & 791 & 946 & 12643 & 43013 & 6141 \\
\hline
\end{tabular}

Table 7.2: Means preference for leisure (PL) for different desired and proposed hours, with standard deviations between brackets and number of observations per cell.

posed hours are below desired hours, and higher the further proposed hours are above desired hours. Table 7.2 presents the mean and standard deviation of our PL measure for different categories of desired and proposed working hours, along with the number of observations used to compute these statistics in each cell. ${ }^{5}$

The table shows that for given desired hours, the required hourly wage tends to increase as the hours proposed increase. This is at least the case for desired hours above 30. For desired hours below 30, the evidence is less clear. This may be due to the lower number of observations. An alternative explanation could be that individuals who desire low number of hours find it difficult to imagine what it would be like to work a lot more, or maybe put some kind of upper limit on the wage they "dare" to require for a full-time job. We can also see that for given proposed hours, the required hourly wage tends to decrease as desired hours increase, at least for desired hours

\footnotetext{
${ }^{5}$ The big standard errors are due to outliers which reach from -400 to +400 , even after we restrict the hourly wage implied by the respondent's answers to be between 0 and 50 .
} 
above 21 . This is not surprising if the desired starting point of individuals is already influenced by their preference for leisure. This means that we will need to control for the desired starting point when studying the relationship between individual characteristics and our preferred measure of preference for leisure.

The data suggests that indifference curves are convex, since slopes are higher on average when individuals are asked to work more. To examine this further, we compute the ratio $(r)$ of both slopes as follows:

$$
r=\frac{P L_{h+4}}{P L_{h-4}}
$$

In order to be able to compute this ratio also for individuals with a 0 downwards slope, we replaced the value of the downwards slope with 0.01 . For positive slopes, the indifference curve is convex if this ratio is above 1, it is linear if this ratio is 1 , and concave if the ratio lies below 1 . Table 7.3 confirms that, even among those who report only weakly positive slopes, less than half of the individuals have strictly convex indifference curves; many have linear ones, and a significant minority has concave ones. In total, about three quarters of those individuals have weakly convex indifference curves.

\begin{tabular}{ccccc}
\hline \hline & \multicolumn{2}{c}{ Whole sample } & \multicolumn{2}{c}{ Weakly positive PL } \\
& Freq. & Percent & Freq. & Percent \\
\hline$r<0$ & 1,125 & 7.01 & & \\
$r=0$ & 787 & 4.91 & 770 & 5.23 \\
$0<r<1$ & 2,728 & 17.01 & 2,706 & 18.37 \\
$r=1$ & 4,414 & 27.52 & 4,397 & 29.85 \\
$r>1$ & 6,911 & 43.08 & 6,859 & 46.56 \\
missing & 77 & 0.48 & & \\
Total & 16,042 & 100 & 14,732 & 100 \\
\hline \hline
\end{tabular}

Table 7.3: Ratio of preference for leisure upwards to preference for leisure downwards.

\subsection{Heterogeneity of Preference for Leisure}

Now that we have information about the shape of the indifference curves of individuals, we can also see whether the shape of the indifference curve varies systematically with individual characteristics. This can tell us more about which individual characteristics are associated with a higher preference for leisure, and therefore who is likely to be made better-off or worse-off by a change in the combination of working time and income.

Table 7.4 presents the relationship between individual characteristics and the desired starting point of individuals in terms of hours and wages. 
Table 7.5 presents the relationship between individual characteristics and the slope of the indifference curve for the four different types of questions which were asked. A positive coefficient in Table 7.5 means a higher preference for leisure. Looking at the results in both tables, we come to the following conclusions.

The estimated coefficients on desired hours, proposed hours and the interaction of both variables in their demeaned form confirm the results presented above about the convexity of the indifference curves. The first and second column show that when desired hours are higher, and therefore the associated proposed hours, people are less willing to accept an increase and more willing to accept a decrease in their hours of work. The third column shows that for average proposed hours, higher desired hours are associated, if anything, with a slightly flatter indifference curve. This could also be seen above in Table 7.2. Conversely, for average values of desired hours, higher proposed hours are associated with a steeper indifference curve. This effects is attenuated as desired hours increase. The coefficients on desired and proposed hours in the fourth column carry the opposite sign and are somewhat counter-intuitive, probably due to the very high correlation between the variables and the interaction term in an estimation based on relatively few observations. We further observe that people who expect a higher hourly wage also appear to have a higher preference for leisure.

At the start of their careers women desire less working hours, expect less weekly wage, and less hourly wage compared to men (Table 7.4). When controlling for these differences in the starting point (Table 7.5), we no longer find a difference in the slope of the indifference curve. Women only seem to require less extra wage than men for hours well above their desired working time, but this difference is only marginally statistically significant.

Individuals from Eastern Germany desire less hours, and expect less wage, and lower hourly wages at the start of their career. Even after controlling for this, they still have a steeper indifference curve downwards from their desired hours (i.e. they accept bigger decreases in wage for a given decrease in hours).

Individuals who are in a stable relationship desire shorter hours at the start of their career, but roughly the same hourly wage as single individuals. Even after controlling for this, they require bigger increases in wage when asked to work four hours more. Individuals who have a student job desire lower hours at the start of their career, but a marginally higher hourly wage. After controlling for this, they require bigger increases in wages when asked to work four hours more, and smaller decreases when asked to work a lot less than they would like to.

Older students (i.e. students who started studying later, given that we control for the number of semesters studied) desire shorter hours and expect lower wages, both monthly and hourly, at the start of their career. Even after controlling for this, they require smaller increases in wages when asked to work more. The number of semester studied is not systematically related 
to the desired starting point of respondents. But students who have studied more semesters require bigger increases in wages when asked to work more, and accept smaller decreases in wages when asked to work a lot less than they would like to. Age and the number of semesters studied have opposite effects on wage requirements. Our results mean that those who started studying earlier have higher wage requirements. But the estimated effects of both variables are also found when they are taken up one at a time in the model.

Students of natural sciences expect higher hourly wages, and also require higher wage increases when presented with other hours than they desire. Students of humanities desire lower hours, expect lower wages and lower hourly wages, and after controlling for this, accept bigger decreases in wages when asked to work a lot less than they would like to. Students of social sciences are the references group in this analysis.

At the end of the questionnaire, respondents could answer additional questions designed to measure their personality traits (Big 5). This means that we can investigate how the desired starting point and preference for leisure relates to these traits. ${ }^{6}$

More conscientious individuals desire longer hours at the start of their career, but they also expect a higher hourly wage. After controlling for these differences in starting point, the shape of the indifference curve is not significantly related to conscientiousness. More agreeable individuals desire less hours and expect lower hourly wages, and after controlling for this, do not differ much from others in the shape of their indifference curve. More extrovert individuals desire longer hours and higher hourly wages at the start of their career. Even after controlling for this, they appear to have flatter indifference curves, and therefore a lower preference for leisure overall. Emotional stability is barely related to the desired starting point of individuals or to their preference for leisure. Individuals who score higher on openness desire both longer hours and higher wages, which results in no significant relationship of openness with the desired hourly wage. However, more open individuals appear to have an indifference curve that is flatter downwards and steeper upwards.

To sum up, respondents from Eastern Germany, who are in a stable relationship, who study natural sciences or humanities (as opposed to social sciences), and who expect a higher hourly wage appear to have a higher preference for leisure overall. On the contrary, having started to study later or being more extravert are associated with a lower preference for leisure. People who hold a student job, who have studied more semesters, and who are more open, seem to have more curved indifference curves, i.e. to have a stronger preference for their desired starting point.

\footnotetext{
${ }^{6}$ The inclusion of personality traits measures in the sample causes the drop in the number of observations.
} 


\begin{tabular}{|c|c|c|c|}
\hline & Hours & Wage & Hourly wage \\
\hline Female & $\begin{array}{c}-1.301^{\text {*** }} \\
(0.117)\end{array}$ & $\begin{array}{c}-45.401^{\text {*** }} \\
(3.240)\end{array}$ & $\begin{array}{c}-0.690^{* * *} \\
(0.081)\end{array}$ \\
\hline From Eastern Germany & $\begin{array}{c}-0.313^{* *} \\
(0.151)\end{array}$ & $\begin{array}{c}-27.650^{* * *} \\
(4.173)\end{array}$ & $\begin{array}{c}-0.670^{* * *} \\
(0.104)\end{array}$ \\
\hline Partner & $\begin{array}{c}-0.381^{\text {*** }} \\
(0.105)\end{array}$ & $\begin{array}{l}-1.195 \\
(2.891)\end{array}$ & $\begin{array}{c}0.113 \\
(0.072)\end{array}$ \\
\hline Student job & $\begin{array}{c}-0.310^{* * *} \\
(0.110)\end{array}$ & $\begin{array}{c}2.334 \\
(3.023)\end{array}$ & $\begin{array}{l}0.128^{*} \\
(0.075)\end{array}$ \\
\hline Age & $\begin{array}{c}-0.160^{* * *} \\
(0.019)\end{array}$ & $\begin{array}{c}-5.845^{* * *} \\
(0.531)\end{array}$ & $\begin{array}{c}-0.094^{* * *} \\
(0.013)\end{array}$ \\
\hline Semesters studied & $\begin{array}{c}0.005 \\
(0.017)\end{array}$ & $\begin{array}{l}-0.598 \\
(0.471)\end{array}$ & $\begin{array}{l}-0.014 \\
(0.012)\end{array}$ \\
\hline Studies natural sciences & $\begin{array}{l}-0.081 \\
(0.114)\end{array}$ & $\begin{array}{c}27.241^{* * *} \\
(3.141)\end{array}$ & $\begin{array}{c}0.763^{* * *} \\
(0.078)\end{array}$ \\
\hline Studies humanities & $\begin{array}{c}-1.037^{* * *} \\
(0.169)\end{array}$ & $\begin{array}{c}-38.734^{* * *} \\
(4.656)\end{array}$ & $\begin{array}{c}-0.594^{* * *} \\
(0.116)\end{array}$ \\
\hline Conscientiousness & $\begin{array}{c}0.588^{* * *} \\
(0.054)\end{array}$ & $\begin{array}{c}16.017^{* * *} \\
(1.491)\end{array}$ & $\begin{array}{c}0.206^{* * *} \\
(0.037)\end{array}$ \\
\hline Agreeableness & $\begin{array}{c}-0.270^{* * *} \\
(0.059)\end{array}$ & $\begin{array}{c}-13.954^{* * *} \\
(1.616)\end{array}$ & $\begin{array}{c}-0.265^{\text {*** }} \\
(0.040)\end{array}$ \\
\hline Extraversion & $\begin{array}{c}0.329^{* * * *} \\
(0.056)\end{array}$ & $\begin{array}{c}14.707^{* * *} \\
(1.539)\end{array}$ & $\begin{array}{c}0.262^{* * *} \\
(0.038)\end{array}$ \\
\hline Emotional stability & $\begin{array}{l}0.099^{*} \\
(0.055)\end{array}$ & $\begin{array}{c}1.923 \\
(1.527)\end{array}$ & $\begin{array}{c}0.017 \\
(0.038)\end{array}$ \\
\hline Openness & $\begin{array}{c}0.185^{* * *} \\
(0.056)\end{array}$ & $\begin{array}{c}4.046^{* * *} \\
(1.545)\end{array}$ & $\begin{array}{c}0.026 \\
(0.038)\end{array}$ \\
\hline Constant & $\begin{array}{c}44.855^{* * *} \\
(0.430)\end{array}$ & $\begin{array}{c}689.455^{* * *} \\
(11.853)\end{array}$ & $\begin{array}{c}15.725^{* * *} \\
(0.295)\end{array}$ \\
\hline $\begin{array}{l}\text { R-squared } \\
\mathrm{N}\end{array}$ & $\begin{array}{c}0.042 \\
12986\end{array}$ & $\begin{array}{c}0.082 \\
12986\end{array}$ & $\begin{array}{c}0.044 \\
12986\end{array}$ \\
\hline
\end{tabular}

Table 7.4: Determinants of the chosen starting point in terms of hours, wage and hourly wage.

\subsection{Robustness Checks}

\subsubsection{Testing for Measurement Error}

We find a great variation in the preference for leisure of different individuals. The questions is how much of this variation is due to real inter-individual differences, and how much is due to measurement error. Comparing required wages for different proposed hours that are close to each other can 


\begin{tabular}{|c|c|c|c|c|}
\hline & $\mathrm{H}-4$ & $\mathrm{H}+4$ & $\mathrm{H}-$ random & $\mathrm{H}+$ random \\
\hline \multirow[t]{2}{*}{ Female } & -0.074 & -0.627 & -0.120 & $-1.241^{*}$ \\
\hline & $(0.265)$ & $(0.398)$ & $(0.076)$ & $(0.729)$ \\
\hline \multirow[t]{2}{*}{ From East Germany } & $0.724^{* *}$ & -0.123 & $0.160^{*}$ & -0.686 \\
\hline & $(0.338)$ & $(0.509)$ & $(0.097)$ & $(0.911)$ \\
\hline \multirow[t]{2}{*}{ Partner } & -0.345 & $0.767^{* *}$ & -0.006 & 0.464 \\
\hline & $(0.234)$ & $(0.352)$ & $(0.067)$ & $(0.655)$ \\
\hline \multirow[t]{2}{*}{ Student job } & -0.287 & $1.084^{* * *}$ & $-0.199^{* * *}$ & -0.371 \\
\hline & $(0.245)$ & $(0.368)$ & $(0.070)$ & $(0.690)$ \\
\hline \multirow[t]{2}{*}{ Age } & 0.027 & $-0.273^{* * *}$ & -0.001 & $-0.283^{* * *}$ \\
\hline & $(0.043)$ & $(0.065)$ & $(0.013)$ & $(0.104)$ \\
\hline \multirow[t]{2}{*}{ Semesters studied } & -0.002 & $0.180^{* * *}$ & $-0.024^{* *}$ & $0.289^{* * *}$ \\
\hline & $(0.038)$ & $(0.057)$ & $(0.011)$ & $(0.098)$ \\
\hline \multirow[t]{2}{*}{ Studies natural sc. } & -0.124 & $0.853^{* *}$ & 0.015 & -0.279 \\
\hline & $(0.255)$ & $(0.384)$ & $(0.073)$ & $(0.742)$ \\
\hline \multirow[t]{2}{*}{ Studies humanities } & 0.448 & -0.802 & $0.418^{* * *}$ & 0.174 \\
\hline & $(0.378)$ & $(0.568)$ & $(0.110)$ & $(0.865)$ \\
\hline \multirow[t]{2}{*}{ Conscientiousness } & 0.072 & -0.168 & 0.019 & -0.267 \\
\hline & $(0.122)$ & $(0.183)$ & $(0.035)$ & $(0.331)$ \\
\hline \multirow[t]{2}{*}{ Agreeableness } & -0.126 & 0.191 & 0.016 & -0.021 \\
\hline & $(0.131)$ & $(0.197)$ & $(0.038)$ & $(0.355)$ \\
\hline \multirow[t]{2}{*}{ Extraversion } & $-0.273^{* *}$ & $-0.369^{*}$ & $-0.077^{* *}$ & -0.585 \\
\hline & $(0.125)$ & $(0.188)$ & $(0.036)$ & $(0.359)$ \\
\hline \multirow[t]{2}{*}{ Emotional stability } & -0.128 & 0.067 & -0.051 & 0.253 \\
\hline & $(0.124)$ & $(0.186)$ & $(0.035)$ & $(0.335)$ \\
\hline \multirow[t]{2}{*}{ Openness } & $-0.403^{* * *}$ & $1.007^{* * *}$ & -0.038 & $0.607^{*}$ \\
\hline & $(0.125)$ & $(0.188)$ & $(0.036)$ & $(0.322)$ \\
\hline \multirow[t]{2}{*}{ Desired starting hours } & $0.040^{* *}$ & $0.106^{* * *}$ & -0.012 & $0.344^{* * *}$ \\
\hline & $(0.020)$ & $(0.030)$ & $(0.008)$ & $(0.066)$ \\
\hline \multirow[t]{2}{*}{ Desired hourly wage } & $1.288^{* * *}$ & $0.085^{* *}$ & $0.987^{* * *}$ & 0.061 \\
\hline & $(0.029)$ & $(0.043)$ & $(0.009)$ & $(0.044)$ \\
\hline \multirow[t]{2}{*}{ Proposed hours } & & & $0.115^{* * *}$ & $-1.004^{* * *}$ \\
\hline & & & $(0.007)$ & $(0.195)$ \\
\hline Proposed hours $\times$ & & & $-0.005^{* * *}$ & $-0.044^{* * *}$ \\
\hline Desired starting hours & & & $(0.001)$ & $(0.009)$ \\
\hline \multirow[t]{2}{*}{ Constant } & $-6.746^{* * *}$ & $13.544^{* * *}$ & $-4.336^{* * *}$ & $50.261^{* * *}$ \\
\hline & $(1.446)$ & $(2.180)$ & $(0.472)$ & $(8.230)$ \\
\hline R-squared & 0.139 & 0.006 & 0.347 & 0.045 \\
\hline $\mathrm{N}$ & 12986 & 12981 & 24253 & 1559 \\
\hline
\end{tabular}

${ }^{*} p<0.10,{ }^{* *} p<0.05,{ }^{* * *} p<0.01$

Table 7.5: Determinants of preference for leisure for the different alternations of weekly working hours. 
be considered as a proxy for a test re-test correlation. The difference between two different proposed hours is smallest when the hours proposed in the random questions (3rd and 4th question) come close to either four hours less than the desired working time (1st question) or four hours more (2nd question).

Overall, the correlation between the required wage for random hours and the required wage for hours close to the desired working time is around 0.55 ( 0.57 with four hours less than desired working time, 0.53 with four hours more). If we restrict random hours to those which are less than eight hours away from the desired working time, i.e. less than four hours away from the hours proposed in the 1st or 2nd question, the correlation is 0.93 between the wage required for those random hours and for four hours less than the desired working time $(\mathrm{n}=854)$, and 0.94 between the wage required for those random hours and for four hours more than the desired working time $(n=132)$. All correlation coefficients presented here are significant at any conventional level $(\mathrm{p}<0.000){ }^{7}$

\subsubsection{Comparison of Open Questions and Vignettes}

The previous analysis showed to what extent future graduates need to be compensated for working more in order to hold their utility constant. The same effect can be derived using the vignette questions. We estimate a model without imposing a certain functional form. Instead we use dummy variables for the respective levels of working hours and wage. ${ }^{8}$ We estimate a logit model. ${ }^{9}$

Holding the prediction of the outcome variable attractiveness fixed allows to generate indifference curves for the average participant. Figure 7.4 shows these indifference curves. The indifference curves are close to linear, but show signs of being convex. This is in line with the previous findings from the open questions. As the vignette question does not include a starting point itself, the analysis cannot be done with respect to such a reference point. Nevertheless, if we pick any point along a convex indifference curve this point will show similar features as those described for the open questions.

\footnotetext{
${ }^{7}$ Due to the small number of cases in which random hours were close to other proposed hours, these tests have been performed using all the data collected, not only the data we use in our estimation sample. The only cleaning we did was to drop answers that imply an hourly wage below 1 or above 200. The more flexible upper bound is due to the fact that the distribution of hourly wage is much wider for the proposed random hours than for hours close to the desired working time, probably because many of the random hours proposed are much lower than the respondents would wish for.

${ }^{8}$ Working hours are included as integers ranging from 25 to 60 hours per week. Wage is truncated into categories of 25 Euros each ranging from 600 to 3200 Euros per month.

${ }^{9}$ To adjust for the varying level of attractiveness of the rounds of vignettes a conditional logit model is more appropriate. However, as this explains only random noise and does not produce asymptotically different coefficients we stick to a normal logit model.
} 


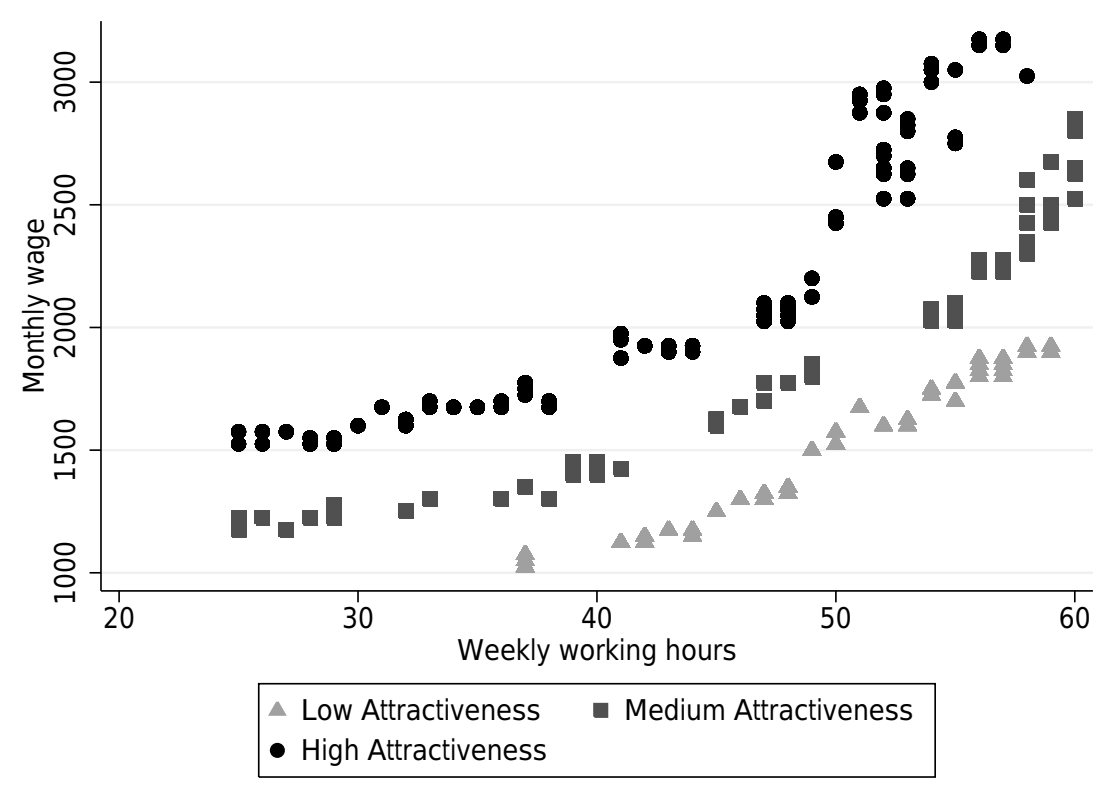

Figure 7.4: Vignette: Indifference curves working hours and wage.

Additionally we can relate the vignette question to the required hourly compensation of the participants in the open questions. As we need to hold attractiveness constant to achieve this, it is nothing else as the slope along the indifference curves. Regressing monthly wage against weekly working hours and the prediction of attractiveness allows to find the line which best fits the indifference curves. We find that the required compensation to be indifferent between working one hour more is 9.77 Euros.

This is certainly within the range of values obtained from the open questions. In that sense the effects are close to each other. Participants show only weak signs of overestimating their wage in the open questions. The difference lies in the estimation. While the open questions come up with an hourly compensation per participant the vignette question comes up with a joint average for all participants. The fact that we get very similar results with different techniques gives credibility to the open questions. ${ }^{10}$ Hence, on the open questions participants seem to neither systematically exaggerate their wage demands for given working hours nor do they assume systematic changes in job characteristics other than wage and working hours.

\footnotetext{
${ }^{10}$ The vignette question were asked prior to the open questions in the data collection. Still, we find no signs of priming in wage as the average wage shown in the vignette does not predict the wage chosen in the open questions.
} 


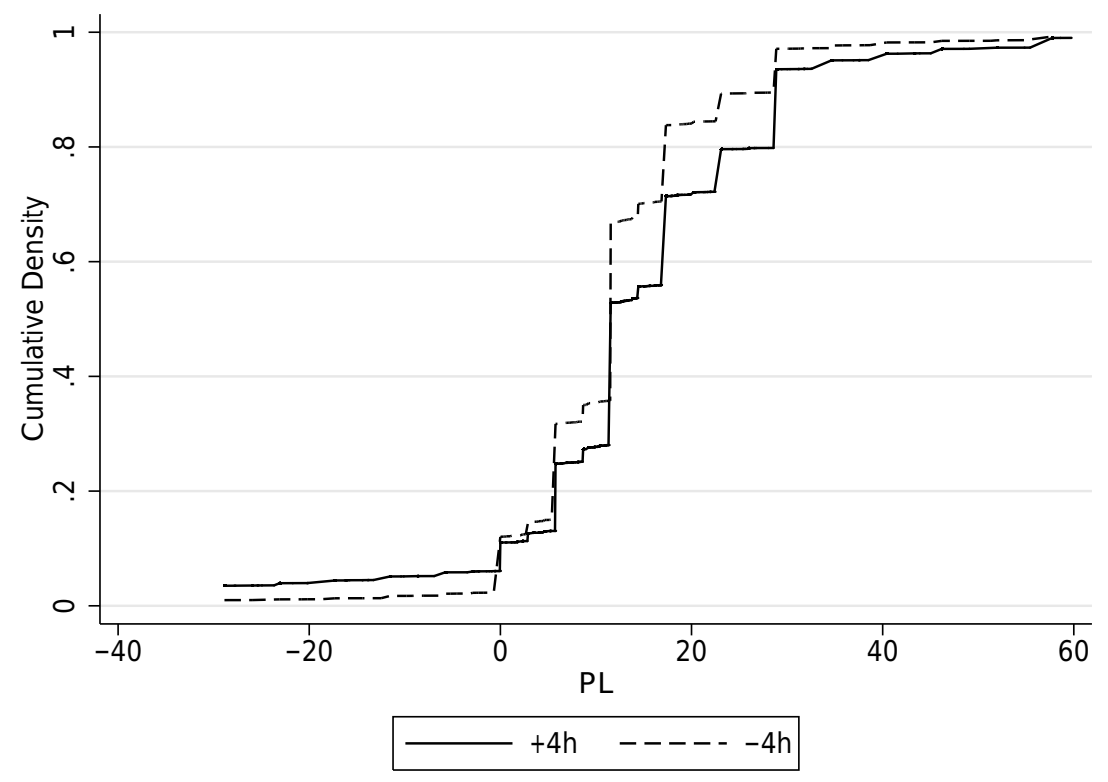

Figure 7.5: Cumulative distribution of preference for leisure when proposed to work four hours more or less.

\subsection{Policy Simulations}

Gaining more insight into how individual indifference curves look like should help us predict better which individuals would be most affected, positively or negatively, by a change in their weekly working time. This is relevant information to evaluate the welfare consequences of policies which change weekly working time, be it indirectly through incentives or directly through setting rules such as the definition of the full-time workweek for instance.

Figure 7.5 shows the cumulative distribution of PL, i.e. the steepness of the indifference curve (or the average hourly wage required by respondents over the range between the desired and the proposed hours), when respondents are asked to work four hours more or four hours less. As expected, the indifference curve is generally steeper when individuals are asked to work four hours more than when they are asked to work four hours less: A smaller proportion of individuals is ready to consider the same average wage an appropriate compensation for additional hours of work. For instance, the graph shows that about half of all future graduates would be left equally well-off if they had to work four hours more and were paid roughly $€ 12$ or less per hour. On the contrary, two thirds of all participants would accept a decrease in their working time by four hours if they had to give up $€ 12$ or less for each additional hour of free time. 


\subsection{Conclusion}

In this Chapter, we presented a new method to elicit preference for leisure of individuals, by presenting them with different working times, and asking them which wages would make them indifferent between these different working times. This method yields information about the shape of their indifference curve between income and leisure. We tested this method using a web survey among more than 16,000 German students.

Our results confirm that indifference curves between leisure and consumption are convex, both on average and for most respondents individually (75 percent). We find that some individual characteristics, like being in a stable relationship or living in East Germany, influence not only the desired starting wage and working time of individuals, but also the steepness of an individual's indifference curve. We also find that individuals with longer desired hours are less likely to derive utility from increases in their working hours.

In order to check the understanding of our questions by the respondents, we compared their answers to these open questions with their choices between job vignettes with several different attributes, including varying weekly working times and monthly wages. The average marginal wage required in the open questions and in the vignette questions is similar, which suggests that individuals do not exaggerate their wage requirements when answering the open questions.

Our results are valid for the student population in Germany only, but they illustrate that it could be interesting for both research and policy to use the method presented here to collect information about preference for leisure in a survey that is representative to the entire working population. It would help improve our understanding of how people value changes in working time, therefore supporting the evaluation of different policies aimed at changing labour supply. 



\section{Chapter 8}

\section{Conclusion}

Within higher education students have to make a variety of choices. To an economist it is important to understand the nature and the impact of such decisions. Unfortunately, the fact that students make deliberate choices complicates the identification of their consequences. If selection is related to some, potentially unobservable, characteristics, then specific empirical strategies need to be used to measure the effects. The methods used in this dissertation range from comparing different groups of students to conducting hypothetical choice experiments.

Such empirical strategies are needed because the assessment of choices in higher education is important to various groups. For one, students should know how their choices alter their set of cognitive and non-cognitive skills and hence, their employability. Second, policy makers who want to improve the employability of students need to know what determines student choices. If the decisions of students alter their set of skills, then the initial choice might be made in anticipation of its effects. Moreover, these effects of educational choices are also important for the evaluation of policies. Finally, companies looking to hire students or graduates should be aware of their preferences. Knowing the preferences is key to understanding how potential employees choose jobs and thereby enables companies to design more efficient jobs.

At the beginning of higher education students choose a subject. This decision is analysed in Chapter 3. The distinction between selection into a study field and the effect of a study field is crucial. Students with certain skill sets are likely to select specific subjects. In return, specific subjects can facilitate the development of certain skills. To disentangle the effects we measure selection by comparing students right at the start of their study across different study fields. Changes as a result of study choice are assessed by fixing the subject and comparing students at the beginning of their study with those that are already advanced. Using this approach, clear signs of selection based on personality can be detected. Furthermore, no systematic 
change in non-cognitive skills as a result of studying a certain subject can be found.

Information on study choice and its consequences is important to students who seek to increase their employability in terms of their non-cognitive skills. For the average student, choosing a certain subject cannot bring about such a change in personality. On the contrary, this information can be used by policy makers who would like to increase the share of students in certain fields. To increase the share of, for example, students in STEM subjects $^{1}$ policy makers can design specific subjects that better fit the personality of those students that select into them. Alternatively, to attract other students new study programmes can be created that appeal to students with a different personality. This is even more important as subject choice determines employment opportunities. Thereby, a sizeable amount of job sorting takes place at the beginning and not after higher education. Further more, companies that look to hire graduates with certain personality profiles need to check whether these non-cognitive skills correlate with other required skills.

In Chapter 4 and Chapter 5 the focus shifts towards student mobility. Using a theoretical approach Chapter 4 creates a two-country framework to analyse the growth effects of international student mobility. The mathematical model that is developed highlights the key variables that determine the conditions under which countries can benefit from degree mobility. Firstly, the share of higher education related costs out of total education costs matters to the receiving country. Second, it is important to develop migration policies that go hand in hand with education and make sure that a large fraction of international students stays in the receiving country after education. Lastly, the difference in productivity between international and domestic education is a key driver of the outcomes. If international education enables students to better grow their human capital, programmes like Erasmus $^{2}$ produce measurable benefits and international education becomes a positive sum game.

Linking up to the previous Chapter, the additional gain of being educated internationally is the subject of the Chapter 5. An empirical strategy to compare groups of students allows to estimate the effect of an international experience during higher education. The groups can be constructed due to a small timing asymmetry in the set-up of the exchange programme at Maastricht University. While all students need to go abroad during the third year of their Bachelor, some students go in the first and others in the second half of that year. This identification strategy is suitable for two reasons. First, the differences between the two groups are at most very small. Second, the study is designed around three questionnaires and thereby al-

\footnotetext{
${ }^{1}$ STEM is the abbreviation of the study fields science, technology, engineering and mathematics.

${ }^{2}$ Erasmus is the abbreviation of the European Community Action Scheme for the Mobility of University Students.
} 
lows to analyse the changes of both going abroad and staying in Maastricht for one semester. The results indicate that students become less neurotic and gain a more inward Locus of Control in response to a semester abroad.

As noted the effect of international education on human capital is important to policy makers. It is, however, also relevant for students and companies. The average students benefits from going abroad through an increased labour productivity which materialises in form of a wage premium. The non-cognitive skills that are developed during an exchange semester are worth as much as $€ 21,525$. As this is an average effect it does not apply to all students, however, a significant share of them should be advised to consider going abroad as an investment in their own personality. Knowing of the effects of international education on personality companies can use this information in their hiring processes. Thereby international education cannot only be interpreted as a signal, but as something that enhances productivity itself.

The last part of this dissertation, namely Chapter 6 and Chapter pfl, are about the job preferences of students. With respect to the trade-offs students face when entering the labour market a different empirical strategy is employed. Hypothetical choice experiments allow confronting students with different job offers. Real life data on such choices is typically not available as only the job that is selected becomes visible. Comparing jobs between students, however, leads to problems in the identification of these trade-offs. Nevertheless, there is another, more practical reason for using hypothetical choice experiments in this dissertation. The data that is collected features students. For them the decision which graduate job to choose is one that will only be made in the future. Hypothetical choices allow to face students with such future decisions.

Chapter 6 features two different vignette type questions on part-time and graduate jobs. In these questions students are asked to choose from three different job offers, respectively. The advantages of the vignette technique are that it is relatively easy for participants to choose, even if a larger amount of different characteristics is included. Furthermore, the decision space can be defined ex ante by the researcher. The results from the vignette question can be used to derive the average trade-offs between different job attributes. Such findings are mainly valuable to policy makers and companies as they should understand the decision of graduates and know their preferences. In terms job mobility and security of employment, for example, the vignette question reveals that students ask a $€ 349$ premium in terms of monthly wage after taxes if the first graduate job is located in a different German state, while they are willing to give up $€ 320$ to gain an open-ended work contract. This is certainly relevant to policy makers who are concerned with worker mobility or employment protection. Even more, companies can benefit from this research by attracting higher skilled employees or paying lower wages. Whenever a company can provide a certain job attribute at a cost that is lower than the value to the employee, efficiency can be en- 
hanced. Generally, information on compensating differentials enables them to design more efficient jobs. Companies that are located in a rural area, for example, may find it cheaper to compensate for this by providing potential employees with increased job security or more flexible working hours compared to a higher wage.

To evaluate the specific trade-off between working hours and wage, a different type of choice experiment in the form of open questions is used in Chapter 7. Students are asked for a preferred combination of working time and compensation. Thereafter, the weekly working hours are altered and participants need to set a wage that leaves them equally well off as their initial preference. While this type of question design is more limited in terms of different job attributes it allows to map indifference curves on the individual level. On the company level the results can be used by firms that are subject to fluctuations in customer demand to convince employees to accept variations in working times. In terms of policy the relationship between working hours and wage is relevant for a wide range of applications like retirement, unemployment benefits or taxation of income. 


\section{References}

Almlund, M., Duckworth, A. L., Heckman, J. J., \& Kautz, T. D. (2011). Personality psychology and economics (Tech. Rep.). Cambridge, Massachusetts (United States): National Bureau of Economic Research.

Angrist, J. D., \& Krueger, A. B. (1991). Does compulsory school attendance affect schooling and earnings? The Quarterly Journal of Economics, $106(4), 979-1014$.

Ashenfelter, O., \& Krueger, A. (1994). Estimates of the economic return to schooling from a new sample of twins. The American Economic Review, 84(5), 1157-1173.

Balsamo, M., Lauriola, M., \& Saggino, A. (2012). Personality and college major choice: Which come first? Psychology, 3(05), 399-405.

Barrick, M. R., \& Mount, M. K. (1991). The big five personality dimensions and job performance: A meta-analysis. Personnel Psychology, $44(1)$, $1-26$.

Becker, A., Deckers, T., Dohmen, T., Falk, A., \& Kosse, F. (2012). The relationship between economic preferences and psychological personality measures. CESifo Working Paper, 3785.

Becker, G. S. (1962). Investment in human capital: A theoretical analysis. Journal of Political Economy, 70(5), 9-49.

Bergerhoff, J., Borghans, L., Seegers, P. K., \& van Veen, T. (2013). International education and economic growth. IZA Journal of European Labor Studies, 2(1), 1-13.

Bergerhoff, J., Hartmann, S., \& Seegers, P. K. (2015). Fachkraft 2020: Erhebung zur wirtschaftlichen und allgemeinen Lebenssituation der Studierenden in Deutschland im WS 2013 / 2014 und SS 2014 [Fachkraft 2020: Study concercing the economic and general conditions of students in germany during the WS 2013 / 2014 and the SS 2014]. Cologne / Maastricht: STUDITEMPS GmbH and Maastricht University.

Bertrand, M., \& Mullainathan, S. (2004). Are Emily and Greg more employable than Lakisha and Jamal? A field experiment on labor market discrimination. American Economic Review, 94(4), 991-1013.

Bijwaard, G. E. (2010). Immigrant migration dynamics model for The Netherlands. Journal of Population Economics, 23(4), 1213-1247. 
Blomquist, S., \& Newey, W. (2002). Nonparametric estimation with nonlinear budget sets. Econometrica, 70 (6), 2455-2480.

Blundell, R., Bozio, A., \& Laroque, G. (2011). Labor supply and the extensive margin. The American Economic Review, 101 (3), 482-486.

Blundell, R., \& MaCurdy, T. (1999). Labor supply: A review of alternative approaches. Handbook of Labor Economics, 3, 1559-1695.

Blundell, R., \& Shephard, A. (2012). Employment, hours of work and the optimal taxation of low-income families. The Review of Economic Studies, $79(2), 481-510$.

Boone, C., van Olffen, W., \& Roijakkers, N. (2004). Selection on the road to a career: Evidence of personality sorting in educational choice. Journal of Career Development, 31(1), 61-78.

Borghans, L., Duckworth, A. L., Heckman, J. J., \& Ter Weel, B. (2008). The economics and psychology of personality traits. Journal of Human Resources, 43(4), 972-1059.

Borghans, L., Meijers, H., \& Ter Weel, B. (2008). The role of noncognitive skills in explaining cognitive test scores. Economic Inquiry, 46(1), $2-12$.

Borghans, L., Romans, M., \& Sauermann, J. (2010). What makes a good conference? Analysing the preferences of labour economists. Labour Economics, $17(5), 868-874$.

Brugiavini, A., \& Peracchi, F. (2005). The length of working lives in Europe. Journal of the European Economic Association, 3(2-3), 477-486.

Bundesministerium der Verteidigung. (2013). Die Geschichte der Wehrpflicht [the history of military service]. retrieved from: goo.gl/ 9vdt9L.

Cobb-Clark, D. A., \& Schurer, S. (2012). The stability of big-five personality traits. Economics Letters, 115(1), 11-15.

Cobb-Clark, D. A., \& Schurer, S. (2013). Two economists' musings on the stability of locus of control. The Economic Journal, 123(570), 358-400.

Costa Jr, P. T., \& McCrae, R. R. (1989). The neo-pi/neo-ffi manual supplement. Odessa, FL: Psychological Assessment Resources.

DeNeve, K. M., \& Cooper, H. (1998). The happy personality: A metaanalysis of 137 personality traits and subjective well-being. Psychological Bulletin, 124(2), 197.

Dohmen, T., \& Falk, A. (2010). You get what you pay for: Incentives and selection in the education system. The Economic Journal, 120(546), 256-271.

Dohmen, T., Falk, A., Huffman, D., \& Sunde, U. (2009). Homo reciprocans: Survey evidence on behavioural outcomes. The Economic Journal, $119(536), 592-612$.

Dohmen, T., Falk, A., Huffman, D., \& Sunde, U. (2012). Interpreting time horizon effects in inter-temporal choice. IZA Discussion Paper, 6385. 
Dohmen, T., Falk, A., Huffman, D., Sunde, U., Schupp, J., \& Wagner, G. G. (2011). Individual risk attitudes: Measurement, determinants, and behavioral consequences. Journal of the European Economic Association, $9(3), 522-550$.

Dunn, W. S., Mount, M. K., Barrick, M. R., \& Ones, D. S. (1995). Relative importance of personality and general mental ability in managers' judgments of applicant qualifications. Journal of Applied Psychology, $80(4), 500-509$.

Ehrenberg, R. G. (1980). Retirement system characteristics and compensating wage differentials in the public sector. Industrial $\&$ Labor Relations Review, 33(4), 470-483.

Eriksson, T., \& Kristensen, N. (2014). Wages or fringes? Some evidence on trade-offs and sorting. Journal of Labor Economics, 32(4), 899-928.

Falk, A., Becker, A., Dohmen, T., Huffman, D., \& Sunde, U. (2014). An experimentally validated preference survey module (Tech. Rep.). Bonn, Germany: Mimeo, Universität Bonn.

Falk, A., \& Szech, N. (2013). Morals and markets. Science, 340 (6133), 707-711.

Freed, B. F. (1995). Second language acquisition in a study abroad context (Vol. 9). Amsterdam: John Benjamins Publishing.

Frey, B. S., \& Meier, S. (2005). Selfish and indoctrinated economists? European Journal of Law and Economics, 19(2), 165-171.

Goldberg, L. R., Johnson, J. A., Eber, H. W., Hogan, R., Ashton, M. C., Cloninger, C. R., \& Gough, H. G. (2006). The international personality item pool and the future of public-domain personality measures. Journal of Research in Personality, 40(1), 84-96.

Green, P. E., \& Srinivasan, V. (1990). Conjoint analysis in marketing: New developments with implications for research and practice. Journal of Marketing, 54 (4), 3-19.

Harmon, C., \& Walker, I. (1995). Estimates of the economic return to schooling for the United Kingdom. The American Economic Review, $85(5), 1278-1286$.

Hartmann, S., Thiel, M., \& Seegers, P. K. (2012). Fachkraft 2020: Erhebung zur wirtschaftlichen und allgemeinen Lebenssituation der Studierenden in Deutschland im SS 2012 [Fachkraft 2020: Study concercing the economic and general conditions of students in germany during the SS 2012]. Cologne / Maastricht: STUDITEMPS GmbH and Maastricht University.

Hartmann, S., Thiel, M., \& Seegers, P. K. (2013). Fachkraft 2020: Erhebung zur wirtschaftlichen und allgemeinen Lebenssituation der Studierenden in Deutschland im WS 2012 / 2013 [Fachkraft 2020: Study concercing the economic and general conditions of students in germany during the WS 2012 / 2013]. Cologne / Maastricht: STUDITEMPS GmbH and Maastricht University.

Heckman, J. J., Humphries, J. E., Urzua, S., \& Veramendi, G. (2011). The 
effects of educational choices on labor market, health, and social outcomes. Unpublished manuscript, University of Chicago, Department of Economics.

Heckman, J. J., Pinto, R., \& Savelyev, P. A. (2012). Understanding the mechanisms through which an influential early childhood program boosted adult outcomes (Tech. Rep.). Cambridge, Massachusetts (United States): National Bureau of Economic Research.

Heckman, J. J., Stixrud, J., \& Urzua, S. (2006). The effects of cognitive and noncognitive abilities on labor market outcomes and social behavior. Journal of Labor Economics, 24(3), 411-482.

Humburg, M., \& van der Velden, R. (2014). Skills and the graduate recruitment process: Evidence from two discrete experiments. ROA Research Memorandum, 2014/2.

Jackson, J. J., Thoemmes, F., Jonkmann, K., Lüdtke, O., \& Trautwein, U. (2012). Military training and personality trait development: Does the military make the man, or does the man make the military? Psychological Science, 23(3), 270-277.

Judge, T. A., Erez, A., Bono, J. E., \& Thoresen, C. J. (2002). Are measures of self-esteem, neuroticism, locus of control, and generalized selfefficacy indicators of a common core construct? Journal of Personality and Social Psychology, 83(3), 693-710.

Karpinska, K., Henkens, K., \& Schippers, J. (2011, 5). The recruitment of early retirees: A vignette study of the factors that affect managers' decisions. Ageing and Society, 31 (04), 570-589.

Keane, M. P. (2011). Labor supply and taxes: A survey. Journal of Economic Literature, 49(4), 961-1075.

Lazear, E. P., \& Oyer, P. (2012).

In R. Gibbons \& J. Roberts (Eds.), The handbook of organizational economics (chap. Personnel Economics). Princeton: Princeton University Press.

Lazear, E. P., \& Shaw, K. L. (2007). Personnel economics: The economist's view of human resources. The Journal of Economic Perspectives, $21(4), 91-114$.

Lucas, R. E. (1988). On the mechanics of economic development. Journal of Monetary Economics, 22(1), 3-42.

Lüdtke, O., Roberts, B. W., Trautwein, U., \& Nagy, G. (2011). A random walk down university avenue: Life paths, life events, and personality trait change at the transition to university life. Journal of Personality and Social Psychology, $101(3), 620-637$.

Mankiw, N. G., Romer, D., \& Weil, D. N. (1992). A contribution to the empirics of economic growth. The Quarterly Journal of Economics, $107(2), 407-437$.

Manski, C. F. (2014). Identification of income-leisure preferences and evaluation of income tax policy. Quantitative Economics, 5(1), 145-174.

McCrae, R. R., \& Costa, P. T. (1985). Openness to experience. In R. Hogan 
\& J. W. H (Eds.), Perspectives in Personality (Vol. 1, p. 145-172). Greenwich, CT: JAI Press.

McCrae, R. R., \& Costa, P. T. (1989). Reinterpreting the myers-briggs type indicator from the perspective of the five-factor model of personality. Journal of Personality, 57(1), 17-40.

McMahon, W. W. (2004). The social and external benefits of education. In G. Johnes \& J. J (Eds.), International handbook on the economics of education (p. 211-259). Cheltenham: Edward Elgar Publishing.

Mechtenberg, L., \& Strausz, R. (2008). The bologna process: How student mobility affects multi-cultural skills and educational quality. International Tax and Public Finance, 15(2), 109-130.

Middendorff, E., Apolinarski, B., Poskowsky, J., Kandulla, M., \& Netz, N. (2013). Die wirtschaftliche und soziale Lage der Studierenden in Deutschland 2012 [the economic and social position of students in Germany 2012]. Sozialerhebung des Deutschen Studentenwerks, durchgeführt durch das HIS-Institut für Hochschulforschung.

Nuffic. (2011). Internationalisation in higher education in the Netherlands: Key figures (2010-2011 academic year). Netherlands Universities Foundation for International Cooperation.

Nyhus, E. K., \& Pons, E. (2005). The effects of personality on earnings. Journal of Economic Psychology, 26 (3), 363-384.

Olson, C. A. (2002). Do workers accept lower wages in exchange for health benefits? Journal of Labor Economics, 20(2), 91-114.

Oosterbeek, H., \& Webbink, D. (2006). Assessing the returns to studying abroad. CPB Discussion Paper, 64 .

Perloff, J. M. (2012). Microeconomics - sixth edition. New York: Pearson Education Limited.

Psacharopoulos, G., \& Patrinos, H. A. (2004). Returns to investment in education: A further update. Education Economics, 12(2), 111-134.

Raven, J. C., \& Court, J. H. (1998). Raven's progressive matrices and vocabulary scales. Oxford: OPP.

Roberts, B. W., \& DelVecchio, W. F. (2000). The rank-order consistency of personality traits from childhood to old age: A quantitative review of longitudinal studies. Psychological Bulletin, 126(1), 3-25.

Roberts, B. W., Walton, K. E., \& Viechtbauer, W. (2006). Patterns of mean-level change in personality traits across the life course: A metaanalysis of longitudinal studies. Psychological Bulletin, 132(1), 1-25.

Rossi, P. H., \& Nock, S. L. (1982). Measuring social judgments: The factorial survey approach. Thousand Oaks: SAGE Publications.

Rothmann, S., \& Coetzer, E. (2003). The big five personality dimensions and job performance. SA Journal of Industrial Psychology, 29(1), 68-74.

Rutkowski, K., \& Domino, G. (1975). Interrelationship of study skills and personality variables in college students. Journal of Educational Psychology, 67(6), 784-789. 
Saez, E., Slemrod, J., \& Giertz, S. H. (2012). The elasticity of taxable income with respect to marginal tax rates: A critical review. Journal of Economic Literature, 50(1), 3-50.

Sahm, C. R. (2012). How much does risk tolerance change? The Quarterly Journal of Finance, 2(04), 2001-2038.

Salgado, J. F. (1997). The five factor model of personality and job performance in the european community. Journal of Applied psychology, 82(1), 30-43.

Schupp, J., \& Wagner, G. G. (2002). Maintenance of and innovation in long-term panel studies: The case of the german socio-economic panel (gsoep) (Tech. Rep.). Berlin, Germany: DIW Berlin, German Institute for Economic Research.

Schurer, S., Kassenboehmer, S. C., \& Leung, F. (2015). Do universities shape their students' personality? Discussion Paper Series, 8873.

Solow, R. M. (1956). A contribution to the theory of economic growth. The quarterly journal of economics, 70(1), 65-94.

Statistical Office of the European Communities. (2012). Student flows in Europe. Eurostat.

Statistisches Bundesamt Deutschland. (2014). Schnellmeldungsergebnisse der Hochschulstatistik [first release of high education statistics]. destatis.

Stern, N. (1986). On the specification of labour supply functions. In R. Blundell \& I. Walker (Eds.), Search and labour supply (p. 143-189). Cambridge, UK: Cambridge University Press.

Stern, S. (2004). Do scientists pay to be scientists? Management Science, $50(6), 835-853$.

Sutton, R. C., \& Rubin, D. L. (2004). The glossari project: Initial findings from a system-wide research initiative on study abroad learning outcomes. Frontiers: The Interdisciplinary Journal of Study Abroad, 10, 65-82.

Van Beek, K. W., Koopmans, C. C., \& Van Praag, B. M. (1997). Shopping at the labour market: A real tale of fiction. European Economic Review, 41(2), 295-317.

Vinchur, A. J., Schippmann, J. S., Switzer III, F. S., \& Roth, P. L. (1998). A meta-analytic review of predictors of job performance for salespeople. Journal of Applied Psychology, 83(4), 586-597.

Vossensteyn, H., Lanzendorf, U., \& Souto-Otero, M. (2008). The impact of erasmus on european higher education: Quality, openness and internationalisation. final report to the european commission. (Tech. Rep.). Brussels, Belgium: European Commission.

Wallston, K. A., Wallston, B. S., \& DeVellis, R. (1978). Development of the multidimensional health locus of control (mhlc) scales. Health Education \&3 Behavior, 6(1), 160-170.

World Values Survey. (2014). Official Aggregate v.20140429. World Values Survey Association. 
Zimmermann, J., \& Neyer, F. J. (2013). Do we become a different person when hitting the road? Personality development of sojourners. Journal of Personality and Social Psychology, 105(3), 515-530. 



\section{Valorisation addendum}

Valorisation concerns the transfer of scientific knowledge into something that is useable outside of academia. In that sense I summarize my findings for the interested public, most likely, but hopefully not limited to, students, companies and policy makers.

This dissertation assesses many of the choices students face within higher education. More specifically, it deals with subject choice, mobility and job preferences. For students it is interesting to learn the outcomes of their decisions. In the case of a company it is important to understand who is hired and how payment schemes can be set up more efficiently. Policy makers want to understand how their policies affect higher education and whether they are beneficial.

With regard to study choice this dissertations shows that students pick subjects according to their personality. However, no change in personality as a result of study choice could be found. In other words: We do not become who we are because of a certain subject choice, but much rather choose a subject that suits us. That said, this does not mean that personality itself needs to be stable. Other events may still have an impact.

Why is this important to the general public? The idea that certain study fields change the individuals who major in them is well spread. The most famous example is, maybe, that of economics students. In 2013 the $\mathrm{BBC}$ published an article with the headline "Does studying economics make you more selfish?". The argument goes that teaching concepts of economic rationality, game theory and decision making to students should affect them in a way. And it is true, economics students are different. They are not only more selfish, but, for example, also more conscientious and extrovert, while being less altruistic, risk averse or agreeable. The fact that different studies - including Chapter 3 of this dissertation - find such differences for economics students might be taken as evidence for this argument.

This reasoning, however, falls too short. Education is a matter of choice and, hence, such a correlation does not necessarily hint towards a causal effect. In Chapter 3 we do not find evidence that studying economics alters the personality. Even more, we do not find such evidence for a very broad range of subjects. The differences in personality between study fields 
exist because certain types of students select themselves into them. Yes, economics students are different, but they are different right from the start.

How is this relevant beyond being interesting? Policy makers might, for example, formulate the goal to increase the share of students in science and technology or to make those subjects more appealing to female students. We know from Chapter 3 that natural sciences or mathematics and computer science on average attract introvert and non-agreeable students. Both characteristics are more present in men. From this information one can then derive the idea to design new study programs that attract different types of students. A more open teaching environment with a focus on group work might be more appealing to female students. Such programs can, thus, complement the traditional ones helping to increase the share of females as well as the absolute amount of students in these fields.

For students the findings are applicable as well. If personality were to change as a response to study choice, it would be possible to invest into it by choosing a certain major. First, the idea that education is an investment into cognitive skills is familiar. Second, different authors have stressed that non-cognitive skills have a labour market value as well. Their value might even be as large as that of cognitive skills as is suggested by a large review study. If students can alter their personality by making certain choices then such choices can be seen as an investment in non-cognitive skills. The fact that selection into subjects does not affect personality, then, means that the study choice affects the labour market value only via the accumulation of cognitive skills.

In spite of this, the argument for an investment in non-cognitive skills is still valid. In Chapter 5 the focus shifts towards international student mobility. There, it turns out than a semester abroad changes the personality of students. Students become less neurotic and gain a more inward locus of control, both non-cognitive skills that have a positive labour market value. Going abroad can be thought of as an investment in personality and this investment may carry a net present value larger than $€ 20,000$. From a student perspective it may, hence, well be rational to take on a student loan to be able to study in a different country for some time.

Additionally, companies can benefit from incorporating this information into their hiring decisions. Applying the finding means that a semester abroad is not only a potential signal that correlates with certain valued characteristics as a result of the selection at hand. It has a causal effect on non-cognitive skills and consequently employability.

This is, on a larger scale, equally important for policy makers as education holds, on top of the private return, a social return. Especially, in the context of European education systems such an assessment is vital as investments into education are, at least to a large extent, made by governments. In Anglo-Saxon countries the costs of education are usually borne by the individual making it less important for the policy makers to evaluate 
education programs.

In addition to bearing a large share of the costs of education European countries have designed programs that create incentives for young people to be mobile during education. An example here is the Erasumus program. Such programs are funded from taxes and should, hence, be evaluated carefully. While it is very conceivable that international education has a value that reaches beyond employability, Chapter 5 shows that the effect on employability is, as well, positive. From an economic perspective, international mobility thereby becomes a positive sum game. European policy makers may therefore be well advised to continue focusing their efforts on increasing student mobility.

Does that mean that international mobility is beneficial for every country? Not necessarily. A positive sum game is also present if some countries gain more than others lose. Chapter 4 creates a theoretical model of international student flows that analyses which conditions need to be met for international education to become mutually beneficial. A receiving country might loose if the costs of higher education are relatively high and most students leave again after graduation. On the contrary, if costs of primary and secondary education are relatively high and most students stay in a receiving country, than the sending country may be worse off.

Using empirically motivated parameter values chapter 4 shows that it is possible that international education is beneficial for both, receiving and sending countries. This can either occur if international education is by itself more efficient - something that has been shown to be true in Chapter 5 - or if the receiving country is simply better at educating students than the sending country. Considering the situation in Europe both scenarios are met. The first one with regard to Western European countries exchanging students on a mutual level. The second one in the case of new member states which are subject to systematic student outflows. Student mobility should not only be fostered on the European level, but also by the individual member countries.

Finally, the focus shifts towards the last topic of this dissertation: Job preferences. Knowing the employability of, for example, a certain graduate does not mean that one is able to design an efficient payment scheme. Employees do not only care about their respective wage. Instead, other job characteristics may well be equally important. To learn more about such job preferences two vignette type question - one on student jobs and one on graduate jobs - are analysed in Chapter 6 . The information on compensating differentials is valuable for companies.

With regard to student jobs, the data suggests that companies need to understand the importance of flexibility. The focus of students lies on their study and a job needs to fit into their timetable. Companies that allows students to freely choose their working hours can save more than $€ 2$ in 
hourly wages. Of course, such flexibility is only possible if the amount of working hours does not exceed a certain level. Students consider it optimal to work 12 to 13 hours per week. That said, traveling to the job is consuming time and reducing flexibility. Therefore, students strongly dislike commuting and companies are well advised to hire students from close by universities.

Preferences change as soon as students finish their studies and enter the labour market as graduates. The vast majority of students seeks full term employment and there flexibility becomes less important. Companies can now improve their employment attractiveness by offering increased job security as this is strongly valued by labour market entrants. In numbers, graduates are willing to give up more than $€ 300$ if offered an open-ended work contract. Offering secure jobs should, especially, be considered by companies that are located in rural areas. While different locations are subject to different levels of attractiveness, graduates generally dislike mobility. Moving to a different state requires, on average, an increase in salary of more than $€ 300$ per month. In that sense, an unattractive location may be balanced by a high degree of job security.

Next to such compensating differentials the trade-off between workinghours and wage is central. The reaction of a company to changes in demand may not only be hiring or laying off employees. For a limited time it may be optimal to simply increase or decrease the working time of its labour-force. Assuming a slight increase in working time, a company offering too little in return will fail to convince its workers to work longer hours. Moreover, a company that is offering a lot will, while being able to convince its employees, loose in terms of profitability. Therefore, a company would like to have some kind of information on the indifference curves of its work-force that allows them to adjust weekly working time and wage in a way that leaves the employees equally well off. Chapter 7 presents this kind of analysis.

Knowledge on the indifference curves of workers is, however, not only valuable to companies. Policy makers who want to introduce short-time work programs or wage regulation need information on the interplay between working hours and wage as it determines labour supply. The supply of labour is also affected through retirement, unemployment benefits or taxation. Thus, even in these policy areas the findings of Chapter 7 may be applied.

To conclude, I would like to give a concrete example on how the findings of this dissertation can be used in practice. Since the completion of my Ph.D. I have started a company together with Jan Bergerhoff - one of my co-authors. We are creating empirical models that are helping other companies to decide which candidate to hire. The findings from Chapter 3 allow us to understand what characteristics are associated with study choice. Depending on the job at hand, such characteristics may be needed or 
rather avoided. Chapter 5 improves our ability to rate exchange experiences. Thereby they become more comparable to other relevant hiring criteria like internships or grades. Finally, the technical knowledge on compensating differentials and the preferences of students taken from Chapter 6 allows us to determine whether a certain candidate is suitable to the job design at hand. 



\section{Curriculum Vitae}

Philipp Karl Seegers was born on November 12, 1987 in Cologne, Germany. He attended high school (German: Gymnasium) at Liebfrauenschule Koeln from 1998 - 2007. Thereafter he followed the Bachelor programme "International Economic Studies" at Maastricht University and graduated in August 2010. Within the Bachelor programme he took part in a six month exchange with the Hong Kong University of Science and Technology. Philipp participated in the "Maastricht Research Based Learning" programme. This led to an extended Bachelor thesis which set the foundation of Chapter 4 of this dissertation.

After completion of the Bachelor he enrolled in the "Economic and Financial Research" Master at Maastricht University and completed the twoyear programme with distinction (cum laude) in August 2012. His Master thesis deals with the labour market benefits to non-mobile students if educated in an international environment within their home country. During the second year of his Master he worked as a research assistant at Maastricht University.

Philipp joined the Department of Economics as a Ph.D. candidate in September 2012, under the supervision of Prof. dr. Lex Borghans. At the same time he started the Fachkraft project as cooperation between Maastricht University and Studitemps GmbH in Cologne. The research he conducted as a Ph.D. is collected in this dissertation. Prior, his research has been presented at various international workshops and conferences.

After completion of his Ph.D. he started candidate select GmbH (CASE) together with Jan Bergerhoff. CASE uses empirical models to advise other companies in their hiring decisions. The venture is supported via the EXIST scholarship. Philipp continues his association with Maastricht University and the collection of the Fachkraft data. 
